INSTITUTO DE QUÍMICA DE SÃO CARLOS

PROGRAMA DE PÓS-GRADUAÇÃO EM QUÍMICA

Grupo de Química Medicinal - NEQUIMED

SÍNTESE DE INIBIDORES REVERSÍVEIS DE

CISTEÍNO PROTEASES PARA A AVALIAÇÃO DA

ATIVIDADE ANTILEISHMANIOSE

Candidato: Thiago Kelvin Brito Matos

Orientador: Prof. Dr. Andrei Leitão

SÃO CARLOS 


\section{SÍNTESE DE INIBIDORES REVERSÍVEIS DE CISTEÍNO PROTEASES PARA A AVALIAÇÃO DA ATIVIDADE ANTILEISHMANIOSE}

Dissertação apresentada ao Programa de PósGraduação em Química do Instituto de Química de São Carlos da Universidade de São Paulo, como requisito final para a obtenção do Título de Mestre em Química com ênfase em Química Orgânica e Biológica.

Orientador: Prof. Dr. Andrei Leitão 


\section{AGRADECIMENTOS}

À minha família, principalmente minha mãe, por todo o apoio e compreensão nessa longa jornada.

Ao pesquisador e meu orientador, Prof. Dr. Andrei Leitão, pela excelente orientação e pelo voto de confiança nesta caminhada de novos conhecimentos.

Ao Prof. Dr. Carlos Alberto Montanari por me receber de braços abertos em seu grupo e sempre me incentivar a alcançar o meu máximo potencial.

Ao Grupo de Química Medicinal de São Carlos, à Universidade de São Paulo e à University of Nottingham pela oportunidade e pela infraestrutura fornecida para o desenvolvimento deste trabalho.

Agradeço em especial à pesquisadora Daniela de Vita, pela grande ajuda que recebi desde o meu primeiro dia e por estar sempre disposta a me ajudar. Agradeço também a todos os meus amigos do Grupo de Química Medicinal de São Carlos pelo companheirismo no dia a dia de trabalho e por me ajudarem no meu crescimento profissional, nas reuniões ou apenas discussões sobre os projetos.

Agradeço imensamente ao meu amigo Lucas Catunda, pelo companheirismo e pelos momentos vividos, alegrias, momentos de descontração e principalmente apoio moral.

Agradeço aos meus amigos de todas as horas Allan Ogura, Fellipe Moutinho, Guilherme Monis, Heloísa Megda e Tiago Campos, pela fraternidade e por estarem ao meu lado sempre me apoiando e tendo paciência comigo quando houveram os dias difíceis; vocês foram imprescindíveis para o meu crescimento pessoal.

Agradeço aos meus amigos Amanda Lemos, Davi Rabelo, Grazielly Lima, Igor Alves, Katielle Albuquerque, Luís Alves, Luiza Sena, Robson Martins e Willyane Oliveira por estarem sempre ao meu lado durante toda minha vida acadêmica e pela ajuda mútua.

Agradeço a todas as amizades que construí em São Carlos, especialmente os meus amigos da família vôlei CAASO, sem vocês nada disso teria sido possível aos meus olhos.

À Coordenação de Aperfeiçoamento de Pessoal de Nível Superior, CAPES (programa PROEX processo 1632465 e 139/2015), pelo suporte financeiro e às outras agências de fomento, CNPq e FAPESP (projeto temático 13/18009-4). 


\section{RESUMO}

Dentre os diversos tipos de doenças, as negligenciadas apresentam grande prevalência na população em países tropicais. A leishmaniose é uma doença negligenciada endêmica no Brasil, com incidência em áreas urbanas e rurais. A ineficácia e elevados efeitos colaterais de fármacos como a Anfotericina $\mathrm{B}$, que é atualmente empregada, tem levado à pesquisa e o desenvolvimento de substâncias bioativas antileishmaniose. Um alvo macromolecular de interesse terapêutico é a cisteíno protease B (CPB) devido à sua importância em diversas etapas do ciclo de vida da Leishmania spp. Assim, o Grupo de Química Medicinal (NEQUIMED) estuda inibidores covalentes reversíveis da cisteíno protease CPB com potencial atividade antileishmaniose. Neste trabalho, a síntese de derivados de dipeptidil nitrilas foi realizada. $\mathrm{O}$ potencial da atividade inibidora da CPB foi analisado por meio dos ensaios biológicos correspondentes. Análogos do composto N-(1-cianociclopropil)-3-fenil-2-((-2,2,2-trifluoro-1fenil-etil)amino) propanamida foram produzidos e caracterizados. Um total de dezesseis substâncias foram produzidas e quinze foram purificadas por HPLC-MS, bem como a caracterização por RMN $\left({ }^{1} \mathrm{H}\right.$ e $\left.{ }^{13} \mathrm{C}\right)$ e FT-IR. A estereoisomeria de um dos compostos (codificado como Neq0930) foi confirmada por cristalografia de raios X. A partir desta série, a influência da estereosseletividade das substâncias para a inibição da CPB foi acessada por meio de ensaios bioquímicos, mostrando que os isômeros $(S, S)$ apresentaram maior potência, com aditividade observada para os substituintes nas posições P2 e P3 das substâncias. O composto Neq0636 possui a maior potência de inibição contra a CPB e será testado em ensaios celulares juntamente com os outros derivados.

Palavras-chave: derivados de dipeptidil nitrilas, inibição enzimática, CPB, química medicinal, descoberta de fármacos, doença negligenciada. 


\begin{abstract}
Among several types of pathologies, neglected tropical diseases present high prevalence in the population in tropical countries. Leishmaniasis is a neglected disease endemic in Brazil, with incidence in urban and rural areas. The ineffectiveness and numerous side effects of drugs such as amphotericin B, which is currently used for treatment, has led to the research and development of bioactive antileishmanial substances. A macromolecular target of therapeutic interest is the enzyme cysteine protease $\mathrm{B}(\mathrm{CPB})$ because of its importance at various stages of the Leishmania spp. life cycle. Thus, the Medicinal Chemistry Group (NEQUIMED) studies covalent inhibitors of the cysteine protease CPB with potential antileishmanial activity. In this study, the synthesis of dipeptidyl nitrile derivatives was performed so that the potential inhibitory activity for CPB could be accessed through the corresponding biological assays. In this work, derivatives and stereoisomers of dipeptidyl nitriles of the compound $N$-(1-cyanocyclopropyl)-3-phenyl-2-((2,2,2-trifluoro-1-phenylethyl)amino)propenamide were synthesized and characterized. A total of sixteen substances were produced and fifteen purified by HPLC-MS, characterized by NMR $\left({ }^{1} \mathrm{H}\right.$ and $\left.{ }^{13} \mathrm{C}\right)$ and FTIR. X rays crystallography was employed to confirm the absolute configuration of one derivative (coded Neq0930). From this series, the compound stereoselectivity was analysed in biochemical assays using $\mathrm{CPB}$, where the $(S, S)$ isomers were the most potent. Moreover, the addictive effect was observed for the substituents in compounds positions P2 and P3. Compound Neq0636 was the most potent of the series when tested against the CPB enzyme. Now, these substances are going to be studied in cell-based assays.

Keywords: dipeptidyl nitriles derivatives, enzymatic inhibitors, CPB, medicinal chemistry, neglected disease.
\end{abstract}




\section{LISTA DE FIGURAS}

Figura 1. Distribuição de leishmaniose cutânea (esquerda) e visceral (direita). ............................ 13

Figura 2. Fármacos usados atualmente no tratamento de leishmaniose.

Figura 3. Representação da estrutura química do K777, uma vinilsulfona que forma ligação covalente irreversível com a cisteíno protease.

Figura 4. Representação da estrutura química do Odanacatib. 18

Figura 5. Representação estrutural de um derivado de dipeptidil nitrila sintetizado no grupo de pesquisa NEQUIMED. 18

Figura 6. Representação dos subsítios enzimáticos de cisteíno proteases. 19

Figura 7. Representação do ciclo Síntese-Teste-Análise-Síntese. 21

Figura 8. Atividade biológica de dipeptidil nitrilas frente a amastigota de L. infantum (azul) em comparação com a célula hospedeira (vermelho). 22

Figura 9. Análise de pares moleculares para compostos codificados como Neq0631 e Neq0636.23

Figura 10. Primeira série de compostos sintetizada para analisar a influência da estereoquímica na inibição da enzima CPB. 43

Figura 11. Segunda série de compostos. 44

Figura 12. Estrutura do Neq0631 com destaque para as posições de interação. 45

Figura 13. Etapas para catalogação de novos compostos no grupo NEQUIMED. 46

Figura 14. Cromatograma do composto Neq0799 (7) e os parâmetros para as bandas. 47

Figura 15. Espectro de massas para o Neq0799 (7) evidenciamento da sua razão isotópica. 48

Figura 16. Espectro de $\mathrm{RMN}$ de ${ }^{1} \mathrm{H}\left(500 \mathrm{MHz}, \mathrm{CDCl}_{3}\right)$ do composto Neq0799 (7). .... 49

Figura 17. Espectro de $\mathrm{RMN}$ de ${ }^{13} \mathrm{C}\left(125 \mathrm{MHz}, \mathrm{CDCl}_{3}\right)$ do composto $\mathrm{Neq0799} \mathrm{(7).}$ .52

Figura 18. Espectro de Infravermelho do composto Neq0799 (7). 53

Figura 19. Representação da estrutura cristalina da dipetidil nitrila (12), Neq0930....................55

Figura 20. Interações intermoleculares no cristal de Neq0930. ................................................56

Figura 21. Análise de pares moleculares - enântiomeros e adição do bromo. ...............................57

Figura 22. Análise de pares moleculares - diastereômeros. …...................................................58

Figura 23. Análise de pares moleculares - substituição pelo bromo na posição para. 60 


\section{LISTA DE ESQUEMAS}

Esquema 1. Mecanismo simplificado da catálise do substrato (A) e de inibição por nitrila (B) . 16

Esquema 2. Mecanismo de formação da imina a partir de um aminoéster.................................27

Esquema 3. Mecanismo para redução anti ao grupo fenilalanina............................................2 28

Esquema 4. Mecanismo para redução Syn da imina a partir da complexação com zinco...........29

Esquema 5. Mecanismo do acoplamento com HATU para a produção da dipeptidil nitrila....... 30

Esquema 6. Rota sintética simplificada para a produção do composto Neq0631.......................46 


\section{LISTA DE ABREVIATURAS, SIGLAS, SÍMBOLOS E FÓRMULAS}

\begin{tabular}{|c|c|}
\hline AcOEt & Acetato de etila \\
\hline $\mathrm{ACN}$ & Acetonitrila \\
\hline CAQI & Central de Análises Químicas Instrumentais do IQSC \\
\hline $\mathrm{CHCl}_{3}$ & Clorofórmio \\
\hline $\mathrm{CDCl}_{3}$ & Clorofórmio deuterado \\
\hline DIPEA & Diisopropiletilamina \\
\hline DMF & Dimetilformamida \\
\hline DMSO & Dimetilsulfóxido \\
\hline DMSO- $d_{6}$ & Dimetilsulfóxido deuterado \\
\hline ESI-MS & Espectrometria de massas com ionização por eletrospray \\
\hline FTIR & Espectroscopia de infravermelho por Transformada de Fourier \\
\hline HATU & 2-(1-H-7-azabenzotriazol-1-il)-1,1,3,3-tetrametiluronioexafluorofosfato \\
\hline HPLC & Do inglês High Performance Liquid Chromatography \\
\hline LC-MS & Cromatografia Líquida acoplada ao Espectrômetro de Massas \\
\hline $\mathrm{MeOH}$ & Metanol \\
\hline Neq & Código do banco de dados do grupo NEQUIMED \\
\hline $\mathrm{Ph}$ & Fenila \\
\hline $\mathrm{RMN}$ & Ressonância magnética nuclear \\
\hline RT & Do inglês retention time \\
\hline $\mathrm{rt}$ & Do inglês room temperature \\
\hline THF & Tetraidrofurano \\
\hline TLC & Do inglês thin layer chromatography \\
\hline$\delta$ & Deslocamento químico \\
\hline
\end{tabular}




\section{Sumário}

1 INTRODUÇÃ

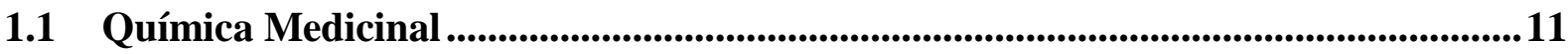

1.2 Doenças tropicais negligenciadas............................................................................................ 11

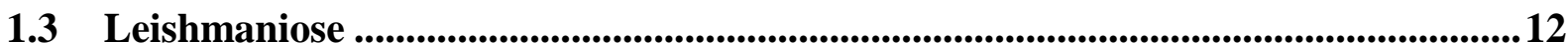

1.4 Cisteíno proteases e seus inibidores....................................................................................... 15

1.5 A Síntese orgânica na química medicinal ........................................................................19

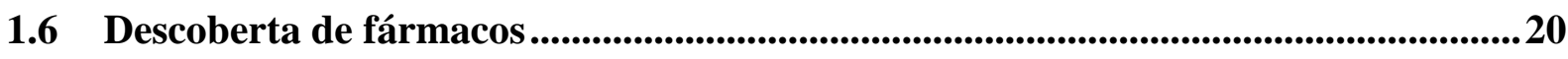

1.6.1 Testes de atividade biológica ............................................................................................... 22

1.6.2 Análise de pares moleculares e formulação da hipótese ...............................................23

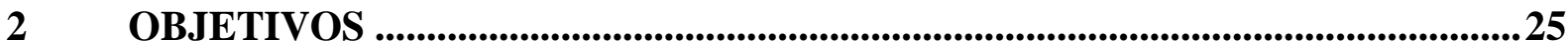

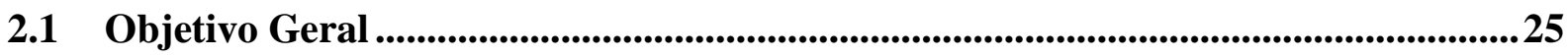

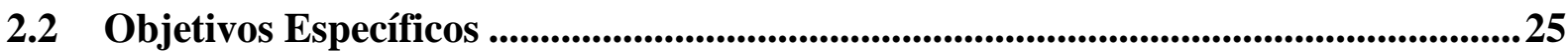

3 MATERIAIS E MÉTODOS ..................................................................................... 26

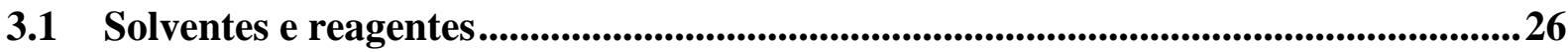

3.2 Síntese das iminas intermediárias 2,2,2-trifluorofenil ..........................................26

3.3 Redução diastereosseletiva para a formação dos intermediários aminoácidos........27

3.3.1 Redução anti ao grupo fenilalanina com boroidreto de sódio ...................................... 27

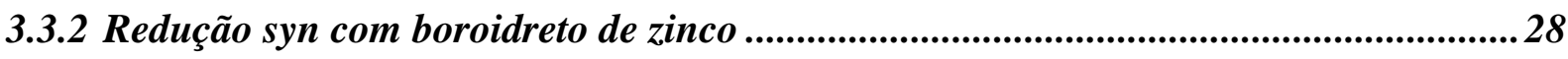

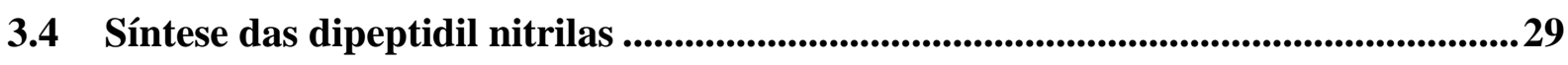

3.5 Identificação e caracterização dos compostos ....................................................30

3.6 Determinação da constante de inibição (Ki) para a enzima CPB.............................41

4 RESULTADOS E DISCUSSÃO

4.1 Síntese de dipeptidil nitrilas com potencial atividade inibitória de cisteíno proteases 43

4.2 Planejamento dos derivados e estratégia sintética ....................................................44

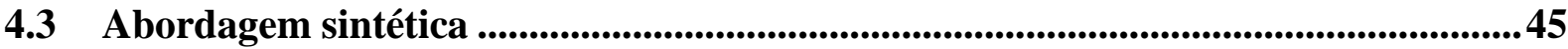




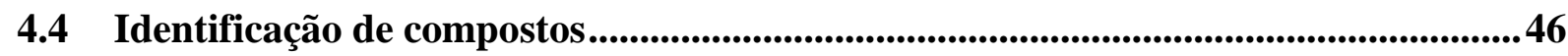

4.4.1 Purificação do composto Neq0799 (7).............................................................................47

4.4.2 Espectrometria de massas do composto Neq0799 (7) ...................................................48

4.4.3 Ressonância Nuclear Magnética de Hidrogênio do Neq0799 (7)..................................49

4.4.4 Ressonância Nuclear Magnética de ${ }^{13}$ C do Neq0799 (7) ............................................51

4.4.5 Espectroscopia no Infravermelho do composto Neq0799 (7)........................................53

4.5 Estrutura cristalina do composto Neq0930 (12) .................................................54

4.6 Testes de inibição da enzima CPB e Análise de pares moleculares ..........................56

5 CONCLUSÃO E PERSPECTIVAS ...............................................................................61

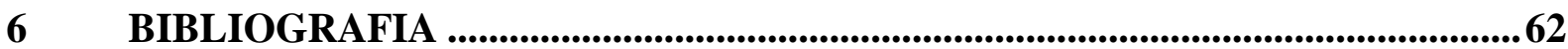

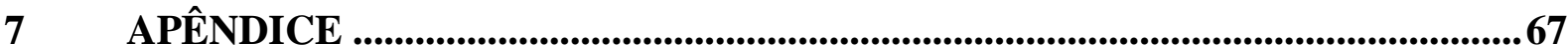




\section{INTRODUÇÃO}

\subsection{Química Medicinal}

A Química Medicinal é uma área essencial para a descoberta e desenvolvimento de candidatos a fármacos, com o planejamento de novos compostos químicos com efeitos terapêuticos de interesse [1,2]. Esta área é multidisciplinar, pois engloba os mais diversos aspectos, como por exemplo; fundamentos de química (em especial a química orgânica para a síntese dos compostos), bioquímica, biologia molecular, farmacologia, entre outros [3].

O processo de descoberta e desenvolvimento é complexo, de longa duração (em torno de 20 anos) e de alto custo, tendo suas raízes também ligadas às inovações científicotecnológicas para que possa acontecer. Nesta última década, a estimativa padrão para o custo do desenvolvimento de um fármaco estava acima de 2 bilhões de dólares americanos, divididos em duas fases: pré-clínica e clínica $[4,1]$.

No início da fase de descobertas de substâncias químicas bioativas é comum que se estude um determinado alvo macromolecular que será usado na pesquisa das pequenas moléculas. Desta forma, os compostos são sintetizados e testados in vitro de modo a encontrar a melhor substância em termos de potência para a modulação da atividade desta macromolécula alvo. Os compostos mais potentes são avaliados quanto às suas características farmacocinéticas, toxicidade e segurança, inicialmente em ensaios celulares e, posteriormente com uma pureza mais elevada, em animais. A etapa final deste processo é a solicitação junto à agência regulatória responsável pelo início dos ensaios clínicos em humanos utilizando-se os resultados obtidos como justificativa [5].

Os altos custos relacionados ao desenvolvimento de fármacos aliado ao baixo retorno econômico de medicamentos ligados a certas doenças que se desenvolvem em regiões úmidas, quentes e com subdesenvolvimento social, acabou levando ao negligenciamento no desenvolvimento de terapias para doenças tropicais [6].

\subsection{Doenças tropicais negligenciadas}

As Doenças Tropicais Negligenciadas são um grupo de doenças endêmicas que proliferam em regiões quentes e úmidas. Geralmente estas são consequências de 
subdesenvolvimento social, possuem alto índice de mortalidade e são de difícil tratamento, pois as mesmas possuem microrganismos resistentes aos escassos tratamentos existentes [7].

Essas doenças podem ser causadas por protozoários (doença de Chagas, doença do sono, leishmaniose e malária), helmintos (filaríase, ascaridíase, oncocercose, esquistossomose), bactérias (tuberculose, lepra, tracoma) e vírus (dengue e febre amarela) [8]. Esse grupo de doenças tropicais se tornou negligenciado, principalmente pelo baixo retorno financeiro à indústria farmacêutica. Embora exista uma necessidade cada vez maior de medicamentos eficazes, seguros e financeiramente acessíveis para estas doenças, a indústria argumenta que é essencial garantir a rentabilidade, crucial para que se possa reinvestir na pesquisa de novos fármacos. As patentes permitem a exclusividade de uma nova substância bioativo por um período de 20 anos a partir da data do seu depósito. Por outro lado, na prática, devido ao grande período de tempo necessário para desenvolver um novo fármaco para o mercado, a exclusividade de comercialização diminui para cerca de 12-14 anos. Como essas doenças acometem regiões menos desenvolvidas e, analisando o alto custo de investimento para o desenvolvimento de novos fármacos combinado com o retorno financeiro inadequado já mencionado, a pesquisa e desenvolvimento $(\mathrm{P} \& \mathrm{D})$ nessa área ainda é precária $[6,7]$.

Para reverter esse panorama, parcerias envolvendo uma tríade governo-universidadeempresa vêm sendo estabelecidas, como por exemplo Iniciativas de Medicamentos para Doenças Negligenciadas (DNDi - Drugs for Neglected Diseases Initiative). Este tipo de parceria viabiliza a descoberta de novas substâncias bioativas, utilizando o conhecimento científico presente na academia, gerando uma nova configuração de pesquisa e desenvolvimento no ambiente universitário. A partir dessas parcerias, tem-se desenvolvido medicamentos para doenças tropicais como, por exemplo, praziquantel (Bayer) para esquistossomose, Ivermectina (Merck) para oncocercose e miltefosina (Zentaris) para leishmaniose, que é endêmica no Brasil e encontrada no ambiente urbano e rural, destaque neste trabalho e descrita a seguir [6,9].

\subsection{Leishmaniose}

A leishmaniose é causada pelo protozoário Leishmania spp. e é transmitida principalmente pelo inseto popularmente conhecido como mosquito palha, birigui, entre outros nomes [10]. Cerca de 350 milhões de pessoas em 98 países, tropicais e subtropicais em sua 
maioria, são afetadas pela leishmaniose ou estão em áreas de risco da doença. A leishmaniose leva de 20 a 40 mil mortes anuais e 2 milhões de novos casos por ano [11,12]. Existem três tipos básicos da doença: leishmaniose visceral, muco-cutânea e cutânea, esta última é a forma mais frequente. A Figura 1 mostra a distribuição da doença pelo mundo.

Figura 1. Distribuição de leishmaniose cutânea (esquerda) e visceral (direita).

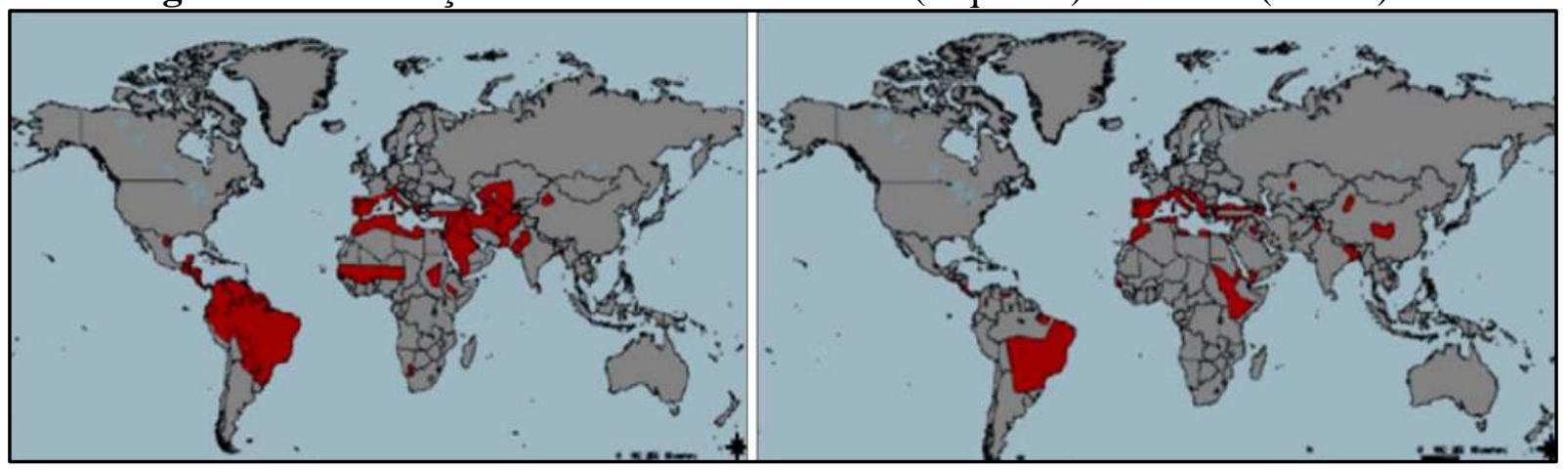

Fonte: Santos, D.O.; et al. Leishmaniasis treatment - a challenge that remains: a review.

Parasitol Res. 2008, 103, 1-10.

Pode-se observar na Figura 1 que a maior concentração dos casos de leishmaniose em geral encontra-se na África, Oriente Médio e na América do Sul. Cerca de 90\% dos casos de leishmaniose cutânea ocorrem no Irã, Afeganistão, Arábia Saudita, Síria, Peru e Brasil; e a maior incidência de leishmaniose visceral está na Índia, Bangladesh, Nepal, Sudão e Brasil $[12,13]$. Não existe tratamento efetivo para a leishmaniose e a melhor estratégia é o controle do inseto vetor da doença, ou seja, desinsetização das áreas de risco.

A leishmaniose visceral, também chamada Kalazar, febre negra ou esplenomegalia tropical, é uma doença crônica e endêmica em várias regiões do mundo. Afeta especialmente crianças e pessoas imunodeprimidas. O início da doença consiste em vários sintomas, com palidez, febre alta (sintoma mais notável devido à grande constância), aumento de volume do baço e do fígado, perda de apetite, anemia e hemorragias digestiva e da gengiva, e pode também afetar a medula óssea e os vasos linfáticos. A perda de apetite leva a um quadro de desnutrição, assim a doença tem uma evolução mais rápida e pode levar à morte em algumas semanas $[14,15]$.

A leishmaniose muco-cutânea caracteriza-se por lesões tardias, que surgem geralmente meses ou anos após a cura de uma lesão cutânea, destruindo preferencialmente mucosas do nariz, boca e garganta, que se estende progressivamente aos tecidos moles, com inflamação e ulceração. Posteriormente a lesão se aprofunda, e nestas lesões se encontram poucos parasitos 
[16,17]. Na maioria dos casos, a leishmaniose muco-cutânea resulta da leishmaniose cutânea com evolução crônica e curada sem tratamento ou com tratamento ineficiente.

A forma clínica cutânea é a mais frequente, provoca ulcerações na pele que tendem a cicatrização, conhecida como ferida brava ou úlcera de Bauru. Ela é caracterizada pela presença de lesões cutâneas de vários tipos, geralmente progredindo lentamente para uma úlcera crônica que pode disseminar progressivamente causando metástase nos tecidos. [16,18] As lesões podem variar no tamanho, medindo vários centímetros com características comuns como contornos regulares, inodoras, pouco exsudativas e fundo granuloso [19].

O tratamento quimioterápico é baseado no uso de antimoniais pentavalentes como medicamentos de primeira linha, com anfotericina B, paromicina, mitefosina e pentamidina como medicamentos de segunda linha [20] (Figura 2). Todos esses fármacos, apresentam grandes efeitos colaterais e sua eficácia não é alta, especialmente para os casos de leishmaniose visceral. A demanda por novos fármacos que possuem distintos mecanismos de ação em relação aos existentes está crescendo. Assim inibidores de cisteíno proteases apresentam-se como uma alternativa interessante para a terapêutica da leishmaniose devido à importância destas enzimas em diversos processos bioquímicos do parasito [13]. 
Figura 2. Fármacos usados atualmente no tratamento de leishmaniose.

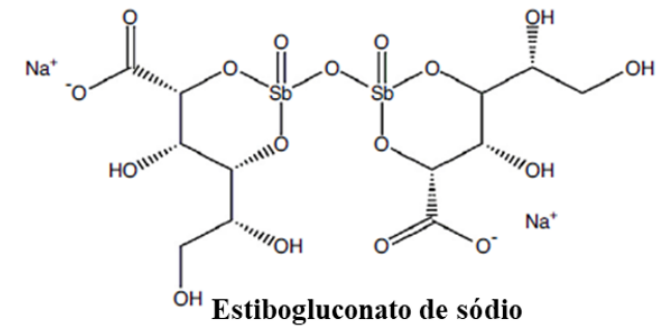

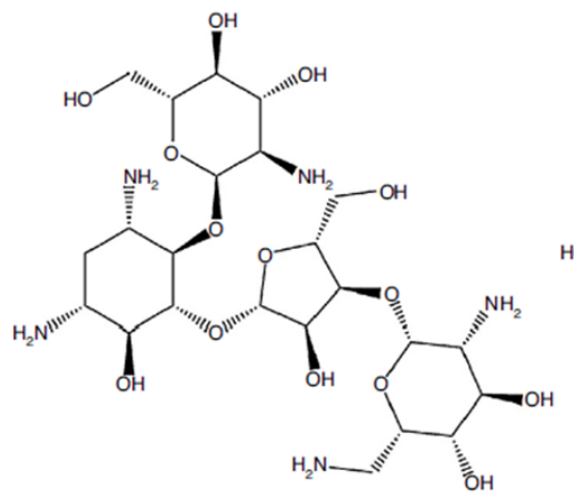<smiles>O=S(=O)(O)O</smiles>

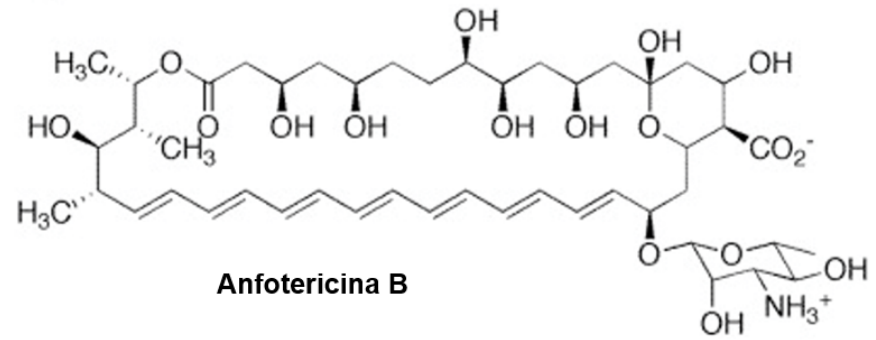

Paromomicina<smiles>N=C(N)c1ccc(OCCCCCOc2ccc(C(=N)N)cc2)cc1</smiles><smiles>CCCCCCCCCCCCCCCCOP(=O)([O-])OCC[N+](C)(C)C</smiles>

Fonte: Adaptado de Zulfiqar; Shelper, T. B.; Avery, V. M. Leishmaniasis drug discovery: recent progress and challenges in assay development. Drug Discovery Today, 2017, 1-16.

\subsection{Cisteíno proteases e seus inibidores}

Proteases são enzimas que hidrolisam ligações peptídicas em peptídios através de um ataque nucleofílico no carbono da amida, seguido da hidrólise de um intermediário tetraédrico. Dentre estas peptidases, tem-se o grupo das cisteíno proteases, das quais fazem parte algumas catepsinas das células de mamíferos (superexpressas em diversos tipos de câncer), cruzipaína (expressa em todas as formas do Trypanossoma cruzi), CPA, CPB e CPC (identificada em Leishmania spp.) [21].

O mecanismo de hidrólise de peptídeos desempenhado pelas cisteíno proteases é mostrado no Esquema 1 e inicia-se com uma reação ácido-base, com desprotonação do grupo tiol do resíduo de cisteína pelo resíduo de histidina, o que resulta em um aumento da nucleofilicidade deste grupo. O nucleófilo ataca a carbonila da ligação peptídica formando o primeiro intermediário tioéster tetraédrico da reação. Este intermediário é então estabilizado através de ligação de hidrogênio com um resíduo de glutamina altamente conservado presente 
na cavidade do oxiânion. Em sequência, há a liberação do fragmento amino terminal do substrato, com formação do intermediário acil-enzima. Este último é atacado por um nucleófilo proveniente da molécula de água, com formação de um segundo intermediário tetraédrico, que é estabilizado pela cavidade do oxiânion. Por fim o carboxilato é liberado restabelecendo a enzima, após a restituição do estado inicial do sítio catalítico. Quando um inibidor de cisteíno protease é adicionado em meio enzimático, o tiolato formado a partir da reação ácido-base irá formar uma ligação covalente com o grupo reativo deste composto, causando assim a inibição da enzima $[22,23,24]$.

Esquema 1. Mecanismo simplificado da catálise do substrato (A) e de inibição por nitrila (B)

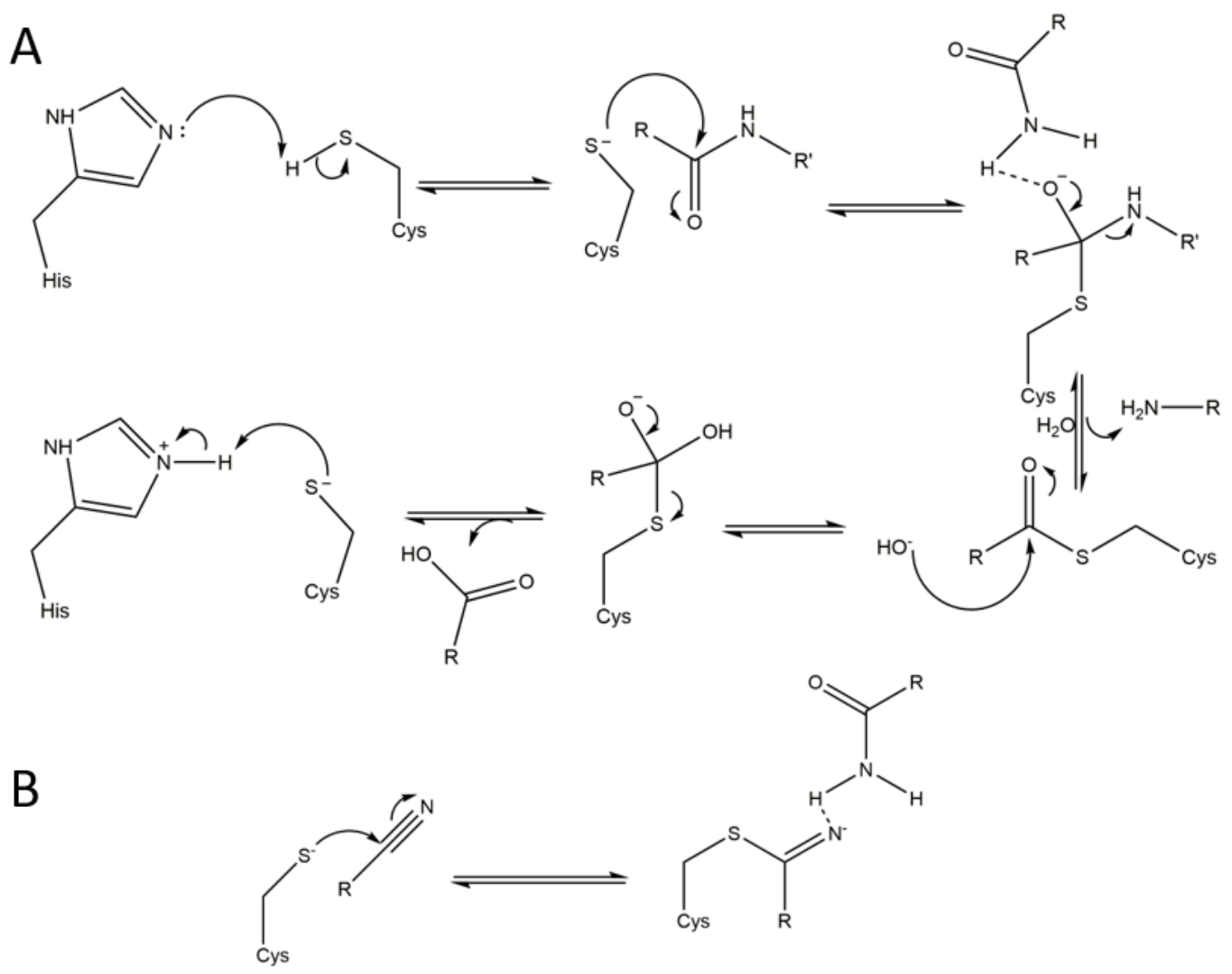

Fonte: autoria própria

Três tipos de inibidores de cisteíno proteases são descritos na literatura: (I) covalentes irreversíveis, como a vinilsulfona K777 (Figura 3), que atuam como aceitadores de Michael, dentre outros grupos com centros eletrofílicos que serão atacados pelo nucleófilo (tiolato da cisteína) formando uma ligação covalente estável. Há uma inativação da enzima, que pode acarretar efeitos colaterais severos. A vinilsulfona K777 foi desenvolvida até o final da fase 
pré-clínica, mas não recebeu autorização do órgão regulamentador dos Estados Unidos para prosseguir a fase clínica. (II) inibidores covalentes reversíveis, que interagem e forma a ligação covalente com o centro reativo na enzima, mas esta ligação é instável e se quebra, com retorno ao estado inicial, como foi discutido anteriormente (Esquema 1). (III) inibidores não covalentes reversíveis - que interagem reversivelmente e formam um complexo não covalente com a enzima, mas usualmente apresentam baixa afinidade pela enzima. [21,25]

Figura 3. Representação da estrutura química do K777, uma vinilsulfona que forma ligação covalente irreversível com a cisteíno protease.

Fonte: Autoria própria

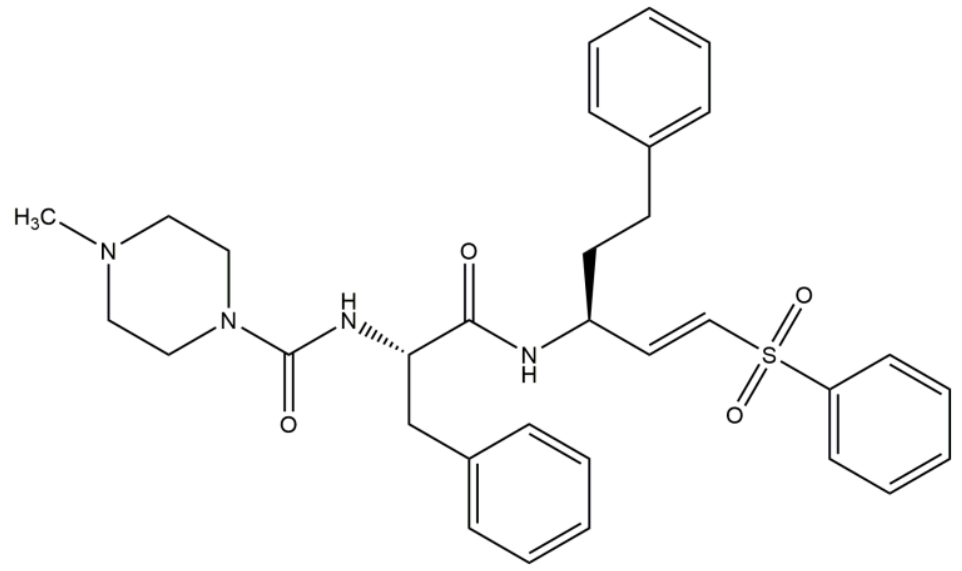

As nitrilas vêm sendo usadas frequentemente como inibidoras covalentes reversíveis de cisteíno proteases (Esquema 1) e estudos têm demonstrado que este tipo de composto apresenta propriedades farmacocinéticas e farmacodinâmicas adequadas para se tornar um fármaco, como observado para o Odanacatib. O composto Odanacatib (Figura 4) é um derivado de dipeptidil nitrila inibidor de catepsina $\mathrm{K}$ que foi desenvolvido até a fase clínica III para o tratamento da osteoporose. O estudo do candidato a fármaco foi descontinuado ao final devido a um problema cardíaco identificado somente após uso crônico em ensaios que demandaram mais de uma década [26]. No entanto, a administração de um fármaco com atividade antiparasitária ou antineoplásica demandaria um curto intervalo de tempo (semanas), o que não levaria a este tipo de efeito colateral. Desta forma, este tipo de substância apresenta uma arquitetura estrutural interessante para novos candidatos a fármacos com menores reações adversas. Além disso, estudos estão sendo desenvolvidos para alterar a estrutura do Odanacatib para evitar a cardiopatia crônica, o que poderá levar a obtenção de um derivado para uso crônico (anos) para o tratamento da osteoporose. 
Figura 4. Representação da estrutura química do Odanacatib.<smiles>CC(C)(F)C[C@H](N[C@@H](C(=O)NC1(C#N)CC1)c1ccc(-c2ccc(S(C)(=O)=O)cc2)cc1)C(F)(F)F</smiles>

Fonte: Siklos, M.; Benaissa, M.; Thatcher, G.R. Cysteine proteases as therapeutic targets: does selectivity matter? A systematic review of calpain and cathepsin inhibitors. Acta Pharm. Sinica B 2015, 5, 506519.

O Grupo de Química Medicinal (NEQUIMED) tem estudado nitrilas como inibidoras de cisteíno proteases com simplificação de estrutura em relação ao Odanacatib. Diversos derivados de dipeptidil nitrilas têm sido sintetizados e publicados pelo grupo, sobretudo com atividade anti-T. cruzi reportada para o composto Neq0409 (Figura 5) [27].

Figura 5. Representação estrutural de um derivado de dipeptidil nitrila sintetizado no grupo de pesquisa NEQUIMED.

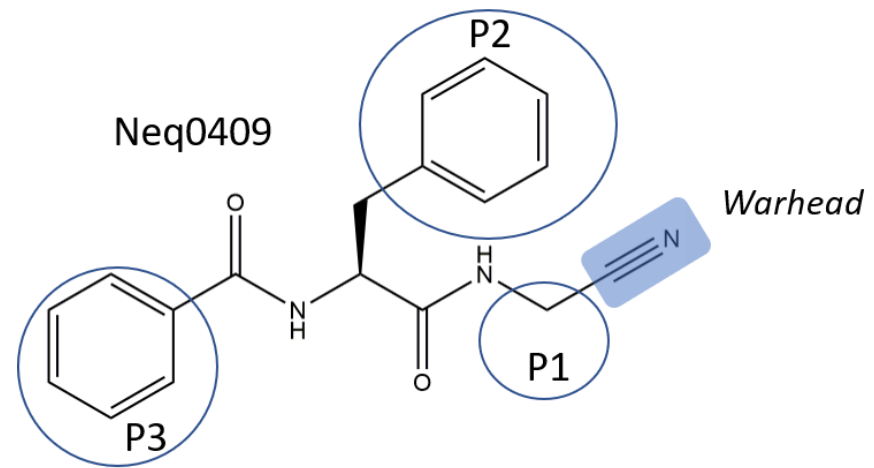

Fonte: AVELAR, L. A.; AL., E. Molecular Design, Synthesis and Trypanocidal Activity of Dipeptidyl Nitrile as Cruzain Inhibitors. PLoS Negl. Trop. Dis. 2015, e0003916.

Ao analisar a estrutura de um fármaco a ser estudado, deve-se considerar os grupos que interagirão com os sítios ativos das enzimas a serem inibidas. $\mathrm{O}$ grupo ciano interage com o sítio catalítico. Vizinho a esta se encontra o subsítio $\mathrm{S} 1$, onde substituintes podem ser adicionados ao carbono alfa ao grupo ciano na posição P1. Outras posições devem ter interação 
com os subsequentes subsítios, sendo as posições P2 e P3 as mais importantes, pois o subsítio S2 é responsável pela seletividade do substrato e S3 pela afinidade (Figura 6) [28].

Figura 6. Representação dos subsítios enzimáticos de cisteíno proteases.

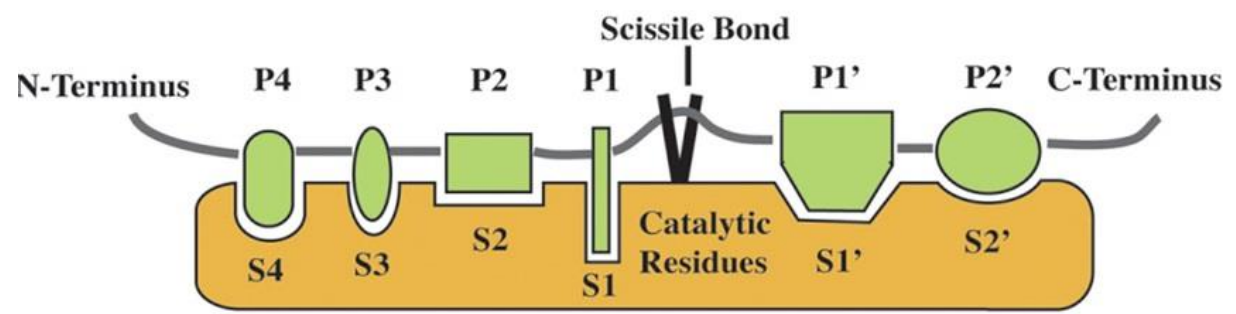

Fonte: FARADY, C. J.; CRAIK, C. S. Mechanisms of macromolecular protease inhibitors. ChemBioChem 2010, 11, 2341-2346.

No caso do Neq0409, as posições P2 e P3 podem ser alteradas em busca de uma maior potência. A amida presente entre as posições P2 e P3 foi alterada para um de seus bioisósteros, que é um substituinte químico ou grupo que produz efeitos biológicos similares ao substituinte originalmente presente na molécula. Este é o caso do grupo $\mathrm{CF}_{3}$ em relação à carbonila originalmente presente. No entanto, o derivado trifluorado possui maior estabilidade química e biológica e auxilia a estrutura a manter um ângulo de ligação próximo aos $120^{\circ}$ devido ao volume deste grupo [29]. A maior parte destes compostos tem sido estudada como inibidores de cruzaína do $T$. cruzi, com poucas informações disponíveis em relação a atividade frente a CPB e leishmaniose. Desta forma, derivados de dipeptidil nitrilas têm sido mais recentemente estudados frente ao alvo enzimático e celular, o que requer a síntese de substâncias bioativas.

\subsection{A Síntese orgânica na química medicinal}

Devido à sua grande presença no processo de obtenção de moléculas bioativas, tanto sintéticas, quanto em moléculas de outras fontes que venham a precisar de modificações estruturais em etapas posteriores no desenvolvimento de um fármaco, o avanço da Química Medicinal é dito estar relacionado principalmente com o avanço da ciência da Síntese Orgânica [30].

Dentro da síntese orgânica, as estratégias de síntese podem ser dividas de duas formas: (I) síntese orientada pela diversidade, do inglês Diversity Oriented Synthesis (DOS), onde as reações resultam em produtos com estruturas diversificadas; (II) síntese orientada pelo alvo, do 
inglês Target Oriented Synthesis (TOS), que será abordada neste trabalho, na qual os passos reacionais culminam em análogos que poderão interagir com um alvo específico, o que leva a utilização de vias sintéticas lineares ou convergentes. É utilizado a análise retrossintética dos compostos, partindo-se do produto até a determinação de materiais de partida mais simples [31]. No contexto da Química Medicinal, geralmente acontece através da síntese de compostos a partir de um arcabouço químico, realizando modificações nos substituintes com o objetivo de avaliar as suas propriedades físico-químicas e a resposta biológica [30].

Após a escolha da abordagem sintética, o próximo passo é definir quais reações são necessárias para a síntese do produto desejado. Em um estudo conduzido por Carey et al. 2005 analisando 1039 reações realizadas para a síntese de 128 candidatos a fármaco, foi observado que 8 etapas em média são necessárias para a finalização de uma síntese. As reações podem ser divididas em dois grupos principais: reação de construção, que constituem formação de ligações carbono-carbono, como alquilação e arilação de heteroátomos, acilação entre outras; e reações de modificação, que são representadas pelas reações de oxirredução, resolução de enantiômeros, proteção e desproteção de funções orgânicas, adição e interconversão de grupos funcionais. Levando em consideração a quiralidade das substâncias em questão, $54 \%$ destas possuem ao menos um centro quiral, sendo que a obtenção do centro estereogênico para esses candidatos pode ocorrer de três formas: (i) na síntese (levando a um produto quiral); (ii) diretamente a partir dos centros estereogênicos dos materiais de partida; (iii) ou ainda em ambas as condições em conjunto [32,33].

\subsection{Descoberta de fármacos}

Existem diversos métodos de descoberta de substâncias bioativas denominadas hits, tal como High-Throughput Screening (HTS) que é um método utilizado na identificação de ligantes e consiste em uma avaliação de milhões de compostos (da ordem de $10^{6}$ ) contra um alvo de interesse. Nos últimos anos um outro método tradicional, alternativo ao HTS, tem se desenvolvido de forma relevante que é a chamada descoberta baseada em fragmentos (do inglês, Fragment Based Drug Design, FBDD) [34]. O FBDD utiliza para a seleção de ligantes uma biblioteca de pequenos fragmentos (massa molecular $\leq 250 \mathrm{Da}$ ), ao invés de bibliotecas de moléculas maiores (massa molecular $\approx 500 \mathrm{Da}$ ) como o utilizado no HTS. Essa abordagem permite rastrear o espaço químico de forma mais eficiente utilizando uma quantidade menor de 
compostos [35]. Outro método de descoberta de fármacos, utilizado neste trabalho, é conhecido como desenvolvimento baseado em hipóteses, que é descrito a seguir.

O desenvolvimento baseado em hipóteses (do inglês Hypothesis-driven Development) consiste em inicialmente fazer observações e formular hipóteses, então projetar um experimento que permita testá-las e definir quais parâmetros serão utilizados para avaliar os resultados obtidos. A seguir são realizados os experimentos e, por fim, é preciso avaliar os resultados para aceitar ou rejeitar as hipóteses e, se necessário, formular e testar novas hipóteses. Este processo é conhecido como ciclo síntese-teste-análise-síntese (mostrado simplificadamente na Figura 7) e cada etapa depende da que a precede para possibilitar uma maior velocidade e qualidade dos resultados obtidos por meio de uma equipe multidisciplinar $[36,37]$.

Figura 7. Representação do ciclo Síntese-Teste-Análise-Síntese.

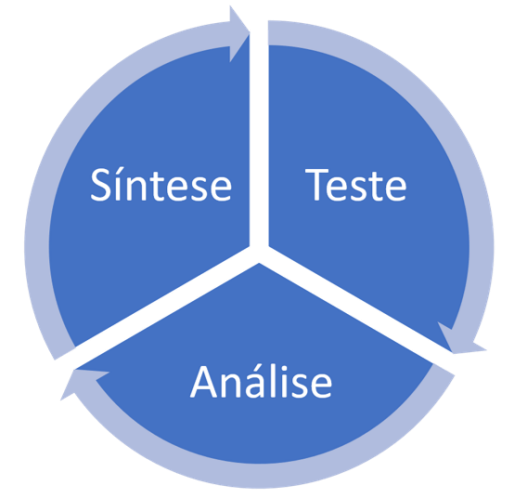

Fonte: Autoria própria.

A pesquisa orientada por hipóteses é uma estratégia altamente eficiente e produtiva para a descoberta de novos fármacos, pois cada molécula projetada e testada gera informações valiosas que orientam o caminho da decisão em direção a um resultado significativo. Quando a informação estrutural sobre um alvo ou macromolécula não está disponível ou não é clara o suficiente, é possível encontrar informações sobre um possível farmacóforo a partir de análogos que possuam características compatíveis com o alvo desejado. Ao mesmo tempo deve-se incorporar grupos que previnam efeitos indesejados, ou direcionar a molécula para o alvo via modificações químicas dirigidas [1]. 


\subsubsection{Testes de atividade biológica}

Previamente a este trabalho foram realizados testes de atividade biológica frente à forma amastigota da Leishmania infantum e que servium como base para a estruturação deste trabalho. Os testes foram realizados em parceria com o Instituto de Ciências Biomédicas (ICB-USP) em São Paulo pelos pesquisadores Dr. Lúcio Freitas Jr. e Dra. Carolina Borsoi Moraes.

Na Figura 8 é observado a resposta celular dos compostos tidos como ponto de partida na primeira série de substâncias sintetizadas: Neq0594, Neq0631 e Neq0636. A linha vermelha nos gráficos representa um grupo de células hospedeiras não infectadas na qual o composto foi testado, o que avaliou a citotoxicidade da molécula. A linha azul representa as células infectadas com a forma amastigota da Leishmania infantum, que avaliou se a molécula leva a morte dos parasitos.

Figura 8. Atividade biológica de dipeptidil nitrilas frente a amastigota de L. infantum (azul) em comparação com a célula hospedeira (vermelho).
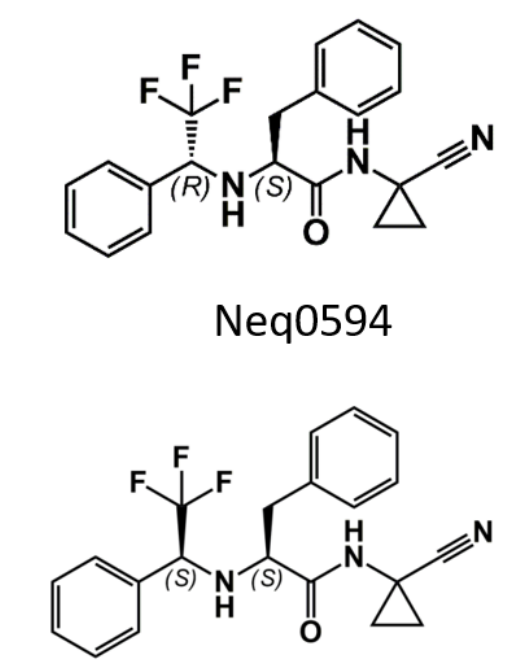

Neq0631

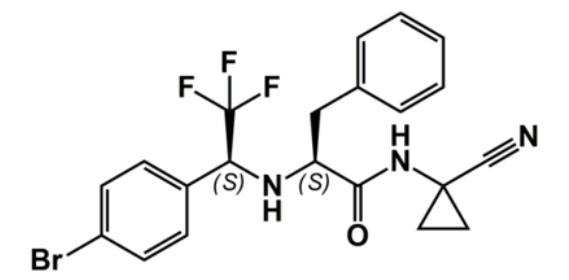

Neq0636
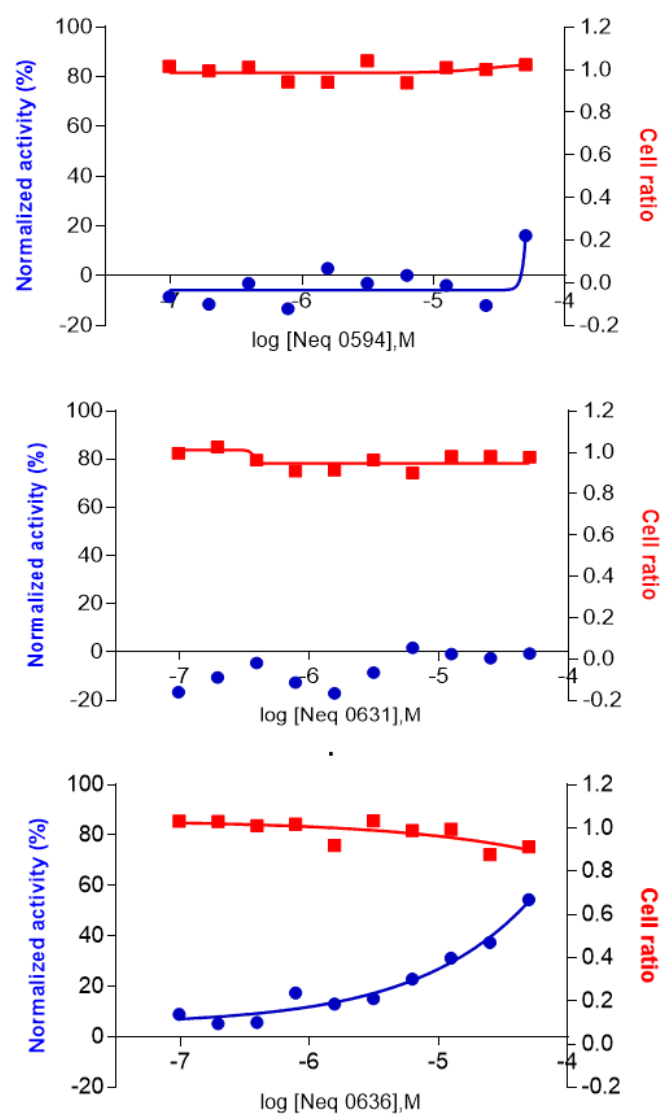

Inativo

Inativo

Ativo

Seletivo

Fonte: Autoria própria 
Os compostos Neq0594 e Neq0631 foram inativos frente às células saudáveis, e parasitos. O gráfico referente ao composto Neq0636 mostra um resultado bastante interessante. O composto mostrou-se ativo nas amastigotas do parasito, com morte celular quando a concentração de Neq0636 foi aumentada, porém o mesmo não ocorreu quando exposto às células saudáveis. Ou seja, o composto é seletivo. Desta forma, este é um bom ponto de partida para estudar uma série de substâncias bioativas.

\subsubsection{Análise de pares moleculares e formulação da hipótese}

A Análise de pares moleculares é um método comparativo no qual pares de compostos, diferenciando-se por uma única transformação química, são analisados em relação às mudanças no potencial de inibição contra uma enzina de interesse, neste caso a cisteíno protease $\mathrm{B}(\mathrm{CPB})$ [38].

Devido aos resultados obtidos na análise de atividade biológica, foi investigado o potencial de inibição dos compostos contra a enzima CPB. Os resultados para as substâncias Neq0631 e Neq0636 são mostrados na Figura 9.

Figura 9. Análise de pares moleculares para compostos codificados como Neq0631 e Neq0636.

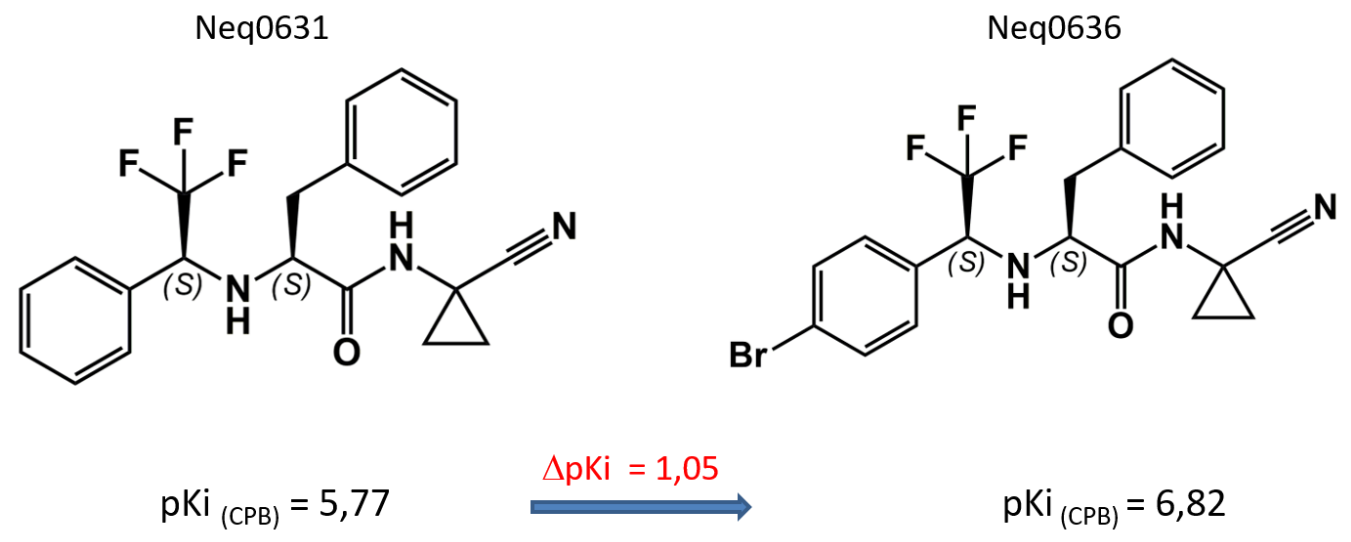

Fonte: Autoria própria.

A análise trazida na Figura 9 mostra que a substituição do hidrogênio (Neq0631) por um brometo (Neq0636) na posição para da fenila na posição P3 da molécula resulta num aumento no potencial de inibição na ordem de 10 vezes, o que corroborou com os resultados de atividade biológica que mostraram o maior potencial do Neq0636. 
Com esses resultados combinados criou-se a hipótese inicial desse trabalho: sintetizar análogos dessas moléculas mostradas na Figura 9 incluindo seus estereoisômeros para que pudesse ser estudado através da análise de pares moleculares qual análogo possui maior potencial de inibição e qual estereoisômero possui a maior afinidade para a enzima CPB. 


\section{OBJETIVOS}

\subsection{Objetivo Geral}

O presente trabalho teve como objetivo a síntese diastereosseletiva planejada baseado em hipótese de uma série de quinze derivados de dipeptidil nitrilas que podem potencialmente atuar como inibidores covalentes reversíveis de cisteíno proteases, com potencial bioatividade contra Leishmania sp.

\subsection{Objetivos Específicos}

Baseando-se em compostos já utilizados pelo grupo NEQUIMED e cujas propriedades bioquímicas, biofísicas e tóxicas são conhecidas pelo grupo, tem-se a síntese dirigida de derivados variando os substituintes nas posições P2 e P3, correspondentes aos subsítios das enzimas (S2 e S3), visando o aumento na potência da atividade antiparasitária.

Caracterização das substâncias de interesse, com grau de pureza mínimo de 95\% necessário para realizar ensaios, de acordo com padrões da literatura [39].

Estabelecimento do ciclo síntese-teste-análise-síntese baseado no planejamento usando as hipóteses de interação intermolecular observadas entre a cisteíno protease CPB, a partir de estudos bioquímicos realizados por outros membros do grupo. 


\section{MATERIAIS E MÉTODOS}

\subsection{Solventes e reagentes}

Na síntese dos compostos de interesse foram utilizados solventes orgânicos com grau de pureza P.A. como acetato de etila (AcOEt), $n$-hexano, tetraidrofurano (THF) dimetilformamida (DMF) da marca Synth e Fisher Scientific. Quando necessário, foram destilados e armazenados em peneira molecular $3 \AA(20 \% \mathrm{~m} / \mathrm{v})$. Também foram utilizados solventes anidros como metanol e THF, enquanto que para a utilização da cromatografia líquida de alta performance (do inglês HPLC), foram empregados solventes de pureza grau HPLC provenientes da Tedia ou Fisher Scientific, ou ainda de pureza grau LC-MS, quando utilizada a técnica acoplada a um espectrômetro de massas.

Os demais reagentes foram fornecidos pelas empresas Combi-Blocks, Enamine e SigmaAldrich, todos com pureza superior a $97 \%$.

Para o monitoramento das reações foi utilizada Cromatografia em Camada Delgada (uma placa com matriz sílica gel, com espessura de camada de $200 \mu \mathrm{m}$, em suporte de alumínio da marca Sigma-Aldrich), revelador ácido fosfomolíbdico $(20 \% \mathrm{~m} / \mathrm{v})$, luz UV $254 \mathrm{~nm}$. Para a purificação dos compostos intermediários e finais por cromatografia em coluna utilizou-se sílica gel com tamanho de poro $60 \AA$ e tamanho de partícula 220-440 mesh $(35-75 \mu \mathrm{m})$ da Sigma-Aldrich ou da Fluorochem, com solventes destilados previamente ou de alta pureza.

\subsection{Síntese das iminas intermediárias 2,2,2-trifluorofenil}

O método usado nesta etapa foi descrito por Chen e colaboradores [40], Esquema 2. Brevemente, em um balão de duas bocas de $100 \mathrm{~mL}$, os aminoésteres de partida reagiram com 2,2,2- trifluoroacetofenona (ou outro derivado de 2,2,2-trifluoroacetofenona de interesse), na presença de carbonato de potássio (2,5 eq.) em metanol (concentração final $0,5 \mathrm{~mol} \mathrm{x} \mathrm{L}^{-1}$ ), em sistema de refluxo a $50{ }^{\circ} \mathrm{C}$ e sob atmosfera de argônio por $18 \mathrm{~h}$, para fornecer as respectivas iminas.

Ao término da reação, a mistura reacional foi filtrada em papel de filtro e o produto concentrado sob pressão reduzida (para a redução com boroidreto de sódio) ou mantido na sua solução em metanol (para a redução com boroidreto de zinco). O composto formado foi usado na próxima etapa sem passar por qualquer purificação cromatográfica devido à instabilidade da imina. 
Esquema 2. Mecanismo de formação da imina a partir de um aminoéster.

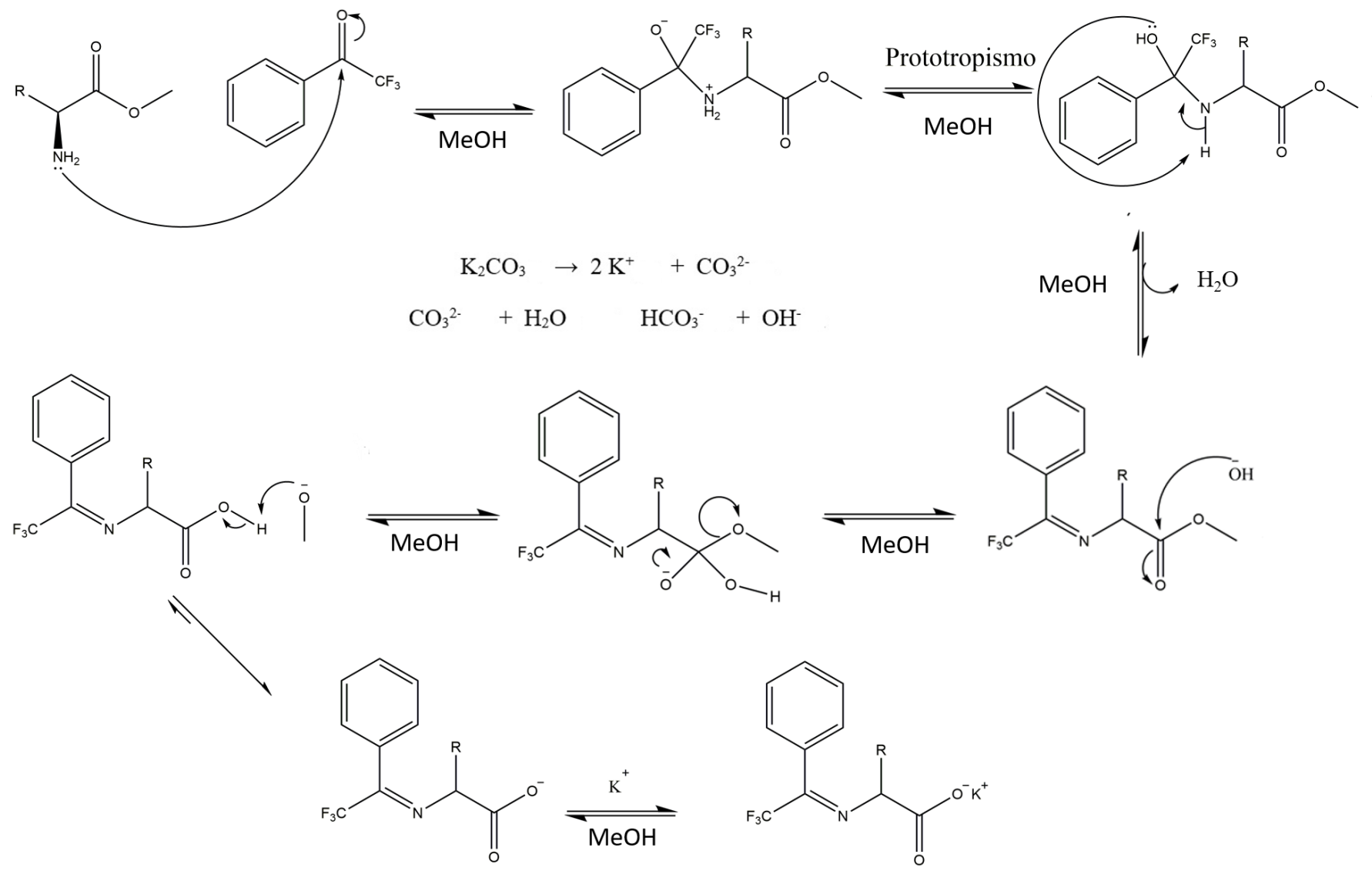

Fonte: Adaptado de Chen, C. Y.; Devine, P. N.; Foster, B. S.; Hughes, G.; O’Shea, P. US Patent, 0030731 A1, 2006.

\subsection{Redução diastereosseletiva para a formação dos intermediários aminoácidos}

Como a imina em forma de sal de potássio é bastante instável, a mesma deve ser reduzida imediatamente. Nessa etapa reacional ocorre a definição da estereoquímica dos produtos finais. Dois procedimentos experimentais distintos foram descritos por Hughes, Greg et al. [41]. Ambos foram adaptados e serão abordados detalhadamente nos tópicos a seguir.

\subsubsection{Redução anti ao grupo fenilalanina com boroidreto de sódio}

As iminas foram dissolvidas em THF anidro e colocadas na presença de boroidreto de sódio. A reação foi mantida sob agitação magnética por $4 \mathrm{~h}$ a temperatura ambiente para 
fornecer os aminoácidos derivados de 2,2,2-trifluorofenil. Ao final, o solvente foi evaporado e o resíduo dissolvido em água destilada. Uma extração líquido-líquido utilizando acetato de etila foi feita. Em seguida, a fase aquosa foi acidificada com $\mathrm{HCl}$ até pH 3 e uma segunda extração líquido-líquido utilizando acetato de etila foi efetuada. A fase orgânica foi seca com sulfato de magnésio anidro, filtrada e concentrada sob pressão reduzida. O produto foi obtido em rendimentos bons, acima de $70 \%$ de acordo com Hughes, Greg et al., sem a necessidade de purificação cromatográfica.

Para esse procedimento, o produto majoritário formado foi o isômero anti, na qual se obtém uma relação diastereoisomérica em torno de 95/05 [41]. A face $R e$ do intermediário trigonal planar encontra-se mais impedida em comparação a sua face $s i$ devido à presença da fenila no centro estereogênico do aminoácido de partida (Esquema 3).

Esquema 3. Mecanismo para redução anti ao grupo fenilalanina.
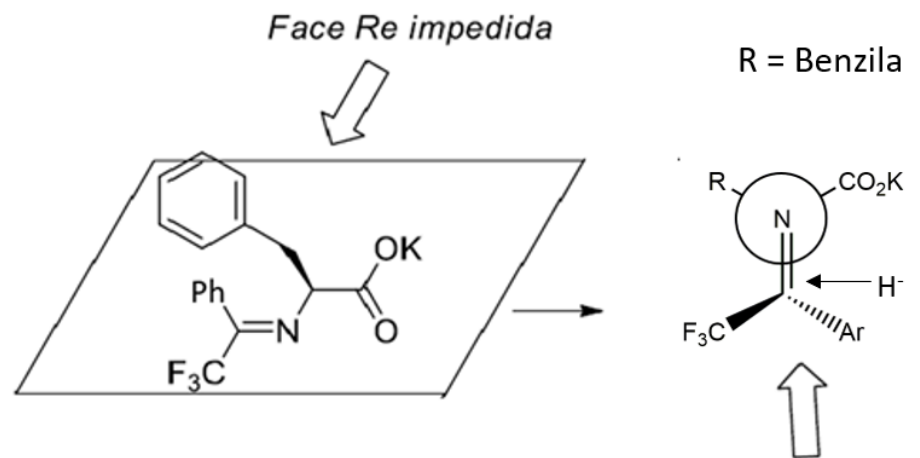

Ataque preferencialmente
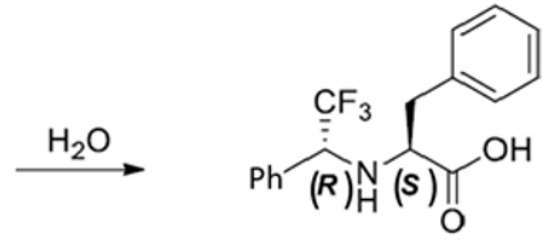

pela face Si

Isômero Majoritário

Fonte: Adaptado de Hughes, G. E. A.; Devine, P.; Naber, J.; O'Shea, P.; Foster, B.; McKay, D.; Volante, R. Diastereoselective Reductive Amination of Aryl Trifluoromethyl Ketones and $\alpha$-Amino Esters. Angewandte Chemie. Int. Ed. 2007, 46, 1839-1842.

\subsubsection{Redução syn com boroidreto de zinco}

As iminas em $\mathrm{MeOH}$ anidro foram diluídas em 10 vezes (v/v) em ACN tratada, resfriadas a $-40{ }^{\circ} \mathrm{C}$ e colocadas na presença de boroidreto de zinco previamente preparado. A reação foi mantida sob agitação magnética por 4-6 horas. Passado esse tempo, adicionou-se 10 $\mathrm{mL}$ de acetona e, a $0{ }^{\circ} \mathrm{C}$, acidificou-se a mistura reacional até $\mathrm{pH} 3 \mathrm{com} \mathrm{HCl}$, com posterior elevação lenta da temperatura para a ambiente sob agitação durante 20 minutos ou até a solução se tornar límpida. Uma extração líquido-líquido utilizando acetato de etila foi feita. A fase orgânica foi seca com sulfato de magnésio anidro, filtrada e concentrada sob pressão reduzida. 
O produto foi purificado por cromatografia em coluna com sílica gel utilizando-se como eluente da fase móvel, $n$-hexano/acetato de etila: $7 / 3$. O produto foi obtido em rendimentos de $15-30 \%$ para a série sintetizada no Brasil e $80-95 \%$ para a série sintetizada com o procedimento desenvolvido na Universidade de Nottingham, na Inglaterra, sob orientação do Prof. Dr. Barrie Kellam.

Para esse procedimento, o produto majoritário formado é o isômero syn em relação a fenilalanina, na qual se obtém uma relação diastereoisomérica em torno de 80/20 [41]. A face $S i$ do intermediário trigonal planar encontra-se mais impedida em comparação a sua face $R e$, pois neste caso há a formação de um complexo do zinco com o nitrogênio da imina, o que torna a face $R e$ mais suscetível ao ataque do íon hidreto (Esquema 4).

Esquema 4. Mecanismo para redução Syn da imina a partir da complexação com zinco.

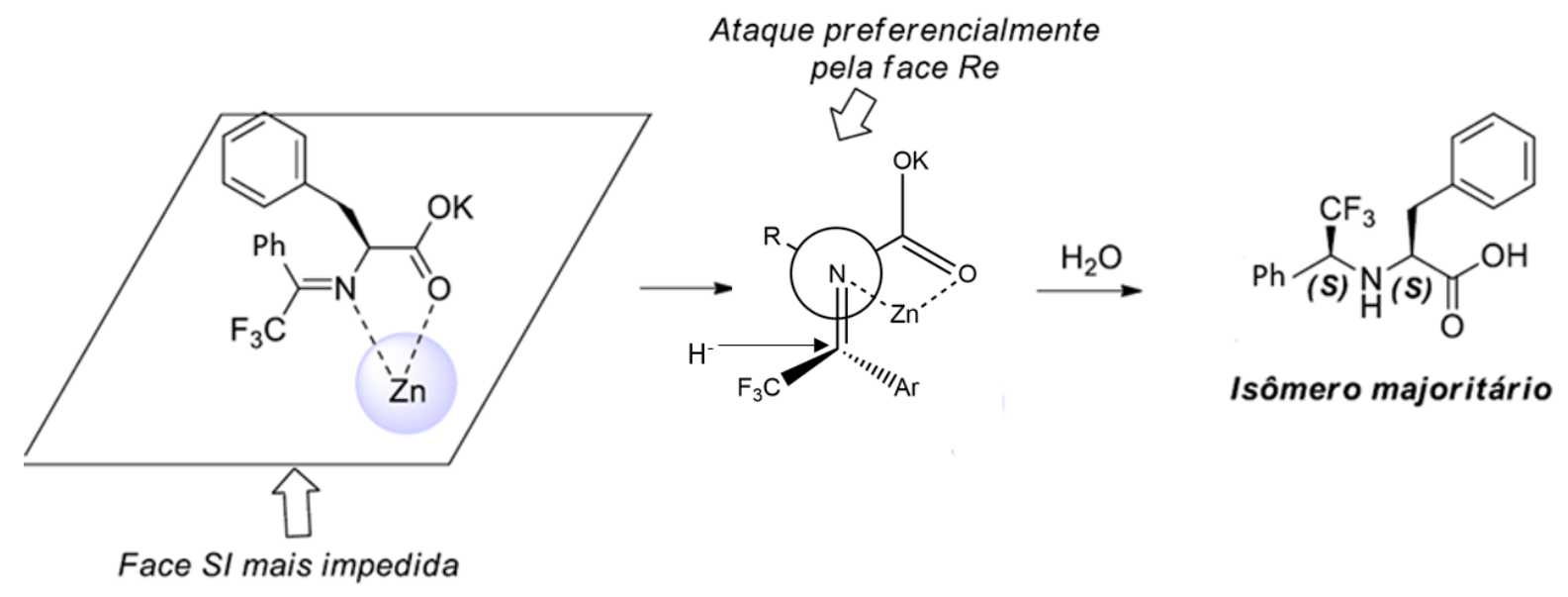

Fonte: Adaptado de Hughes, G. E. A.; Devine, P.; Naber, J.; O'Shea, P.; Foster, B.; McKay, D.; Volante, R. Diastereoselective Reductive Amination of Aryl Trifluoromethyl Ketones and $\alpha$-Amino Esters. Angewandte Chemie. Int. Ed. 2007, 46, 1839-1842.

\subsection{Síntese das dipeptidil nitrilas}

A última etapa da síntese das substâncias deste trabalho foi o acoplamento entre os aminoácidos 2,2,2-trifluorofenil (R) com a ciclopropilaminonitrila (R'). Este tipo de acoplamento peptídico é comumente realizado pela ativação do ácido carboxílico do aminoácido com um grupo benzotriazol, como é o caso do reagente escolhido, o hexafluorofosfato de 2-(1-H-7-azabenzotriazol-1-il)1,1,3,3-tetrametilurônio (HATU), juntamente com a di-isopropiletilamina (DIPEA) [42]. O Esquema 5 mostra o mecanismo desta etapa reacional. 
Os aminoácidos 2,2,2-trifluorofenil foram dissolvidos em dimetilformamida (DMF) seca, sob atmosfera de argônio, com adição de ciclopropilaminonitrila, HATU e DIPEA à solução. A reação permaneceu sob agitação magnética à temperatura ambiente por 90 minutos em média. O progresso da reação foi acompanhado por cromatografia em camada delgada (CCD). Ao término, foi adicionado à solução acetato de etila (10 vezes o volume de DMF) e em seguida a mistura foi lavada com solução saturada de cloreto de sódio (10 vezes) para a remoção de DMF. O produto resultante foi purificado por cromatografia em coluna de sílica gel utilizando como eluente $n$-hexano:acetato de etila (7:3). As dipeptidil nitrilas foram obtidas em rendimentos na faixa de 30-40\% na série de compostos feita no Brasil e 70-80\% após a otimização da síntese, realizada na Universidade de Nottingham (Inglaterra).

Esquema 5. Mecanismo do acoplamento com HATU para a produção da dipeptidil nitrila.
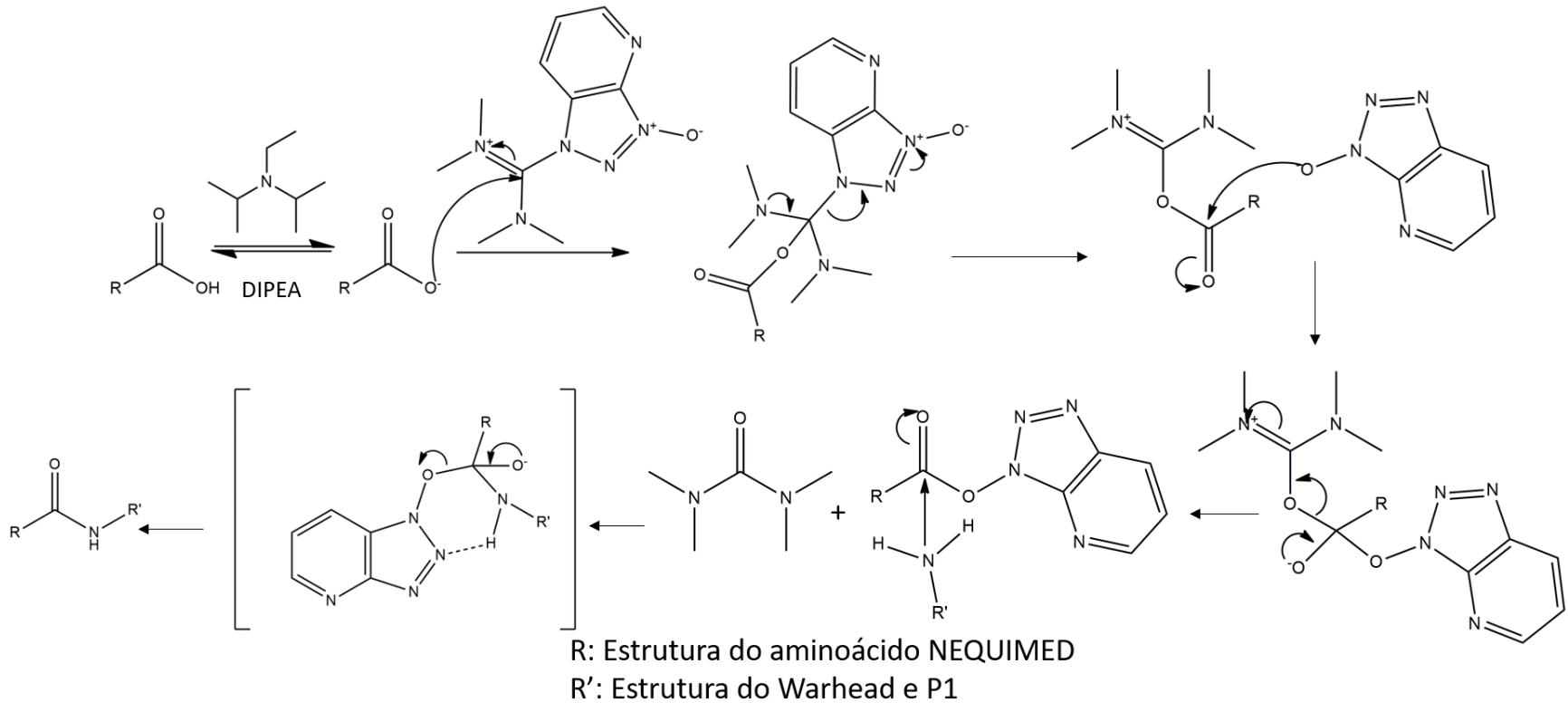

Fonte: Adapatado de Valeur, E.; Bradley, M. Amide bond formation: beyond the myth of coupling reagents. Chem. Soc. Rev. 2009, 38, 606-631.

\subsection{Identificação e caracterização dos compostos}

Para a Cromatografia Líquida de Alta Performance, foi utilizado um Cromatógrafo a Líquido, série Prominence 20AT da Shimadzu, com detecção por arranjo de diodos (DAD) spdM20A, coletor de frações FRC-10, coluna Luna C18 da Phenomenex (tamanho de partícula 5 $\mu \mathrm{m}$, tamanho do poro $1000 \AA$, 250 x 4,6 mm), duas colunas Gemini C18 da Phenomenex 
(tamanho de partícula $5 \mu \mathrm{m}$, tamanho do poro $110 \AA$ A, 250 x $4.6 \mathrm{~mm}$ e outra tamanho de partícula $5 \mu \mathrm{m}$, tamanho do poro $110 \AA 250$ x $21,2 \mathrm{~mm}$ ), coluna quiral de celulose 2-fases da Phenomenex (tamanho de partícula $5 \mu \mathrm{m}$, tamanho do poro $1000 \AA$ A, 250 x 4,6 mm), e uma coluna quiral Chiralpak IC ( $5 \mu \mathrm{m}$ de tamanho de partícula e 250 x 4,6 mm de diâmetro interno) para verificar se houve epimerização dos compostos. A quantificação da pureza enantiomérica das moléculas, considerando que o critério de pureza mínimo estabelecido para que se possa avançar para os testes biológicos foi de 95\% [39].

Para a análise estrutural dos produtos foram utilizadas as técnicas de Ressonância Magnética Nuclear de ${ }^{1} \mathrm{H}$ e ${ }^{13} \mathrm{C}$ no equipamento Agilent Technologies modelos 500/54 Premium Shield e 400/54 Premium Shield, da Central de Análises Químicas do Instituto de Química de São Carlos (CAQI) e 400 MHz Avance III HD Bruker spectrometer (1H, 13C, 19F e 31P) com um autosampler BACS120 da Universidade de Nottingham.

Também foi utilizada a técnica de Espectrometria de Massas no Espectrômetro de Massas do tipo Ion Trap amaZon SL da Bruker na CAQI-IQSC.

A técnica Espectroscopia de Infravermelho com Transformada de Fourier foi realizada em um Espetrofotômetro de Infravermelho, modelo IRAffinity 1, da Shimadzu (também disponibilizado pela CAQI-IQSC) e um equipamento Agilent Cary630, modelo com reflectância total atenuada (ATR), tecnologia DialPath (substitui células líquidas) disponibilizado pela Universidade de Nottingham.

Para a obtenção dos espectros de RMN, foram utilizados solventes como dimetilsulfóxido deuterado (DMSO- $\left.d_{6}\right)$ e clorofórmio deuterado $\left(\mathrm{CDCl}_{3}\right)$ da Sigma-Aldrich.

No caso da cristalografia de raio X, foi utilizado um difratômetro SuperNova Atlas S2 e os dados foram tratados com o software Olex2. A estrutura foi resolvida utilizando-se ShelXT e refinados intrinsecamente com procedimentos no ShelXL. Determinação da estrutura cristalina [TKNMPA] $\mathrm{C}_{22} \mathrm{H}_{22} \mathrm{~F}_{3} \mathrm{~N}_{3} \mathrm{O}$ ( $\mathrm{MM}=401,42 \mathrm{~g} / \mathrm{mol}$ ): ortorrômbico, grupo espacial P212121 (no. 19), $\mathrm{a}=9,65500$ (10) $\AA, \mathrm{b}=13,59830$ (10) $\AA$, $\mathrm{c}=15,78070(10) \AA, \mathrm{V}=2071,87(3)$ $\AA 3, \mathrm{Z}=4, \mathrm{~T}=120(2) \mathrm{K}, \mu(\mathrm{CuK} \alpha)=0,832 \mathrm{~mm}^{-1}$, Dcalc $=1,287 \mathrm{~g} / \mathrm{cm}^{3}, 19803$ reflexões foram medidas $\left(8,584^{\circ} \leq 2 \Theta \leq 149,212^{\circ}\right)$. Reflexões independentes: 4179 (Rint $=0,0221$, Rsigma $=$

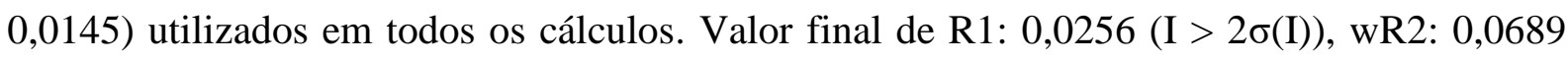
(utilizando todos os dados). Descrição do modelo de refinamento: Número de restrições nenhuma restrição reportada. As análises foram feitas na Universidade de Nottingham, Inglaterra, em parceria com o especialista em cristalografia Dr. Nicholas Pearce. 


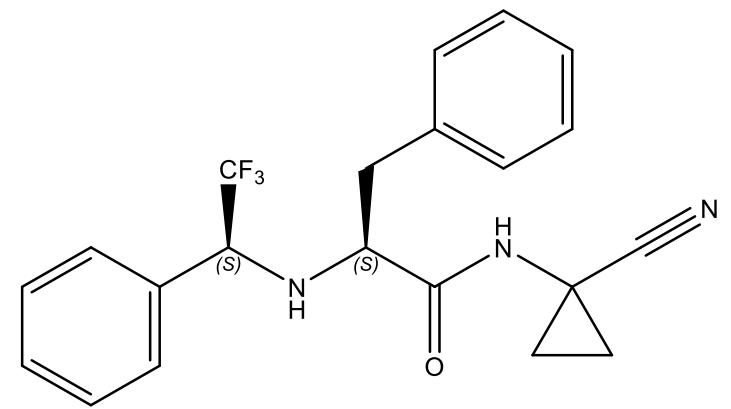

Rendimento global $=34 \%$ Sólido branco. $[\alpha] \mathrm{D}^{24}=+45,0^{\circ}\left(\mathrm{MeOH}, \mathrm{c}=1,07 \times 10^{-3} \mathrm{~g} / \mathrm{L}\right)$. FT-IR (KBr, vmax): 3329, 3246, 3032, 2237, 1649, 1539, 1499, 1456, 1263, 1171, 1126, 850, $742,567 \mathrm{~cm}^{-1}$. RMN ${ }^{1} \mathrm{H}\left(400 \mathrm{MHz}, \mathrm{CDCl}_{3}\right): \delta=0,86-0,91(\mathrm{~m}, 1 \mathrm{H}), 0,98-1,04(\mathrm{~m}, 1 \mathrm{H}), 1,40-$ $1,52(\mathrm{~m}, 2 \mathrm{H}), 2,17(\mathrm{~s}, 1 \mathrm{H}), 3,07(\mathrm{~m}, 2 \mathrm{H}), 3,42(\mathrm{t}, J=7,5 \mathrm{~Hz}, 1 \mathrm{H}), 3,98(\mathrm{q}, J=8,00 \mathrm{~Hz}, 1 \mathrm{H})$, 7,17-7,40 (m, 10H) ppm. RMN ${ }^{13} \mathrm{C}\left(100 \mathrm{MHz}, \mathrm{CDCl}_{3}\right): \delta=16,4,16,7,19,9,37,9,60,8,63,5$ (q, $J=63,49 \mathrm{~Hz}), 119,5,123,8,127,5,128,6,129,0,129,1,129,3,129,6,133,1,135,8,173,4$ ppm. HRMS (ESI): $m / z$ calculado para $\mathrm{C}_{21} \mathrm{H}_{21} \mathrm{~F}_{3} \mathrm{~N}_{3} \mathrm{O}[\mathrm{M}+\mathrm{H}]^{+}: 388,16312$; encontrado: 388, 16379 . CLAE: Chiralpak IC DAICEL, 25cm x 4,6 $\mu \mathrm{m}$, acetonitrila/água: 45:55, rt: 18,213 min, 206 $\mathrm{nm}$.

Este é um composto não original deste trabalho, porém refeito para fins de testes e as caracterizações foram condizentes com as da referência do trabalho de um membro anterior do grupo [43].

(S)-N-(1-cianociclopropil)-3-fenil-2-(((R)-2,2,2-trifluoro-1-fenil-etil)amino) propanamida (2)

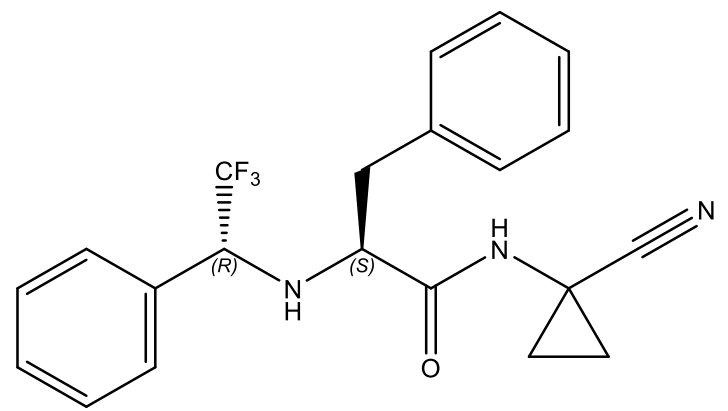

Rendimento global $=15 \%$ Óleo incolor. $[\alpha] \mathrm{D}^{24}=-59,57^{\circ}\left(\mathrm{MeOH}, \mathrm{c}=1,17 \mathrm{x} 10^{-3} \mathrm{~g} / \mathrm{L}\right)$. FT-IR (KBr, vmax): 3329, 3246, 3032, 2237, 1649, 1539, 1499, 1456, 1263, 1171, 1126, 850, $742,567 \mathrm{~cm}^{-1}$. RMN ${ }^{1} \mathrm{H}\left(400 \mathrm{MHz}, \mathrm{CDCl}_{3}\right): \delta=1,16-1,22(\mathrm{~m}, 1 \mathrm{H}), 1,26-1,32(\mathrm{~m}, 1 \mathrm{H}), 1,55-$ $1,65(\mathrm{~m}, 2 \mathrm{H}), 2,13(\mathrm{~s}, 1 \mathrm{H}), 2,68(\mathrm{dd}, J=9,87$ e $13,86 \mathrm{~Hz}, 1 \mathrm{H}), 3,14(\mathrm{dd}, J=4,25$ e $13,87 \mathrm{~Hz}$, 
1H), 3,24 (dd, $J=4,25$ e 9,85Hz, 1H), 3,74 (q, $J=7,73 \mathrm{~Hz}, 1 \mathrm{H}), 6,81(\mathrm{~d}, J=7,52 \mathrm{~Hz}, 2 \mathrm{H}), 7,19$ 7,33 (m, 6H), 7,71 (s, 1H) ppm. RMN ${ }^{13} \mathrm{C}\left(100 \mathrm{MHz}, \mathrm{CDCl}_{3}\right): \delta=16,4 ; 17,0 ; 20,1 ; 39,2 ; 63,6$ $(\mathrm{q}, J=63,59 \mathrm{~Hz}) ; 119,7 ; 123,7 ; 125,9 ; 127,4 ; 127,8 ; 128,8 ; 129,0 ; 129,1 ; 129,2 ; 132,2 ; 135,7$; 173,6 ppm. HRMS (ESI): $m / z$ calculado para $\mathrm{C}_{21} \mathrm{H}_{21} \mathrm{~F}_{3} \mathrm{~N}_{3} \mathrm{O}[\mathrm{M}+\mathrm{H}]^{+}: 388,16312$; encontrado: 388,16379. CLAE: Phenomenex celulose II, $25 \mathrm{~cm}$ x 4,6 $\mu \mathrm{m}$, acetonitrila/água: 50:50, rt: 21,115 $\min , 206 \mathrm{~nm}$.

Este é um composto não original deste trabalho, porém refeito para fins de testes e as caracterizações foram condizentes com as da referência do trabalho de um membro anterior do grupo [43].

(R)- $N$-(1-cianociclopropil)-3-fenil-2-(((S)-2,2,2-trifluoro-1-fenil-etil)amino) propanamida (3)<smiles>N#CC1(NC(=O)[C@H](Cc2ccccc2)N[C@@H](c2ccccc2)C(F)(F)F)CC1</smiles>

Rendimento global $=28 \%$ óleo incolor. $[\alpha]^{24}=+76,74^{\circ}\left(\mathrm{MeOH}, \mathrm{c}=0,86 \times 10^{-3} \mathrm{~g} / \mathrm{L}\right)$. FT-IR (KBr, vmax): 3319, 3001, 2953, 2247, 1687, 1596, 1517, 1263, 1173, 1125, 1074, 1012, $873,813,734,718,529 \mathrm{~cm}^{-1}$. RMN ${ }^{1} \mathrm{H}\left(500 \mathrm{MHz}, \mathrm{CDCl}_{3}\right): \delta=1,20-1,33(\mathrm{~m}, 2 \mathrm{H}) ; 1,55-1,64$ $(\mathrm{m}, 2 \mathrm{H}) ; 2,10(\mathrm{~s}, 1 \mathrm{H}) ; 2,67(\mathrm{dd}, J=10,00$ e $14,0 \mathrm{~Hz}, 1 \mathrm{H}) ; 3,14-3,24(\mathrm{~m}, 2 \mathrm{H}) ; 3,73$ (q, $J=10$, 1H); 6,82 (m, 2H); 7,00 (m, 2H); 7,27-7,36 (m, 6H); 7,71 (s, 1H) ppm. RMN ${ }^{13} \mathrm{C}(125 \mathrm{MHz}$, $\left.\mathrm{CDCl}_{3}\right): \delta=16,4,16,9,20,1,27,7,39,2,61,5,63,5$ (q, $\left.J=28.75 \mathrm{~Hz}, 1 \mathrm{C}\right), 119,6,127,4 ; 127,8$; 128,$8 ; 129,0 ; 129,1 ; 129,1 ; 129,2 ; 132,2 ; 135,7 ; 173,6$ ppm. HRMS (ESI): $m / z$ calculado para $\mathrm{C}_{21} \mathrm{H}_{21} \mathrm{~F}_{3} \mathrm{~N}_{3} \mathrm{O}[\mathrm{M}+\mathrm{H}]^{+}:$388,16312; encontrado: 388,16. CLAE: Chiralpak IC DAICEL, $25 \mathrm{~cm}$ x 4,6 $\mu \mathrm{m}$, acetonitrila/água: 45:55, rt: 19,218 min, $206 \mathrm{~nm}$. 
$(R)-N$-(1-cianociclopropil)-3-fenil-2-(((R)-2,2,2-trifluoro-1-fenil-etil)amino) propanamida (4)<smiles>C[C@H](N[C@@H](Cc1ccccc1)C(=O)NC1(C#N)CC1)c1ccccc1</smiles>

Rendimento global $=31,5 \%$ sólido branco. $[\alpha] \mathrm{D}^{24}=-43,8^{\circ}\left(\mathrm{MeOH}, \mathrm{c}=0,72 \times 10^{-3} \mathrm{~g} / \mathrm{L}\right)$. FT-IR (KBr, vmax): 3319, 3007, 2853, 2249, 1687, 1596, 1518, 1261, 1173, 1125, 1074, 1012, $873,813,734,718,529 \mathrm{~cm}^{-1}$. RMN ${ }^{1} \mathrm{H}\left(500 \mathrm{MHz}, \mathrm{CDCl}_{3}\right): \delta=0,85-0,93(\mathrm{~m}, 1 \mathrm{H}), 0,96-1,04$ (m, 1H), 1,40-1,49 (m, 2H), 2,18 (s, 1H), 3,07 (m, 2H), 3,42 (t, $J=7,50 \mathrm{~Hz}, 1 \mathrm{H}, 3,97$ (q, $J=$ $9,00 \mathrm{~Hz}, 1 \mathrm{H}), 7,17-7,40(\mathrm{~m}, 10 \mathrm{H}) \mathrm{ppm} . \mathrm{RMN}{ }^{13} \mathrm{C}\left(125 \mathrm{MHz}, \mathrm{CDCl}_{3}\right): \delta=16,4,16,9,20,1,27,7$, $39,2,61,5,63,4(\mathrm{q}, J=28.75 \mathrm{~Hz}, 1 \mathrm{C}), 119,6,127,4 ; 127,8 ; 128,8 ; 129,0 ; 129,1 ; 129,1 ; 129,2 ;$ 132,2; 135,7; 173,6 ppm. HRMS (ESI): $m / z$ calculado para $\mathrm{C}_{21} \mathrm{H}_{21} \mathrm{~F}_{3} \mathrm{~N}_{3} \mathrm{O}[\mathrm{M}+\mathrm{H}]^{+}: 388,16312$; encontrado: 388,17. CLAE: Chiralpak IC DAICEL, $25 \mathrm{~cm} \mathrm{x} \mathrm{4,6} \mu \mathrm{m}$, acetonitrila/água: 45:55, rt: 17,304 min, $206 \mathrm{~nm}$.

(S)-2-(((S)-1-(4-bromofenil)-2,2,2-trifluoroetil)amino)- $N$-(1-cianociclopropil)-3fenilpropanamida (5)<smiles>N#CC1(NC(=O)[C@H](Cc2ccccc2)N[C@@H](c2ccc(Br)cc2)C(F)(F)F)CC1</smiles>

Rendimento global $=24 \%$ sólido branco. $[\alpha] \mathrm{D}^{24}=+45,0^{\circ}\left(\mathrm{MeOH}, \mathrm{c}=1,07 \times 10^{-3} \mathrm{~g} / \mathrm{L}\right)$. FT-IR (KBr, vmax): 3329, 3246, 3032, 2237, 1649, 1539, 1499, 1456, 1263, 1171, 1126, 850, $742,567 \mathrm{~cm}^{-1} . \mathrm{RMN}^{1} \mathrm{H}\left(400 \mathrm{MHz}, \mathrm{CDCl}_{3}\right): \delta=0,95-1,07$ (m, 2H), 1,47-1,54 (m, 2H), 2,17 (s, $1 \mathrm{H}), 3,08$ (dd, $J=8.5$ e 14,00Hz, 1H), 3,39 (q, $J=5,00 \mathrm{~Hz}, 1 \mathrm{H}), 3,97$ (q, $J=8,00 \mathrm{~Hz}, 1 \mathrm{H}), 7,05-$ 7,18 (m, 5H), 7,26-7,38 (m, 3H), 7,50-7,54 (m, 2H)ppm. RMN ${ }^{13} \mathrm{C}\left(100 \mathrm{MHz}, \mathrm{CDCl}_{3}\right): \delta=16,5$, $16,7,20,0,38,0,60,7,62,82(\mathrm{q}, J=29,04 \mathrm{~Hz}), 119,4,123,5,123,9,125,8,127,5,129,1,129,2$, 130,2, 132,0, 132,2, 135,7, 173,2 ppm. HRMS (ESI): $\mathrm{m} / z$ calculado para $\mathrm{C}_{21} \mathrm{H}_{21} \mathrm{~F}_{3} \mathrm{~N}_{3} \mathrm{O}[\mathrm{M}+$ 


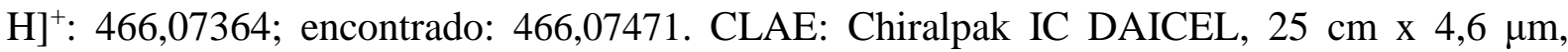
acetonitrila/água: 45:55, rt: 27,222 min, $206 \mathrm{~nm}$.

Este é um composto não original deste trabalho, porém refeito para fins de testes e as caracterizações foram condizentes com as da referência do trabalho de um membro anterior do grupo [43].

(S)-2-(((R)-1-(4-bromofenil)-2,2,2-trifluoroetil)amino)- $N$-(1-cianociclopropil)-3-

\section{fenilpropanamida (6)}

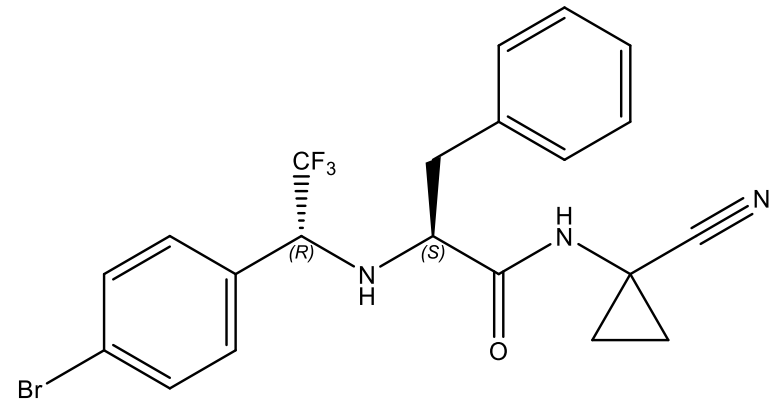

Rendimento global $=17 \%$ óleo incolor. $[\alpha] \mathrm{D}^{24}=-54,20^{\circ}\left(\mathrm{MeOH}, \mathrm{c}=0,77 \times 10^{-3} \mathrm{~g} / \mathrm{L}\right)$. FTIR (KBr, vmax): 3319, 3005, 2850, 2247, 1732, 1688, 1518, 1263, 1170, 1124, 1072, 1010, $885,815,727,702,505 \mathrm{~cm}^{-1} . \mathrm{RMN}{ }^{1} \mathrm{H}\left(500 \mathrm{MHz}, \mathrm{CDCl}_{3}\right): \delta=1,14-1,30(\mathrm{~m}, 2 \mathrm{H}), 1,53-1,64$ (m, 2H), 2,06 (d, $J=12,0 \mathrm{~Hz}, 1 \mathrm{H}), 2,62$ (dd, $J=13,5$ e 18,00Hz, 1H), 3,14-3,19 (m, 2H), 3,67$3,74(\mathrm{~m}, 1 \mathrm{H}), 6,63(\mathrm{~d}, J=10,5 \mathrm{~Hz}, 2 \mathrm{H}), 7,00(\mathrm{~d}, J=9,5 \mathrm{~Hz} 2 \mathrm{H}), 7,24-7,32(\mathrm{~m}, 5 \mathrm{H}), 7,60(\mathrm{~s}, 1 \mathrm{H})$ ppm. $\mathrm{RMN}{ }^{13} \mathrm{C}\left(125 \mathrm{MHz}, \mathrm{CDCl}_{3}\right): \delta=16,4,16,9,20,1,39,2,61,6,62,9$ (q, $\left.J=36.5 \mathrm{~Hz}, 1 \mathrm{C}\right)$, $119,6,123,5,125,5,127,5,128,9,129,2,129,3,131,2,132,0,135,8,173,4$ ppm. HRMS (ESI): $m / z$ calculado para $\mathrm{C}_{21} \mathrm{H}_{21} \mathrm{~F}_{3} \mathrm{~N}_{3} \mathrm{O}[\mathrm{M}+\mathrm{H}]^{+}$: 466,07364; encontrado: 466,07. CLAE: Chiralpak IC DAICEL, $25 \mathrm{~cm}$ x 4,6 $\mu \mathrm{m}$, acetonitrila/água: 45:55, rt: 31,482 min, $206 \mathrm{~nm}$.

\section{(R)-2-(((S)-1-(4-bromofenil)-2,2,2-trifluoroetil)amino)- $N$-(1-cianociclopropil)-3-}

\section{fenilpropanamida (7)}<smiles>N#CC1(NC(=O)[C@H](Cc2ccccc2)N[C@@H](c2ccc(Br)cc2)C(F)(F)F)CC1</smiles> 
Rendimento global $=15 \%$ óleo incolor. $[\alpha] \mathrm{D}^{21}=+80.11\left(\mathrm{MeOH}, \mathrm{c}=0,72 \times 10^{-3} \mathrm{~g} / \mathrm{L}\right)$. FT-IR (KBr, vmax): 3336, 3028, 2850, 2243, 1732, 1593, 1490, 1262, 1170, 1124, 1072, 1010, $885,815,727,702,505 \mathrm{~cm}^{-1}$. $\mathrm{RMN}^{1} \mathrm{H}\left(500 \mathrm{MHz}, \mathrm{CDCl}_{3}\right): \delta(\mathrm{ppm})=1,15-1,30(\mathrm{~m}, 2 \mathrm{H}), 1,55-$ $1,65(\mathrm{~m}, 2 \mathrm{H}), 2,07(\mathrm{~d}, J=11,0 \mathrm{~Hz}, 1 \mathrm{H}), 2,62(\mathrm{dd}, J=11,44$ e $14,52 \mathrm{~Hz}, 1 \mathrm{H}), 3,15-3,19(\mathrm{~m}, 2 \mathrm{H})$, 3,67-3,73 (m, 1H), 6,64 (d, $J=8,25 \mathrm{~Hz}, 2 \mathrm{H}), 6,97-7,03$ (d, $J=8,15 \mathrm{~Hz} 2 \mathrm{H}), 7,26-7,36(\mathrm{~m}, 5 \mathrm{H}), 7,62$ (s, $1 \mathrm{H})$ ppm. $\mathrm{RMN}{ }^{13} \mathrm{C}\left(125 \mathrm{MHz}, \mathrm{CDCl}_{3}\right): \delta=16,5 ; 16,9 ; 20,1 ; 39,3 ; 61,6 ; 63,1$ (q, $J=37.43 \mathrm{~Hz}$, 1C); 119,6;123,5;125,6;127,5; 129,0;129,2; 129,3;131,2; 132,0;135,8; 173,4 ppm. HRMS (ESI): $m / z$ calculado para $\mathrm{C}_{21} \mathrm{H}_{18} \mathrm{BrF}_{3} \mathrm{~N}_{3} \mathrm{O}[\mathrm{M}+\mathrm{H}]^{+}: 466,07$; encontrado: 466,0747. HPLC: IC, $25 \mathrm{~cm} \mathrm{x} \mathrm{4,6} \mathrm{\mu m,} \mathrm{acetonitrila/água:} \mathrm{55:45,} \mathrm{rt:} \mathrm{29,572} \mathrm{min,} 206 \mathrm{~nm}$.

(R)-2-(((R)-1-(4-bromofenil)-2,2,2-trifluoroetil)amino)- $N$-(1-cianociclopropil)-3-

\section{fenilpropanamida (8)}

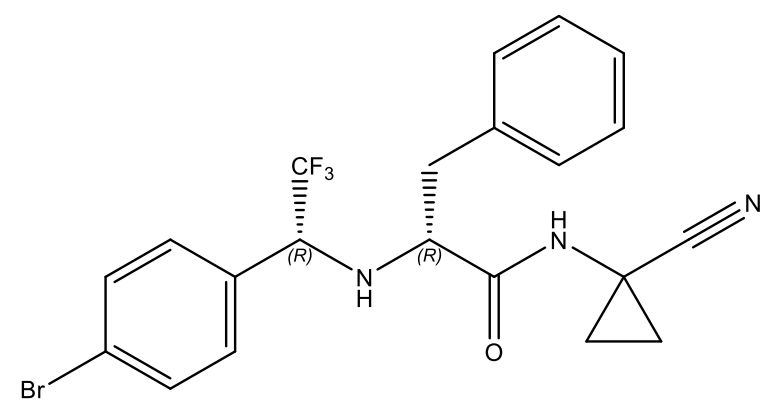

Rendimento global $=30 \%$ sólido branco. $[\alpha] \mathrm{D}^{24}=-62,66^{\circ}\left(\mathrm{MeOH}, \mathrm{c}=0,75 \times 10^{-3} \mathrm{~g} / \mathrm{L}\right)$. FT-IR (KBr, vmax): 3319, 3005, 2850, 2247, 1688, 1593, 1518, 1261, 1170, 1124, 1072, 1010, $885,815,727,702,505 \mathrm{~cm}^{-1}$. RMN ${ }^{1} \mathrm{H}\left(500 \mathrm{MHz}, \mathrm{CDCl}_{3}\right): \delta=0,90-1,06(\mathrm{~m}, 2 \mathrm{H}), 1,40-1,49$ (m, 2H), 2,10 (s, 1H), 3,06 (ddd, $J=7,5,9,75$ e 17,75, 2H), 3,38 (t, $J=7,5 \mathrm{~Hz}, 1 \mathrm{H}), 3,96$ (dd $J$ $=9,00,1 \mathrm{H}), 7,05-7,17(\mathrm{~m}, 5 \mathrm{H}), 7,26-7,38(\mathrm{~m}, 3 \mathrm{H}), 7,50-7,54(\mathrm{~m}, 2 \mathrm{H}) \mathrm{ppm} . \mathrm{RMN}{ }^{13} \mathrm{C}(125$ $\mathrm{MHz}, \mathrm{CDCl}_{3}$ ): $\delta=16,5,16,7,19,99,39,3,60,7,62,9$ (q, $\left.J=28.75 \mathrm{~Hz}, 1 \mathrm{C}\right), 119,4,124,0,127,6$, 129,1, 129,2, 130,1, 132,0, 132,2, 132,3, 135,7, 173,2 ppm. HRMS (ESI): $m / z$ calculado para $\mathrm{C}_{21} \mathrm{H}_{21} \mathrm{~F}_{3} \mathrm{~N}_{3} \mathrm{O}[\mathrm{M}+\mathrm{H}]^{+}$: 466,07364; encontrado: 466,07. CLAE: Chiralpak IC DAICEL, $25 \mathrm{~cm}$ x 4,6 $\mu \mathrm{m}$, acetonitrila/água: 45:55, rt: 26,095 min, $206 \mathrm{~nm}$. 
(S)-2-(((S)-1-(4-metila)-2,2,2-trifluoroetil)amino)- $N$-(1-cianociclopropil)-3-

\section{fenilpropanamida (9)}

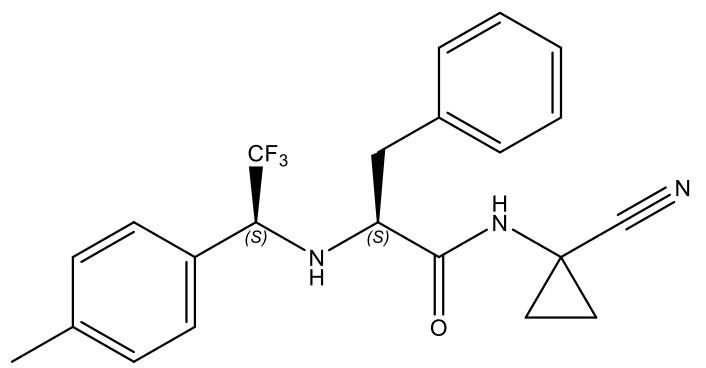

Rendimento global $=52 \%$ sólido branco. $[\alpha] \mathrm{D}^{23}=+51,43^{\circ}\left(\mathrm{MeOH}, \mathrm{c}=7,0 \times 10^{-3} \mathrm{~g} / \mathrm{L}\right)$. FT-IR (KBr, vmax): 3321, 3246, 3031, 2818, 2236, 1647, 1533, 1261, 1170, 1168, 1125, 1009, $878,820,729,702,650 \mathrm{~cm}^{-1}$. RMN ${ }^{1} \mathrm{H}\left(400 \mathrm{MHz}, \mathrm{CDCl}_{3}\right): \delta=0,90-1,08(\mathrm{~m}, 2 \mathrm{H}), 1,43-1,55(\mathrm{~m}$, 2H), 1,69-1,87 (s, 1H), 2,37 (s, 3H), 3,03-3,15 (m ,2H), 3,42 (t, $J=6,04 \mathrm{~Hz}, 1 \mathrm{H}), 3,96$ (q, $J=$ $7,20 \mathrm{~Hz}, 1 \mathrm{H}), 7,11-7,41(\mathrm{~m}, 11 \mathrm{H}) \mathrm{ppm} . \mathrm{RMN}{ }^{13} \mathrm{C}\left(100 \mathrm{MHz}, \mathrm{CDCl}_{3}\right): \delta=16,4,16,7,19,9,21,2$, $37,8,55,4,60,5,63,2$ (q, $J=28.8 \mathrm{~Hz}, 1 \mathrm{C}), 119,5,127,5,128,5,129,1,129,3,129,7,129,9$, 135,9, 139,7, 173,4 ppm. HRMS (ESI): $m / z$ calculado para $\mathrm{C}_{21} \mathrm{H}_{21} \mathrm{~F}_{3} \mathrm{~N}_{3} \mathrm{O}[\mathrm{M}+\mathrm{H}]^{+}:$402,17; encontrado: 402,20. CLAE: Gemini C18 PHENOMENEX, $25 \mathrm{~cm}$ x 4,6 $\mu \mathrm{m}$, gradiente 10-95\% de acetonitrila/água: $\mathrm{rt}:$ 17,798 $\mathrm{min}, 206 \mathrm{~nm}$.

(S)-2-(((R)-1-(4-metila)-2,2,2-trifluoroetil)amino)- $N$-(1-cianociclopropil)-3-

\section{fenilpropanamida (10)}

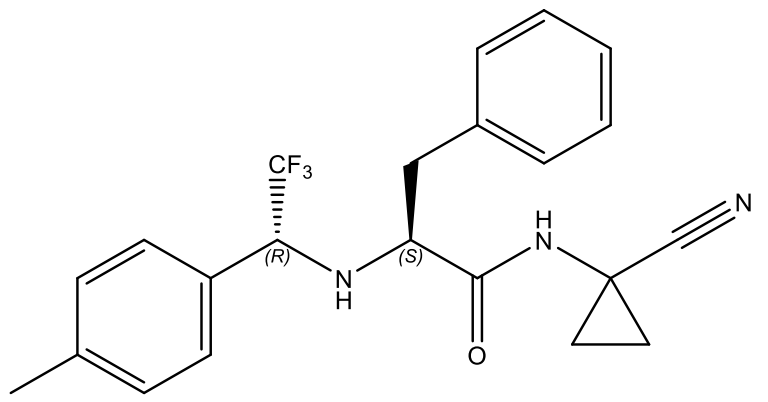

Rendimento global $=52 \%$ sólido branco. $[\alpha] \mathrm{D}^{24}=-12,85^{\circ}\left(\mathrm{MeOH}, \mathrm{c}=7,7 \times 10^{-3} \mathrm{~g} / \mathrm{L}\right)$. FT-IR (KBr, vmax): 3322, 3255, 3030, 2238, 1647, 1531, 1490, 1261, 1168, 1125, 1072, 983, $874,768,729,710,651 \mathrm{~cm}^{-1} .{ }^{1} \mathrm{H} \mathrm{RMN}\left(400 \mathrm{MHz}, \mathrm{CDCl}_{3}\right): \delta=1,17-1,31(\mathrm{~m}, 2 \mathrm{H}), 1,52-1,66$ (m, 2H), 1,72-1,81 (s, 1H), 2,34 (s, 3H), 3,65-3,74 (dd, $J=9,77$ e 13,83 Hz, 1H), 3,11-3,29 (m, 2H), 3,70 (q, J= 7,72 Hz, 1H), 6,67-6,75 (d, J= 7,90 Hz, 2H), 6,99-7,06 (d, J= 7,39 Hz, 2H), 7,23-7,32 (m, 5H), 7,72 (s, 1H) ppm. RMN ${ }^{13} \mathrm{C}\left(100 \mathrm{MHz}, \mathrm{CDCl}_{3}\right): \delta=16,4,17,0,20,0,20,1$, $39,3,61,5,63,5(\mathrm{q}, J=29.1 \mathrm{~Hz}, 1 \mathrm{C}), 119,7,127,4,127,7,129,1,129,2,129,5,135,7,139,2$, 
173,7 ppm. HRMS (ESI): $m / z$ calculado para $\mathrm{C}_{21} \mathrm{H}_{21} \mathrm{~F}_{3} \mathrm{~N}_{3} \mathrm{O}[\mathrm{M}+\mathrm{H}]^{+}: 402,17$; encontrado: 402,20. CLAE: Gemini C18 PHENOMENEX, $25 \mathrm{~cm}$ x 4,6 $\mu \mathrm{m}$, gradiente 10-95\% de acetonitrila/água: rt: 18,124 $\min , 206 \mathrm{~nm}$.

$(R)-2-(((S)-1-(4-m e t i l a)-2,2,2-t r i f l u o r o e t i l) a m i n o)-N$-(1-cianociclopropil)-3-

\section{fenilpropanamida (11)}

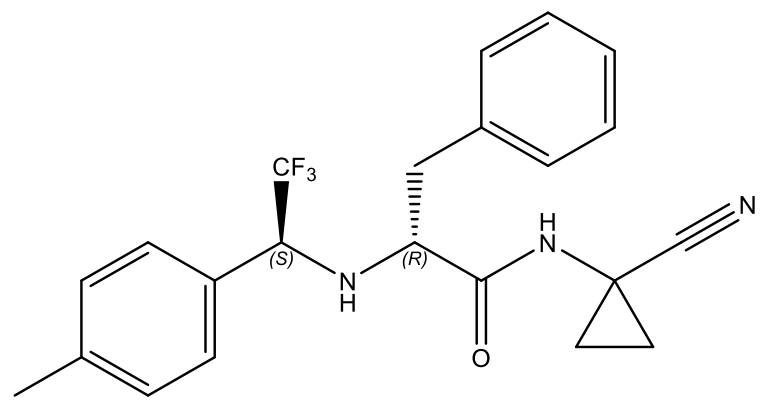

Rendimento global $=89 \%$ óleo incolor. $[\alpha]^{24}=+15,74^{\circ}\left(\mathrm{MeOH}, \mathrm{c}=7,5 \times 10^{-3} \mathrm{~g} / \mathrm{L}\right)$. FT-IR (KBr, vmax): 3321, 3221, 3031, 2818, 2236, 1648, 1533, 1261, 1170, 1168, 1125, 1009, $878,820,729,702,650 \mathrm{~cm}^{-1}$. RMN ${ }^{1} \mathrm{H}\left(400 \mathrm{MHz}, \mathrm{CDCl}_{3}\right): \delta=1,12-1,35(\mathrm{~m}, 2 \mathrm{H}), 1,52-1,66$ (m, 2H), 1,87-2,03 (s, 1H), 2,35 (s, 3H), 2,64-2,77 (m, 1H), 3,09-3,32 (m, 2H), 3,70 (q, J= 7,66 $\mathrm{Hz}, 1 \mathrm{H}), 6,68-6,74(\mathrm{~d}, J=7,92 \mathrm{~Hz}, 2 \mathrm{H}), 6,99-7,04$ (d, $J=7,42 \mathrm{~Hz}, 2 \mathrm{H}), 7,23-7,32$ (m, 5H), $7,70(\mathrm{~s}, 1 \mathrm{H})$ ppm. $\mathrm{RMN}{ }^{13} \mathrm{C}\left(100 \mathrm{MHz}, \mathrm{CDCl}_{3}\right): \delta=16,4,17,0,20,1,21,3,39,2,61,5,63,5$ (q, $J=28.8 \mathrm{~Hz}, 1 \mathrm{C}), 119,7,123,5,127,3,127,6,129,1,129,5,135,8,139,2,173,7$ ppm. HRMS (ESI): $m / z$ calculado para $\mathrm{C}_{21} \mathrm{H}_{21} \mathrm{~F}_{3} \mathrm{~N}_{3} \mathrm{O}[\mathrm{M}+\mathrm{H}]^{+}:$402,17; encontrado: 401,70. CLAE: Gemini C18 PHENOMENEX, $25 \mathrm{~cm} \mathrm{x} \mathrm{4,6} \mathrm{\mu m,} \mathrm{gradiente} \mathrm{10-95 \%} \mathrm{de} \mathrm{acetonitrila/água:} \mathrm{rt:} \mathrm{6,29} \mathrm{min,}$ $206 \mathrm{~nm}$.

(R)-2-(((R)-1-(4-metila)-2,2,2-trifluoroetil)amino)- $N$-(1-cianociclopropil)-3-

\section{fenilpropanamida (12)}

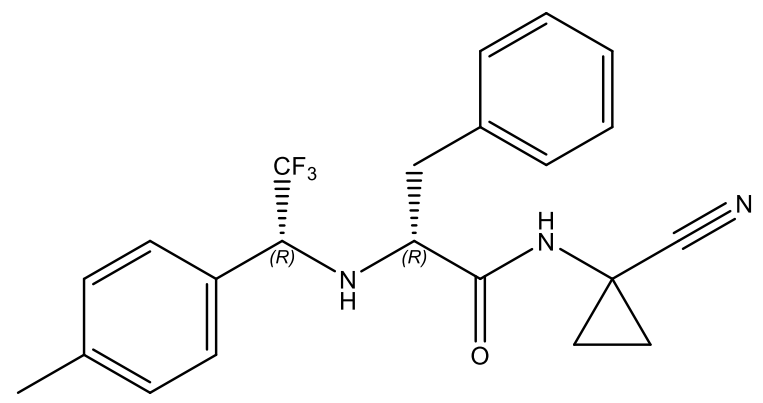

Rendimento global $=89 \%$ sólido branco. $[\alpha] \mathrm{D}^{23}=-55,36^{\circ}\left(\mathrm{MeOH}, \mathrm{c}=7,5 \times 10^{-3} \mathrm{~g} / \mathrm{L}\right)$. FT-IR (KBr, vmax): 3323, 3243, 3035, 2848, 2245, 1679, 1533, 1261, 1170, 1168, 1125, 1009, 
$878,820,729,702,650 \mathrm{~cm}^{-1} . \mathrm{RMN}{ }^{1} \mathrm{H}\left(400 \mathrm{MHz}, \mathrm{CDCl}_{3}\right): \delta=0,90-1,10(\mathrm{~m}, 2 \mathrm{H}), 1,40-1,52$ (m, 2H), 2,04-2,13 (large s, 1H), 2,37 (s, 3H), 3,03-3,15 (m ,2H), 3,43 (t, $J=6,06 \mathrm{~Hz}, 1 \mathrm{H}), 3,96$ $(\mathrm{q}, J=7,19 \mathrm{~Hz}, 1 \mathrm{H}), 7,11-7,42(\mathrm{~m}, 11 \mathrm{H}) \mathrm{ppm} . \mathrm{RMN}{ }^{13} \mathrm{C}\left(100 \mathrm{MHz}, \mathrm{CDCl}_{3}\right): \delta=16,4,16,7$, $19,9,21,2,37,8,55,4,60,5,63,2$ (q, $J=28.8 \mathrm{~Hz}, 1 \mathrm{C}), 119,5,127,6,128,5,129,2,129,3,129,5$, 129,7, 135,9, 139,7, 173,5 ppm. HRMS (ESI): $\mathrm{m} / \mathrm{z}$ calculado para $\mathrm{C}_{21} \mathrm{H}_{21} \mathrm{~F}_{3} \mathrm{~N}_{3} \mathrm{O}[\mathrm{M}+\mathrm{H}]^{+}$: 402,17; encontrado: 402,20. CLAE: Gemini C18 PHENOMENEX, $25 \mathrm{~cm}$ x 4,6 $\mu \mathrm{m}$, gradiente 10-95\% de acetonitrila/água: rt: $11.059 \mathrm{~min}, 206 \mathrm{~nm}$.

(S)-2-(((S)-1-(4-metóxi)-2,2,2-trifluoroetil)amino)- $N$-(1-cianociclopropil)-3-

\section{fenilpropanamida (13)}

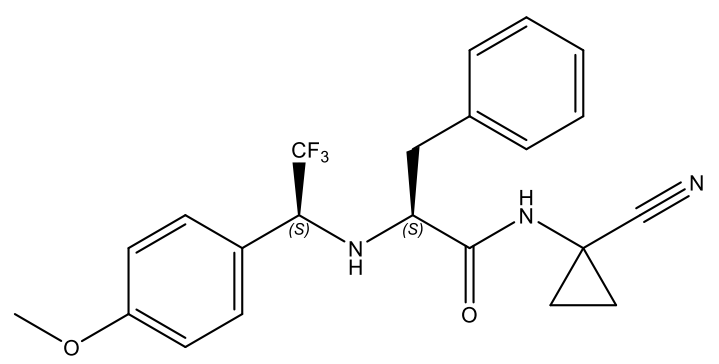

Rendimento global $=78 \%$ sólido branco. $[\alpha] \mathrm{D}^{22}=+44,32^{\circ}\left(\mathrm{MeOH}, \mathrm{c}=28,0 \times 10^{-3} \mathrm{~g} / \mathrm{L}\right)$. FT-IR (KBr, vmax): 3334, 3032, 2961, 2838, 2245, 1679, 1593, 1515, 1254, 1168, 1129, 1092, $1028,887,820,723,707,505 \mathrm{~cm}^{-1} . \mathrm{RMN}^{1} \mathrm{H}\left(400 \mathrm{MHz}, \mathrm{CDCl}_{3}\right): \delta=0,92-1,10(\mathrm{~m}, 2 \mathrm{H}), 1,43-$ 1,57 (m, 2H), 1,90-2,13 (s, 1H), 3,05-3,14 (m, 1H), 3,35-3,45 (t, $J=6,05 \mathrm{~Hz} 2 \mathrm{H}), 3,83$ (s, 3H), $3,96(\mathrm{q}, J=7,15 \mathrm{~Hz}, 1 \mathrm{H}), 6,87-6,95$ (d, $J=8,73 \mathrm{~Hz} 2 \mathrm{H}), 7,17-7,22(\mathrm{dd}, J=3,51 \mathrm{e} \mathrm{7,74} \mathrm{Hz}$, $3 \mathrm{H}), 7,27-7,42(\mathrm{~m}, 5 \mathrm{H}) \mathrm{ppm} . \mathrm{RMN}{ }^{13} \mathrm{C}\left(100 \mathrm{MHz}, \mathrm{CDCl}_{3}\right): \delta=16,5,16,7,19,9,37,8,39,3$, $55,4,60,3,63,0$ (q, $J=27.8 \mathrm{~Hz}, 1 \mathrm{C}), 114,4,119,5,124,6,127,3,127,5,129,1,129,3,129,8$, 135,9, 160,3, 173,5 ppm. HRMS (ESI): $m / z$ calculado para $\mathrm{C}_{21} \mathrm{H}_{21} \mathrm{~F}_{3} \mathrm{~N}_{3} \mathrm{O}[\mathrm{M}+\mathrm{H}]^{+}: 417,17$; encontrado: 417,20. CLAE: Gemini C18 PHENOMENEX, $25 \mathrm{~cm} \mathrm{x} \mathrm{4,6} \mathrm{\mu m,} \mathrm{gradiente} \mathrm{10-95 \%}$ de acetonitrila/água: rt: 17,032 min, $206 \mathrm{~nm}$. 
(S)-2-(((R)-1-(4-metóxi)-2,2,2-trifluoroetil)amino)- $N$-(1-cianociclopropil)-3-

\section{fenilpropanamida (14)}

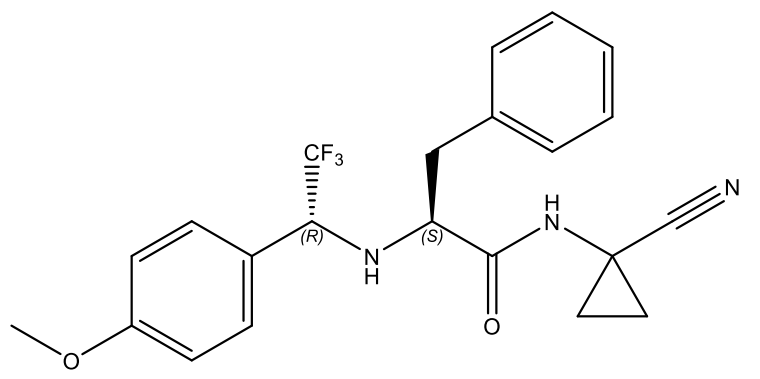

Rendimento global $=78 \%$ óleo incolor. $[\alpha] \mathrm{D}^{22}=-53,10^{\circ}\left(\mathrm{MeOH}, \mathrm{c}=11,2 \times 10^{-3} \mathrm{~g} / \mathrm{L}\right)$. FT-IR (KBr, vmax): 3334, 3032, 2961, 2839, 2245, 1679, 1612, 1515, 1254, 1168, 1129, 1092, $1028,887,820,723,707,505 \mathrm{~cm}^{-1}$. RMN ${ }^{1} \mathrm{H}\left(400 \mathrm{MHz}, \mathrm{CDCl}_{3}\right): \delta=1,14-1,33(\mathrm{~m}, 2 \mathrm{H}), 1,54-$ $1,71(\mathrm{~m}, 2 \mathrm{H}), 1,92-2,06$ (s, 1H), 2,63-2,72 (m, 1H), 3,11-3,29 (m, 2H), 3,69 (q, J = 10,48 Hz, 1H), 3,81 (s, 3H), 6,69-6,77 (m, 4H), 6,99-7,04 (m, 2H), 7,25-7,31 (m, 3H), 7,70 (s, 1H) ppm. $\mathrm{RMN}{ }^{13} \mathrm{C}\left(100 \mathrm{MHz}, \mathrm{CDCl}_{3}\right): \delta=16,4,17,0,20,1,39,2,39,3,55,3,61,5,63,1$ (q, $J=29.16 \mathrm{~Hz}$, 1C), 114,2, 119,7, 124,1, 127,4, 129,0, 129,1, 135,8, 160,2, 173,7 ppm. HRMS (ESI): $m / z$ calculado para $\mathrm{C}_{21} \mathrm{H}_{21} \mathrm{~F}_{3} \mathrm{~N}_{3} \mathrm{O}[\mathrm{M}+\mathrm{H}]^{+}$: 417,17; encontrado: 418,30. CLAE: Gemini C18 PHENOMENEX, $25 \mathrm{~cm} \mathrm{x} \mathrm{4,6} \mathrm{\mu m,} \mathrm{gradiente} \mathrm{10-95 \%} \mathrm{de} \mathrm{acetonitrila/água:} \mathrm{rt:} \mathrm{18,165} \mathrm{min,} 206$ $\mathrm{nm}$.

(R)-2-(((R)-1-(4-metóxi)-2,2,2-trifluoroetil)amino)-N-(1-cianociclopropil)-3-

\section{fenilpropanamida (15)}

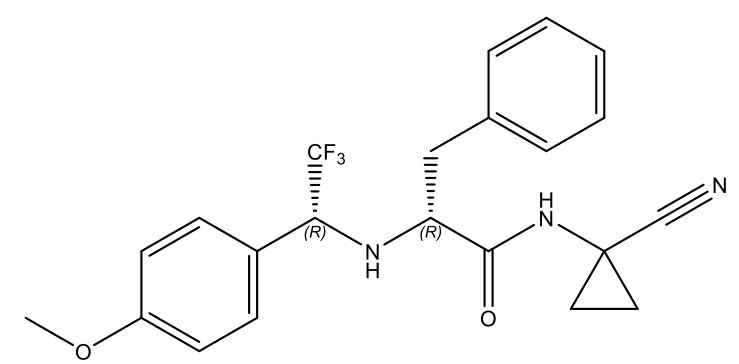

Rendimento global $=56 \%$ sólido branco. $[\alpha] \mathrm{D}^{22}=-66,00^{\circ}\left(\mathrm{MeOH}, \mathrm{c}=10,0 \times 10^{-3} \mathrm{~g} / \mathrm{L}\right)$. FT-IR (KBr, vmax): 3334, 3243, 3032, 2961, 2832, 2245, 1679, 1593, 1515, 1254, 1168, 1129, 1092 , $1028,887,820,723,707,505 \mathrm{~cm}^{-1}$. RMN ${ }^{1} \mathrm{H}\left(400 \mathrm{MHz}, \mathrm{CDCl}_{3}\right): \delta=0,89-1,10$ (m, 2H), 1,411,53 (m, 2H), 1,99-2,03 (s, 1H), 3,04-3,14 (m, 1H), 3,39-3,45 (m, 2H), 3,83 (s, 3H), 3,97 (q, $J$ $=7,13 \mathrm{~Hz}, 1 \mathrm{H}), 6,88-6,95(\mathrm{~m}, 2 \mathrm{H}), 7,17-7,22(\mathrm{dd}, J=2,19$ and 9,02 Hz, 3H), 7,26-7,44 (m, 5H) ppm. $\mathrm{RMN}{ }^{13} \mathrm{C}\left(100 \mathrm{MHz}, \mathrm{CDCl}_{3}\right): \delta=16,5,16,7,20,0,37,7,55,4,60,3,63,0$ (q, $J=29.0 \mathrm{~Hz}$, 1C), 114,4, 119,5, 127,5, 129,1, 129,3, 129,9, 135,9, 160,5, 173,4 ppm. HRMS (ESI): $m / z$ 
calculado para $\mathrm{C}_{21} \mathrm{H}_{21} \mathrm{~F}_{3} \mathrm{~N}_{3} \mathrm{O}[\mathrm{M}+\mathrm{H}]^{+}$: 417,17; encontrado: 418,00. CLAE: Gemini C18 PHENOMENEX, $25 \mathrm{~cm} \mathrm{x} \mathrm{4,6} \mu \mathrm{m}$, gradiente 10-95\% de acetonitrila/água: rt: 6,15 min, $206 \mathrm{~nm}$.

\subsection{Determinação da constante de inibição (Ki) para a enzima CPB}

Para realizar os ensaios de inibição enzimática visando a determinação de $\mathrm{Ki}^{\text {app }}$ foi necessário em um primeiro momento determinar a constante de Michaelis $(\mathrm{Km})$ a partir da obtenção da curva de Michaelis-Menten. Este procedimento trata-se de uma avaliação da atividade enzimática da enzima que foi utilizada nos ensaios de inibição.

Os ensaios de cinética enzimática foram realizados a $25^{\circ} \mathrm{C}$ em uma solução de $200 \mu \mathrm{L}$ contendo o tampão de acetato de sódio 100 mM, NaCl 300 mM e 5 mM de EDTA de pH 5,5, $7 \mathrm{mM}$ de DTT (ditiotreitol), 4\% v/v de DMSO (dimetilsulfóxido), 0,014\% v/v de Triton X-100 e empregando a concentração de enzima de $7 \mathrm{nM}$ para CPB. O sistema foi mantido em microplacas Corning de fundo preto com 96 poços. A taxa de reação foi monitorada durante 5 minutos utilizando um leitor de placas Biotek Synergy HT através da emissão de fluorescência a $460 \mathrm{~nm}$ e excitação em $360 \mathrm{~nm}$, monitorando a taxa de hidrólise do substrato fluorogênico ZFR-AMC (Sigma-Aldrich/Combi-Blocks) [44].

A constante de inibição foi determinada através de um ensaio indireto, onde inibidor e substrato estão presentes na solução juntamente com a enzima. Foi utilizado um protocolo de inibição competitiva, cujo ensaio já realizado previamente por membros do laboratório NEQUIMED [27].

Os ensaios de inibição enzimática foram realizados inicialmente da mesma forma utilizada nos ensaios para a determinação da curva de Michaelis-Menten, como detalhado anteriormente. Porém a concentração de substrato utilizada no experimento foi fixada no valor de $\mathrm{Km}$, obtido no ensaio cinético, onde $[\mathrm{S}]=\mathrm{Km}$. As concentrações das enzimas permaneceram as mesmas. As concentrações iniciais dos inibidores nos ensaios variaram de $0,01 \mu \mathrm{M}$ até 30 $\mu \mathrm{M}$. O experimento foi realizado pela mestranda Fernanda dos Reis Rocho em triplicata para todos os inibidores testados.

A constante de inibição dos compostos foi calculada a partir do $\mathrm{Ki}^{\text {app }}$ utilizando a equação desenvolvida por Cheng e Prusoff [45] em 1973:

$$
\mathrm{Ki}=\frac{K i^{a p p}}{1+\frac{[S]}{K m}}
$$


Devido À concentração do substrato utilizado ser igual ao valor de Km, a Equação 1 se resume a:

$$
\mathrm{Ki}=\frac{K i^{a p p}}{2}
$$

Eq. 2 


\section{RESULTADOS E DISCUSSÃO}

\subsection{Síntese de dipeptidil nitrilas com potencial atividade inibitória de cisteíno proteases}

A primeira série de compostos proposta neste trabalho consistiu em um grupo de substâncias análogas do grupo NEQUIMED codificadas como Neq0631 e Neq0636. A preparação destes análogos objetivou explorar a influência da estereoquímica desses compostos de partida e as mudanças que pudessem ocorrer nos futuros ensaios enzimáticos e celulares. A Figura 10 mostra a primeira série de compostos que foi proposta.

Figura 10. Primeira série de compostos sintetizada para analisar a influência da estereoquímica na inibição da enzima CPB.
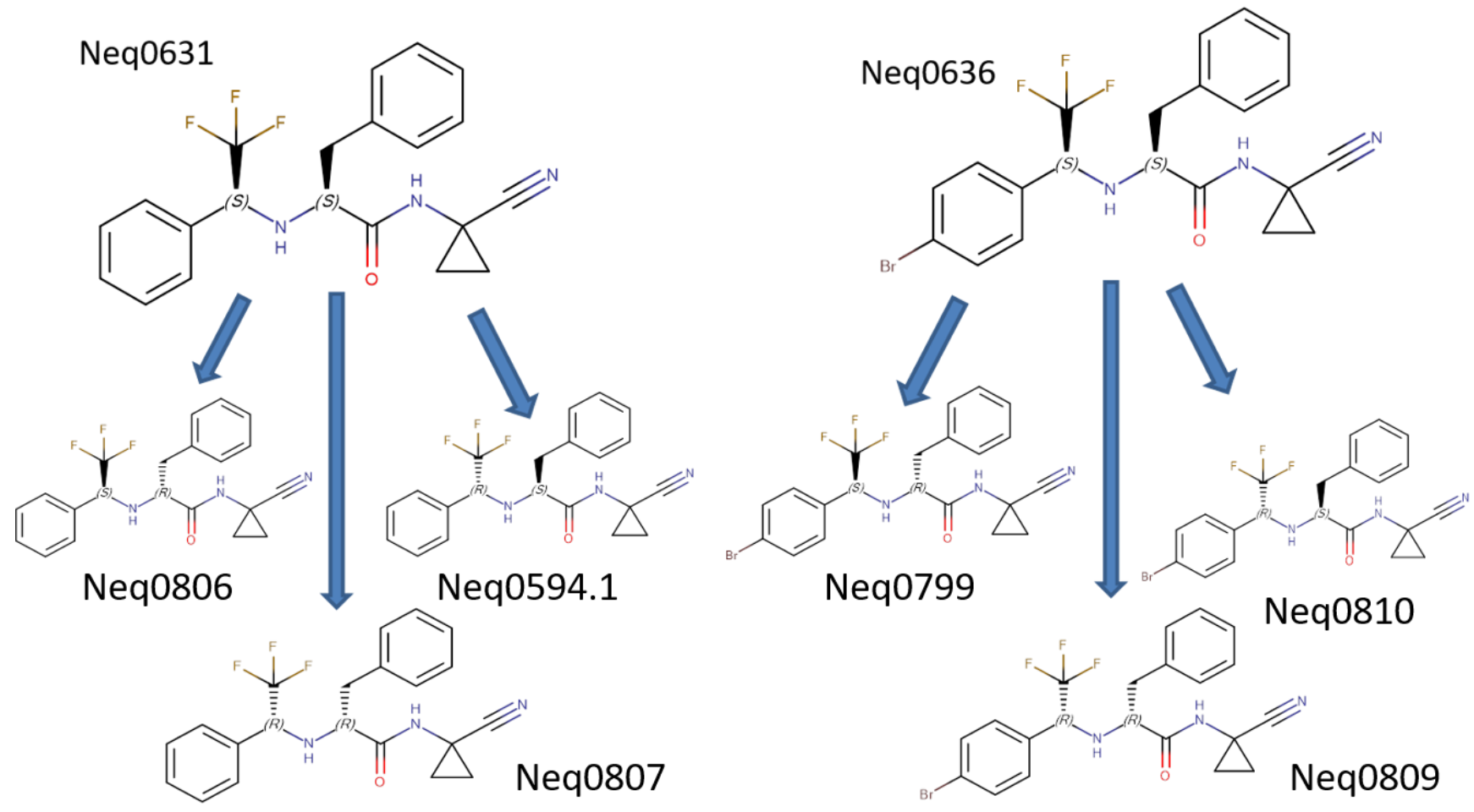

Fonte: Autoria própria.

A primeira série foi sintetizada e caracterizada neste trabalho, com os códigos NEQUIMED atribuídos aos compostos. Os rendimentos mostrados na parte experimental foram globais para cada síntese em função da dificuldade de purificação dos intermediários, em especial, devido à instabilidade do intermediário da imina. 
Os compostos de base da série que já foram sintetizados pelo grupo NEQUIMED foram referenciados de acordo com as caracterizações originais, utilizando-se das técnicas de RMN ${ }^{1} \mathrm{H}$ e HPLC-MS para a elucidação da estrutura do produto sintetizado.

A segunda série de compostos explorou outros análogos do composto Neq0636 e está demonstrada na Figura 11. A série foi sintetizada e caracterizada na Universidade de Nottingham, Inglaterra. Durante o período no exterior, a síntese dos compostos foi otimizada e o rendimento dos compostos foi aumentado. O procedimento experimental descrito é referente apenas à rota otimizada.

Figura 11. Segunda série de compostos.
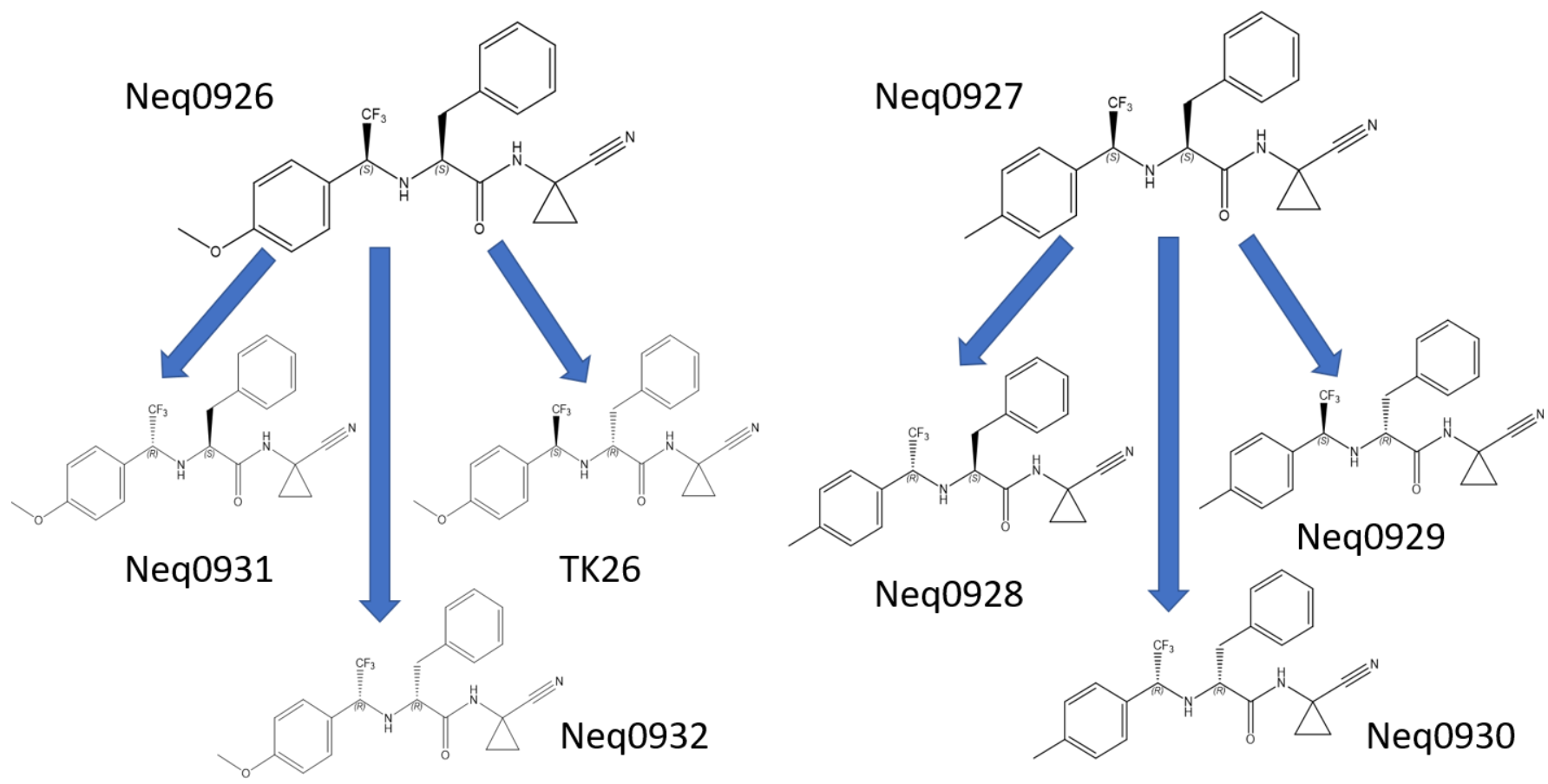

Fonte: Autoria própria.

\subsection{Planejamento dos derivados e estratégia sintética}

O composto Neq0631 constituiu o ponto de partida para a síntese planejada de novos derivados (Figura 12). O grupo ciano atuou sempre como warhead (grupo reativo responsável pela formação da ligação covalente a partir do ataque nucleofílico do tiolato da cisteína) e não foi alterado na série. Os aminoácidos $D$-fenilalanina e $L$-fenilalanina (adequados para o P2) foram usados em toda a série. A posição P3 foi sujeita a alterações a partir da introdução de distintos grupos funcionais. Não há muitas informações sobre as propriedades físico-químicas 
adequadas para esta posição e foi testado por meio da síntese de alguns derivados com modificações químicas clássicas visando analisar o volume, hidrofilia/hidrofobia e ligação hidrogênio.

Figura 12. Estrutura do Neq0631 com destaque para as posições de interação.

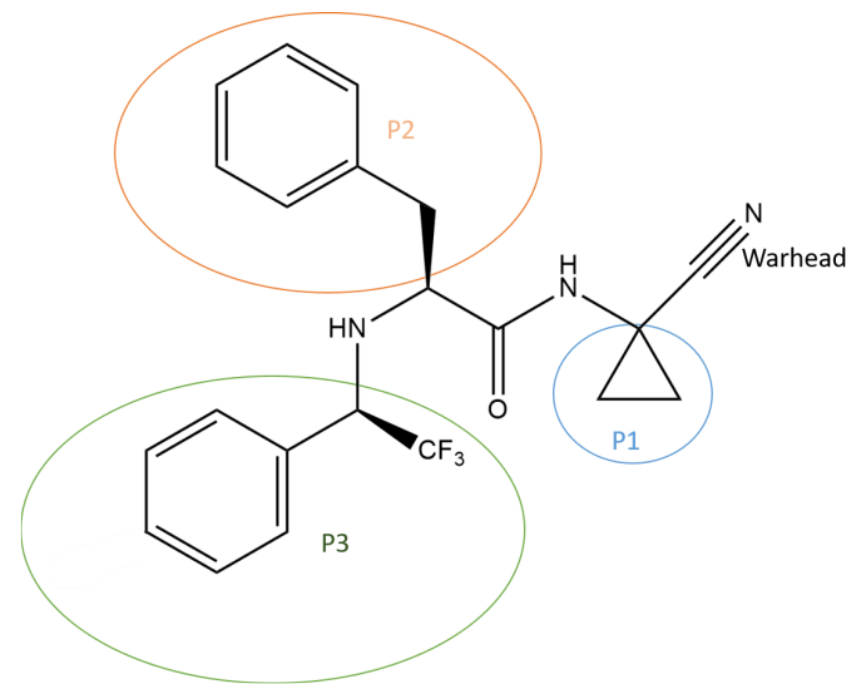

Fonte: Autoria própria

\subsection{Abordagem sintética}

Considerando o potencial de inibição do Neq0636 e seus derivados, a síntese de análogos do Neq0631 foi proposta analisando todos os estereoisômeros possíveis e com a substituição simples de grupos na posição P3. A reação simplificada é demonstrada no Esquema 6 para o Neq0631.

A reação para a síntese das 2,2,2-trifluorometilfenil-dipeptidil nitrilas usou o aminoácido $L$-fenilalanina como ponto de partida. Foi realizada uma reação de condensação entre a amina primária do aminoácido e um derivado de acetofenona de interesse em solvente polar prótico, usualmente metanol. A imina formada como intermediário sofreu uma aminação redutiva diastereosseletivamente e o ácido formado foi então acoplado com o grupo 1-aminociclopropilnitrila, o que levou à obtenção do produto final. [27,46]. 
Esquema 6. Rota sintética simplificada para a produção do composto Neq0631.
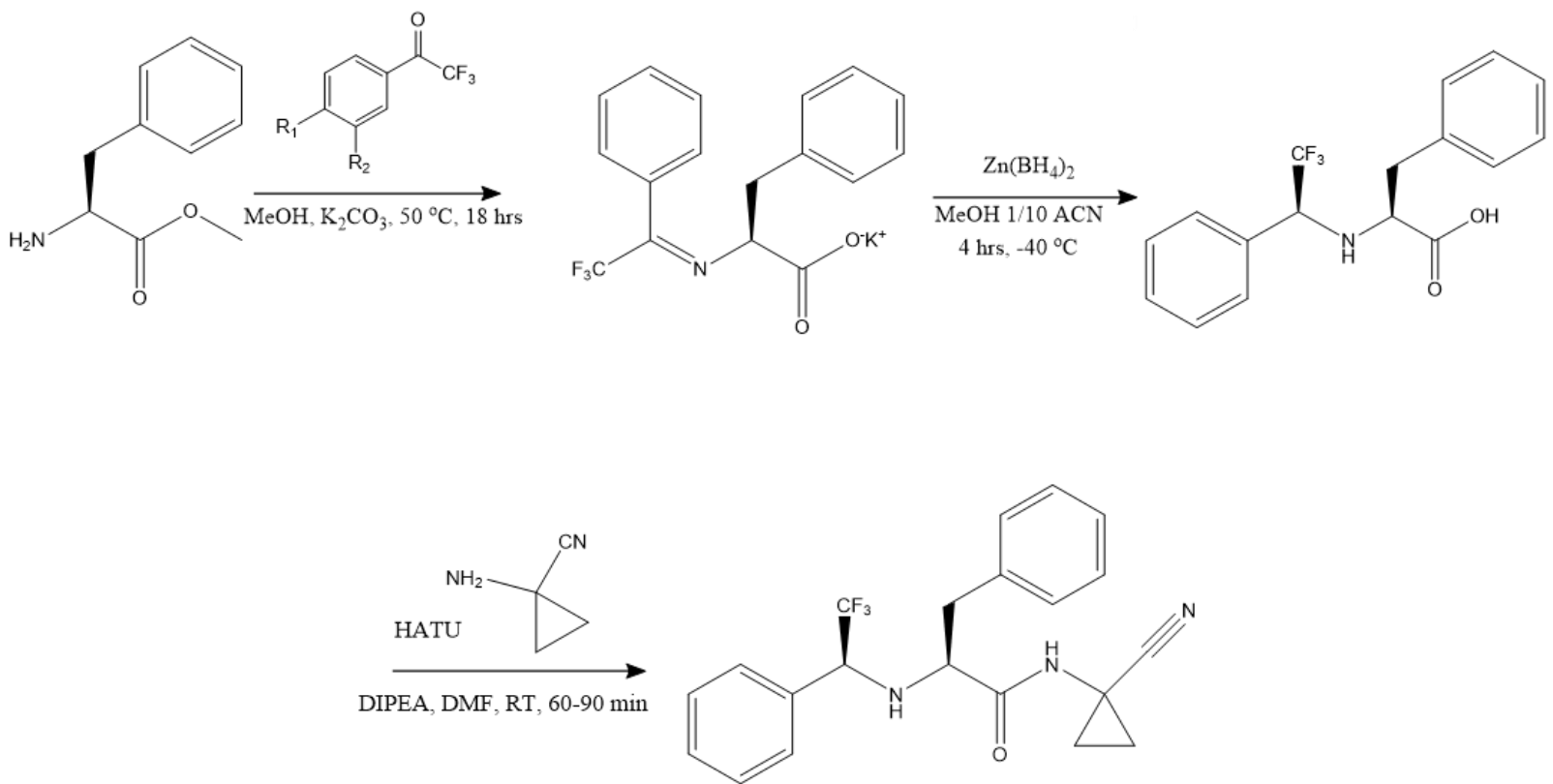

Fonte: Autoria própria.

\subsection{Identificação de compostos}

De acordo com as diretrizes do grupo de pesquisa, todos os novos compostos sintetizados devem ser caracterizados por uma série de técnicas diferentes para receberem o seu código NEQUIMED antes de avançarem para os testes biológicos e biofísicos. A Figura 13 mostra as etapas que os novos compostos devem ser submetidos para avançar para os ensaios bioquímicos.

Figura 13. Etapas para catalogação de novos compostos no grupo NEQUIMED.

\section{Síntese Caracteri
Fonte: Autoria própria.}

A lista de caracterização para os novos compostos consiste em uma variedade de técnicas espectroscópicas, espectrométricas e cromatográficas para a obtenção do máximo de informações possíveis sobre a estrutura dos compostos finais obtidos. 
As técnicas utilizadas foram: Ressonância Nuclear Magnética (RMN) de ${ }^{1} \mathrm{H}$ e de ${ }^{13} \mathrm{C}$, Espectroscopia no Infravermelho, Polarimetria, Espectrometria de massas e Cromatografia Líquida de Alta Performance (HPLC). Esta última foi a primeira etapa na identificação dos novos compostos, pois todos precisam estar com um grau de pureza mínimo de $95 \%$ necessário para realizar ensaios, de acordo com padrões da literatura [39].

Nos próximos tópicos será discutida as identificações e caracterizações de um dos compostos da primeira série sintetizada, trata-se do Neq0799, também representado neste trabalho como a dipeptidil nitrila (7).

\subsubsection{Purificação do composto Neq0799 (7)}

Após a finalização da síntese de um composto e uma purificação por cromatografia feita em coluna de sílica gel utilizando como eluente $n$-hexano: acetato de etila (7:3) para a retirada de maiores contaminantes como subprodutos e reagentes utilizados em excesso como DMF, HATU e DIPEA [42]. O composto então foi submetido a uma purificação por HPLC para que se chegue na pureza mínima de $95 \%$. Os métodos utilizados para a purificação foram no modo isocrático 50/50 ou 55/45 acetonitrila/água adicionados de $0,1 \%$ de ácido trifluoroácetico para auxiliar na purificação dos compostos [47,48]. A Figura 14 traz o cromatograma do composto Neq0799, onde banda menor se refere à presença do seu diastereoisômero.

Figura 14. Cromatograma do composto Neq0799 (7) e os parâmetros para as bandas.

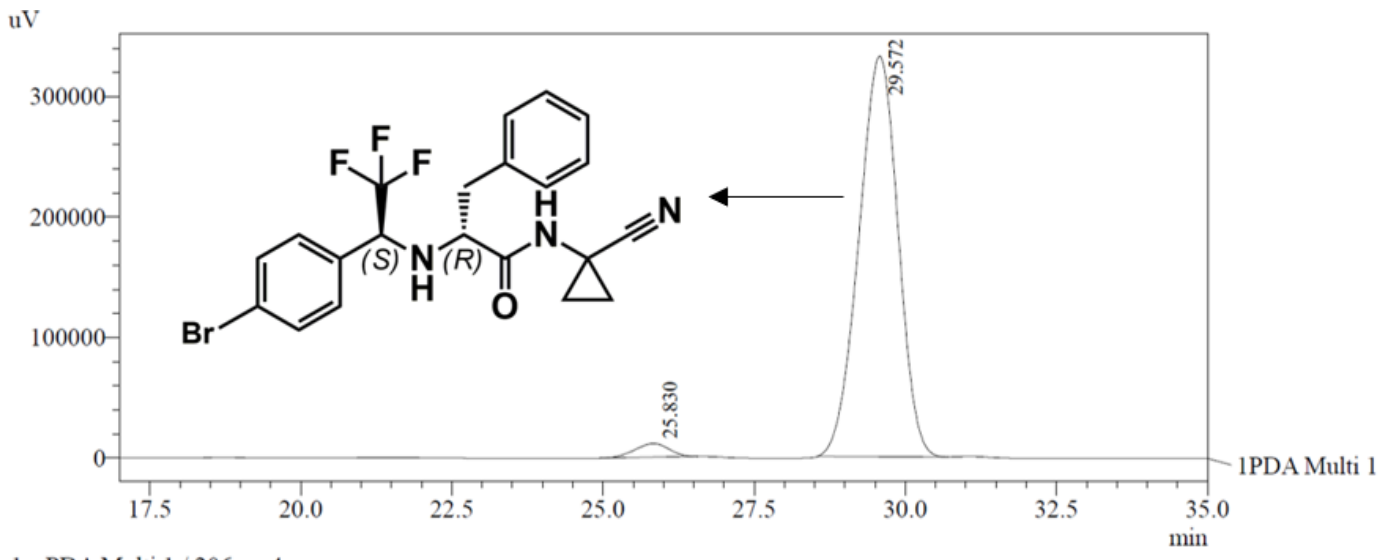

1 PDA Multi $1 / 206 \mathrm{~nm} 4 \mathrm{~nm}$

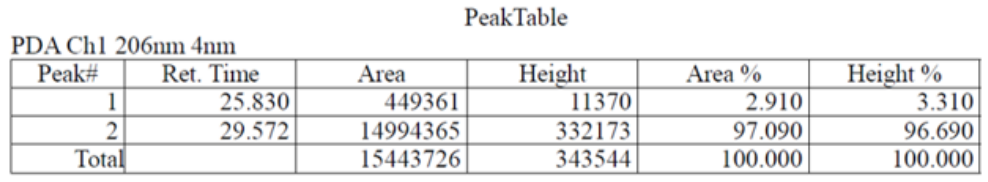

Condições: 55\% ACN/ $\mathrm{H}_{2} \mathrm{O} 45 \%$ Coluna IC Daicel.

Fonte: Autoria própria. 
A utilização de uma coluna quiral para a quantificação de pureza do composto é necessária para certificar que não houve epimerização do aminoácido de partida nas etapas de síntese ou durante a purificação do composto. Após a obtenção do composto Neq0799 (7) com pureza acima do valor de corte, outras técnicas da série de técnicas de caracterização foram realizadas.

\subsubsection{Espectrometria de massas do composto Neq0799 (7)}

Para a espectrometria de massas deste composto foi preparada como amostra uma solução de aproximadamente $1 \mathrm{mg} / \mathrm{mL}$ para ser analisado no equipamento de HPLC acoplado ao espectrômetro de massas. A Figura 15 mostra o espectro de massas obtido para o Neq0799, com destaque as contribuições isotópicas existentes neste composto.

Figura 15. Espectro de massas para o Neq0799 (7) evidenciamento da sua razão isotópica.

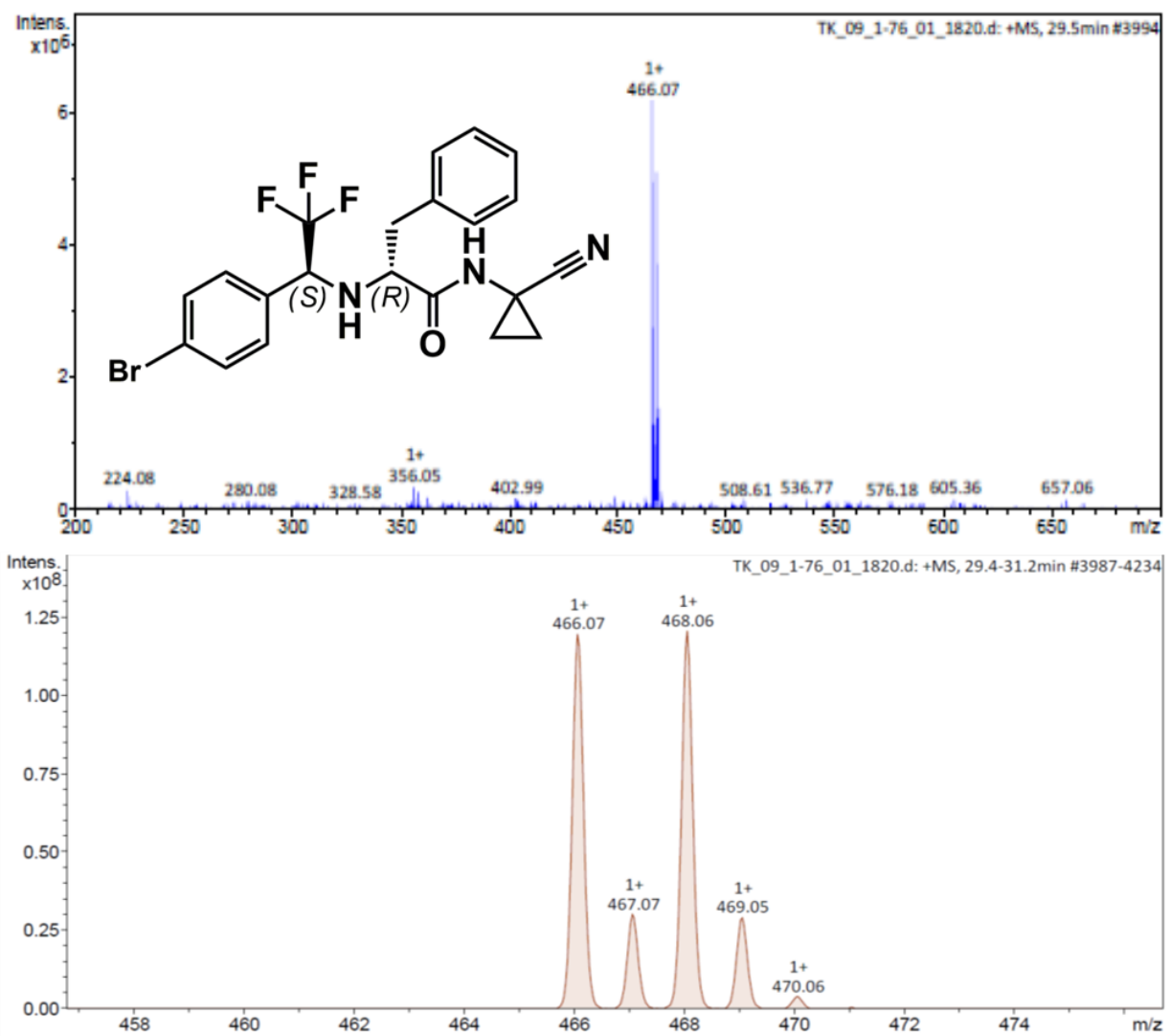

Condições: 55\% ACN/ $\mathrm{H}_{2} \mathrm{O} 45 \%$ Coluna IC Daicel.

Fonte: Autoria própria. 
A massa acurada corrobora com a massa monoisotópica para o íon $[\mathrm{M}+\mathrm{H}]^{+}$(calculado para $\mathrm{C}_{21} \mathrm{H}_{19} \mathrm{BrN}_{3} \mathrm{O}$ ) e a composição monoisotópica mostra o padrão isotópico característico do átomo de bromo presente na molécula Neq0799, na proporção de 1:1, além de revelar o pico $\mathrm{M}+1$ para a contribuição de carbono ${ }^{13} \mathrm{C}$ na molécula, na proporção de 100:20 [49,50].

\subsubsection{Ressonância Nuclear Magnética de Hidrogênio do Neq0799 (7)}

Os espectros de ressonância magnética foram feitos numa frequência de $500 \mathrm{MHz}$ para amostras caracterizadas no Instituto de Química de São Carlos; e numa frequência de $400 \mathrm{MHz}$ nas amostras caracterizadas na Universidade de Nottingham, com soluções entre 5-10 mg de composto em clorofórmio deuterado. A ressonância magnética nuclear é uma das técnicas que pode fornecer o maior número de informações sobre a estrutura do composto, o que corrobora a presença dos grupos funcionais adicionados durante as etapas de síntese [51]. A Figura 16 traz o espectro de hidrogênio do Neq0799.

Figura 16. Espectro de $\mathrm{RMN}$ de ${ }^{1} \mathrm{H}\left(500 \mathrm{MHz}, \mathrm{CDCl}_{3}\right)$ do composto Neq0799 (7).

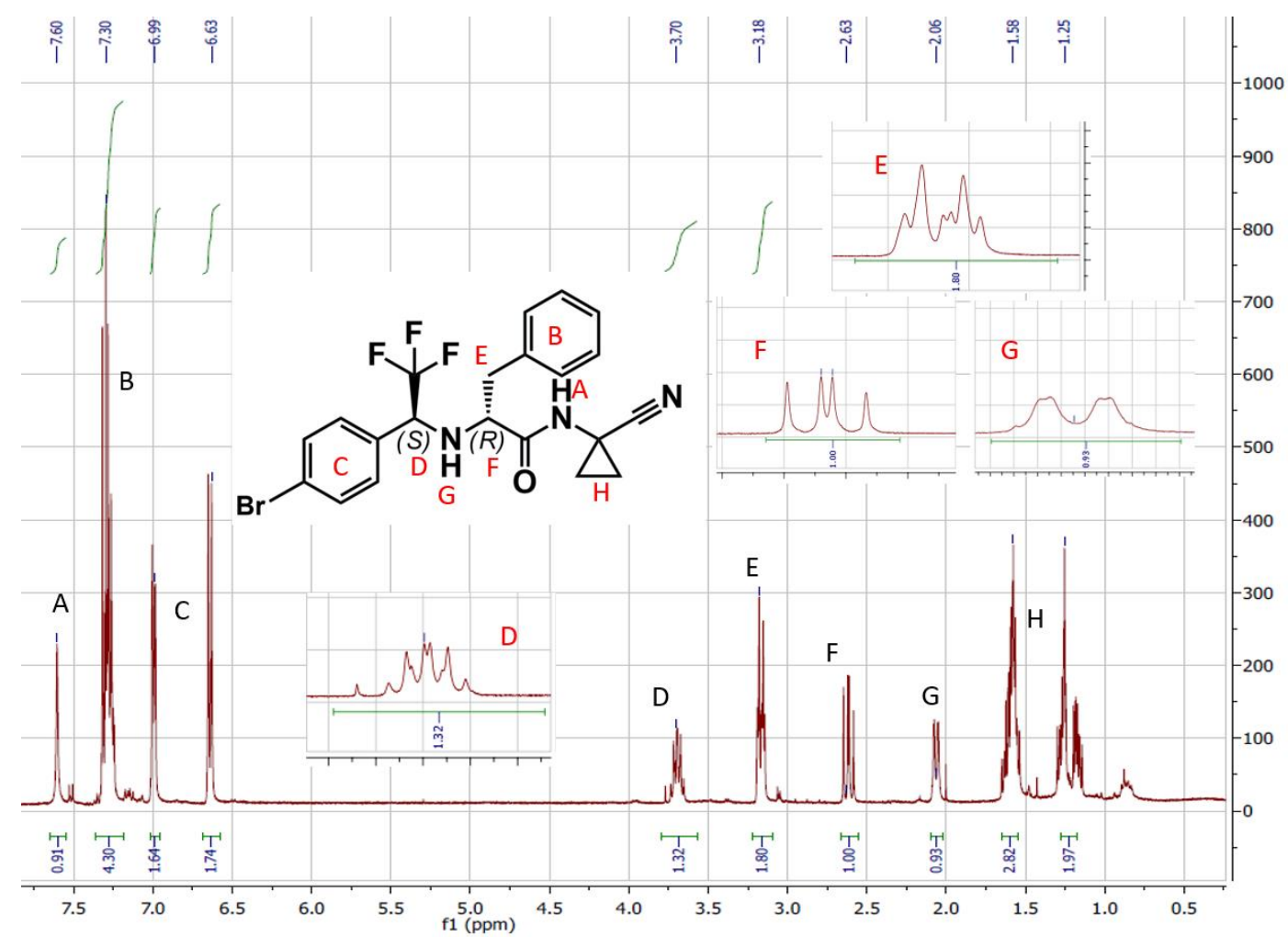

Fonte: Autoria própria 
O simpleto em 7,60 ppm (A) representa o hidrogênio do grupo amida, pois este deslocamento químico é característico deste grupo e este hidrogênio não possui hidrogênios adjacentes para acoplamentos entre si [52].

Os sinais em 7,30 ppm, 6,99 ppm e 6,63 ppm representam a região aromática da molécula. No caso do Neq0799, como em todos os outros análogos neste trabalho, os compostos possuem dois grupos fenilas, um da fenilalanina e outro proveniente do derivado da acetofenona. Os picos puderam ser diferenciados quando analisados em relação aos acoplamentos e a vizinhança química [53].

O multipleto mostrado pela letra B em 7,30 ppm se referente ao grupo fenila da $D$ fenilalanina. A integração deste multipleto mostra a presença de 5 hidrogênios, porém essa informação não é suficiente para esta afirmação ser feita com certeza, pois a análise do sinal C é o que confirma esta atribuição em B [54].

Os dupletos simbolizados pela letra $\mathrm{C}$ podem ser atribuídos ao outro grupo fenila da molécula, pois o padrão mostrado nestes dupletos é típico de uma substituição para em grupos aromáticos, o que corrobora a estrutura já que um dos reagentes utilizados é a 4'-bromo-2,2,2trifluoroacetofenona, um grupo fenila para-substituído [55].

O hidrogênio referente ao multipleto com deslocamento químico em 3,70 ppm ao qual foi atribuído a letra D é um dos sinais mais característicos dessa série de compostos. Ao se observar uma aproximação maior do sinal não é possível de se definir uma multiplicidade a este, pois além de acoplar com os átomos de flúor do grupo $\mathrm{CF}_{3}$ adjacente, também existe um acoplamento com o hidrogênio da amina [56].

O multipleto com deslocamento químico em 3,18 ppm representa os dois hidrogênios adjacentes ao grupo fenila da $D$-fenilalanina. Este sinal ao qual foi atribuída a letra E possui um deslocamento químico condizente com o esperado de grupos alquila ligados diretamente a grupos fenila. Estes hidrogênios são diasterotópicos, portanto há um acoplamento entre si, tornando este sinal ainda mais complexo de se atribuir uma designação. No caso de outros derivados desta série, como o Neq0926 (13) e o Neq0927 (9) que possuem os grupos metóxi e metila respectivamente, os simpletos referentes a estes grupos também possuem deslocamento químico semelhante ao deste sinal (descritos no apêndice) [57].

O duplo dupleto de deslocamento químico em 2,63 ppm é referente ao hidrogênio ligado ao centro estereogênico da $D$-fenilalanina. Este hidrogênio em questão tem esse tipo de sinal, pois os hidrogênios com o qual ocorre o acoplamento são diasterotópicos, ou seja, estes hidrogênios não são equivalentes. Portanto há um acoplamento individual entre o hidrogênio representado pela letra $\mathrm{F}$ e cada um dos hidrogênios representados pela letra $\mathrm{E}$ [56]. 
O dupleto em 2,06 ppm é referente ao sinal do hidrogênio ligado ao nitrogênio da amina presente entre os dois centros estereogênicos da molécula. O deslocamento químico é condizente com aminas secundárias. Ao se observar o sinal numa aproximação maior, é possível de se concluir que esse sinal é ligeiramente desdobrado em um duplo dupleto também, porém não o suficiente para que se possa fazer a medição de uma segunda constante de acoplamento [51].

Os últimos sinais no espectro de hidrogênio do Neq0799 (7) são dois multipletos, 1,58 e 1,25 ppm, aos quais foram atribuídos a letra H. Esses são sinais referentes ao grupo ciclopropila presente nestes compostos. Os hidrogênios deste grupo são todos diastereotópicos. Portanto, acoplamentos individuais acontecem entre esses hidrogênios, o que explica os sinais serem multipletos mesmo estes hidrogênios estando a uma distância maior do que 4 ligações de qualquer outro átomo de hidrogênio na estrutura [54].

\subsubsection{Ressonância Nuclear Magnética de ${ }^{13} \mathrm{C}$ do Neq0799 (7)}

Os espectros de ressonância magnética de carbono treze seguiram um procedimento experimental semelhante aos de hidrogênio 1, ressaltando as diferenças nas frequências: 125 MHz para amostras caracterizadas no Instituto de Química de São Carlos; $100 \mathrm{MHz}$ nas amostras caracterizadas na Universidade de Nottingham. O espectro de ${ }^{13} \mathrm{C}$ é uma válida corroboração dos grupos funcionais identificados no espectro de ${ }^{1} \mathrm{H}$, como mostrado na Figura 17.

O sinal em 173,4 ppm é referente ao carbono da carboxila deste composto. O deslocamento químico está na faixa descrita na literatura para este grupo funcional [51,54].

A letra B representa todos os sinais na faixa de $135,8 \mathrm{ppm}$ até $123,5 \mathrm{ppm}$, onde todos estes sinais representam os carbonos aromáticos dos dois grupos fenila [51,54].

Em torno de 119,6 ppm encontra-se o sinal referente ao carbono da nitrila. Segundo a literatura, nitrilas possuem deslocamento químico de carbono em 120 ppm, aproximadamente. Caso este carbono seja quaternário, é comum observar um pico de baixa intensidade [51,54].

O sinal representado pela letra D é bastante interessante e característico desses compostos. Ele representa o carbono que está ligado ao grupo $\mathrm{CF}_{3}$, com valor da constante de acoplamento $\mathrm{J}=37,43 \mathrm{~Hz}$, apesar da difícil visualização mesmo com o destaque na figura, possui um padrão 1:3:3:1 que é característico de um quarteto. De acordo com a literatura, este é um carbono adjacente ao grupo $\mathrm{CF}_{3}$, pois a atribuição de um sinal ao carbono deste grupo é inviável neste tipo de análise. A sua constante de acoplamento está acima dos $200 \mathrm{~Hz}$ e o seu 
deslocamento químico é semelhante ao dos carbonos aromáticos. Os sinais são comumente de baixa intensidade, pois não se trata de um carbono hidrogenado [58].

Figura 17. Espectro de $\mathrm{RMN}$ de ${ }^{13} \mathrm{C}\left(125 \mathrm{MHz}, \mathrm{CDCl}_{3}\right)$ do composto Neq0799 (7).

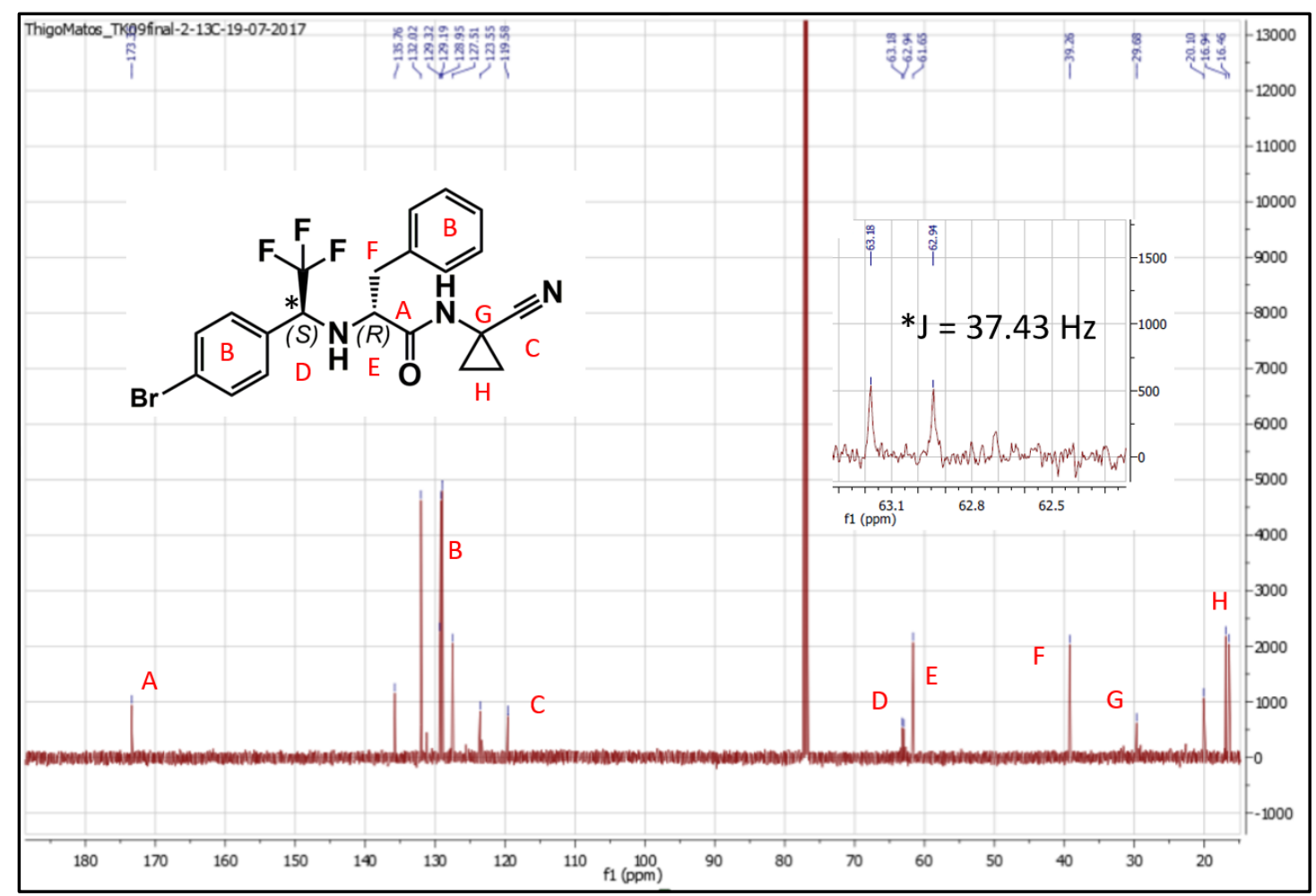

Fonte: Autoria própria.

A letra E representa o carbono estereogênico da $D$-fenilalanina. O deslocamento químico deste carbono está em torno de 61,6 ppm devido ao efeito sofrido por este carbono próximo ao carbono da amida [51,54].

O sinal em 39,3 ppm (F) foi atribuído ao carbono ligado ao grupo benzila da $D$ fenilalanina. A proximidade deste carbono ao anel aromático faz com que este esteja mais desblindado, resultando em um sinal ligeiramente mais deslocado do que o esperado para um carbono saturado [51,54].

Em 29,68 ppm, um baixo sinal representado pela letra G, é referente ao carbono quaternário da ciclopropila. É descrito na literatura que carbonos quaternários possuem sinais de baixa intensidade, usualmente entre 30 e 45 ppm [51,54].

Por último, os sinais representados pela letra H, em 16,9 e 16,5 ppm, são referentes aos carbonos hidrogenados da ciclopropila. Estes carbonos não podem ser diferenciados entre si, mesmo possuindo sinais distintos. Portanto, foi atribuída a mesma letra para ambos [51,54]. 


\subsubsection{Espectroscopia no Infravermelho do composto Neq0799 (7)}

A técnica de espectroscopia no infravermelho é utilizada na caracterização de compostos no NEQUIMED para confirmar os grupos funcionais presentes nas moléculas sintetizadas e observar se os grupos funcionais chave estão presentes na estrutura do composto. A Figura 18 traz o espectro de infravermelho para o Neq0799.

Figura 18. Espectro de Infravermelho do composto Neq0799 (7).

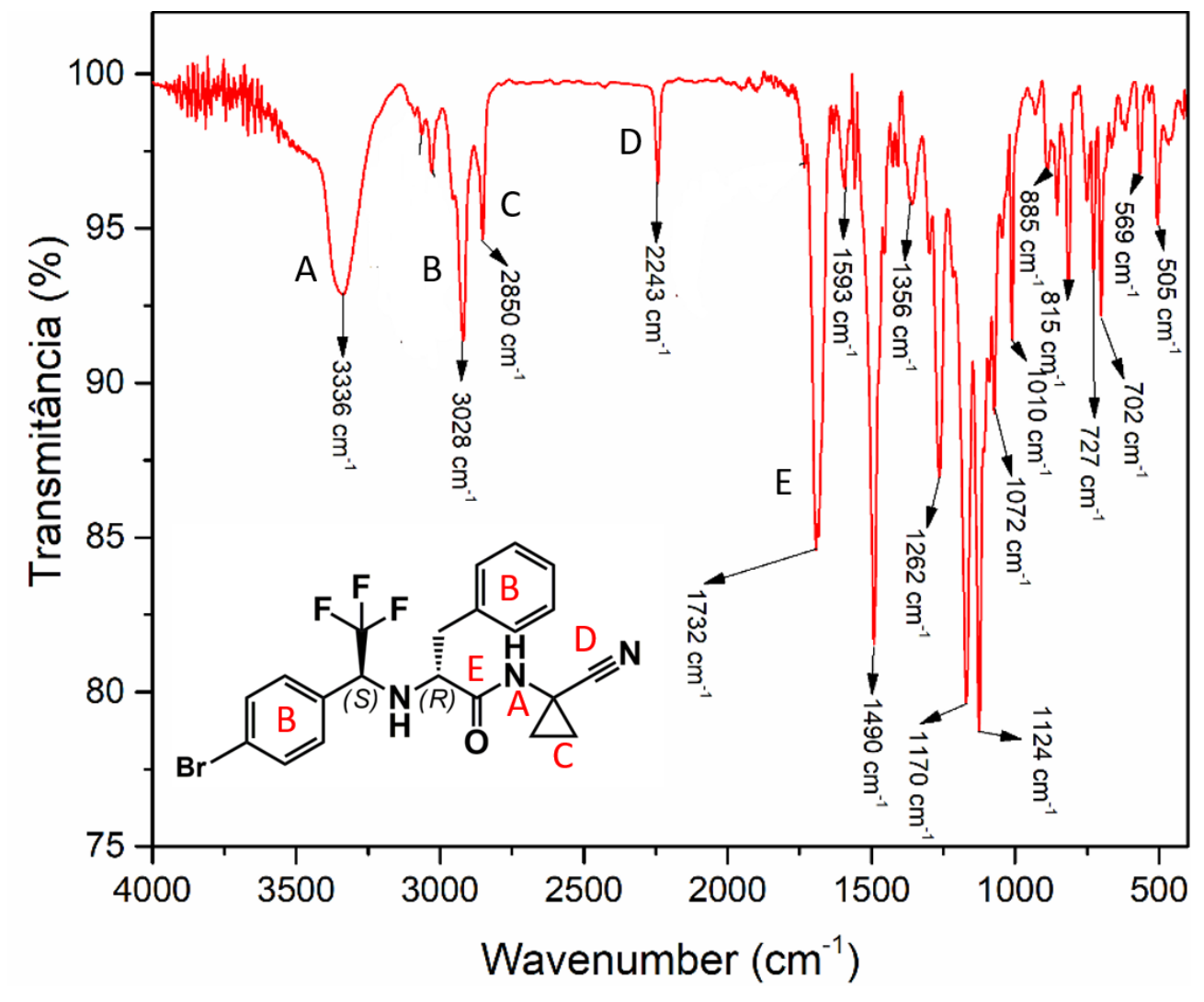

Fonte: Autoria Própria

No caso do Neq0799, todos os grupos funcionais essenciais foram observados no espectro de infravermelho.

A banda larga em torno $3336 \mathrm{~cm}^{-1}$ é característica de grupo amida e de um grupo amina, possivelmente superpostos no espectro acima, mais precisamente o estiramento da ligação N$\mathrm{H}$ destes grupos. Outros grupos funcionais como hidroxila e ácido carboxílico possuem um sinal bem mais largo e ligeiramente acima deste valor detectado [59].

Em seguida, em $3028 \mathrm{~cm}^{-1}$, têm-se a banda referente aos grupos fenila. Esse valor é bem característico de um estiramento $\mathrm{C}-\mathrm{H}$ aromático descrito na literatura $\left(3030 \mathrm{~cm}^{-1}\right)$, pois está 
entre os valores de uma ligação C-H, entre 2960 e $2850 \mathrm{~cm}^{-1}$ e o valor de uma ligação de alceno C-H comum, em torno de $3080 \mathrm{~cm}^{-1}$ [59].

A letra $\mathrm{C}$ representa o estiramento das ligações alifáticas entre os carbonos e os hidrogênios da ciclopropila. Como discutido anteriormente, o valor $2850 \mathrm{~cm}^{-1}$ está na faixa reportada para este grupo funcional [59].

A letra D representa a banda referente ao grupo nitrila. O valor $2243 \mathrm{~cm}^{-1}$ está condizente com o descrito na literatura para o estiramento da ligação tripla entre carbono e nitrogênio [59,51].

O último grupo funcional chave observado pelo espectro de infravermelho é do derivado de carboxila existente no composto Neq0799 (7). A banda fina em torno de $1700 \mathrm{~cm}^{-1}$ é descrita na literatura para o estiramento da ligação $\mathrm{C}=\mathrm{O}$ do grupo amida, o que está de acordo com o resultado obtido experimentalmente para este composto [59].

\subsection{Estrutura cristalina do composto Neq0930 (12)}

Para a obtenção da estrutura cristalina e o empacotamento da molécula do Neq0930 (12), cerca de $10 \mathrm{mg}$ de sólido amorfo foi cristalizado por difusão de $n$-hexano em uma solução do composto em diclorometano em uma parceria com o especialista em cristalografia da Universidade de Nottingham, Inglaterra, Dr. Nicholas Pearce. Um monocristal foi selecionado para ser analisado no difratômetro SuperNova Atlas S2. O cristal foi mantido a uma temperatura de $120 \mathrm{~K}$ durante todo o procedimento. Os dados foram tratados com o software Olex2, com a estrutura foi resolvida utilizando-se o programa ShelXT e refinada intrinsecamente com o uso do programa ShelXL de minimização pelo método dos mínimos quadrados $[60,61,62]$.

A Figura 19 representa a imagem obtida do cristal do composto Neq0930 (12). A disposição espacial da molécula foi feita para salientar a sua estereoquímica, dando destaque em específico aos hidrogênios que foram adicionados na etapa de redução na configuração $s y n$ de acordo com o procedimento utilizando boroidreto de zinco como agente redutor mostrado anteriormente [41]. 
Figura 19. Representação da estrutura cristalina da dipetidil nitrila (12), Neq0930.

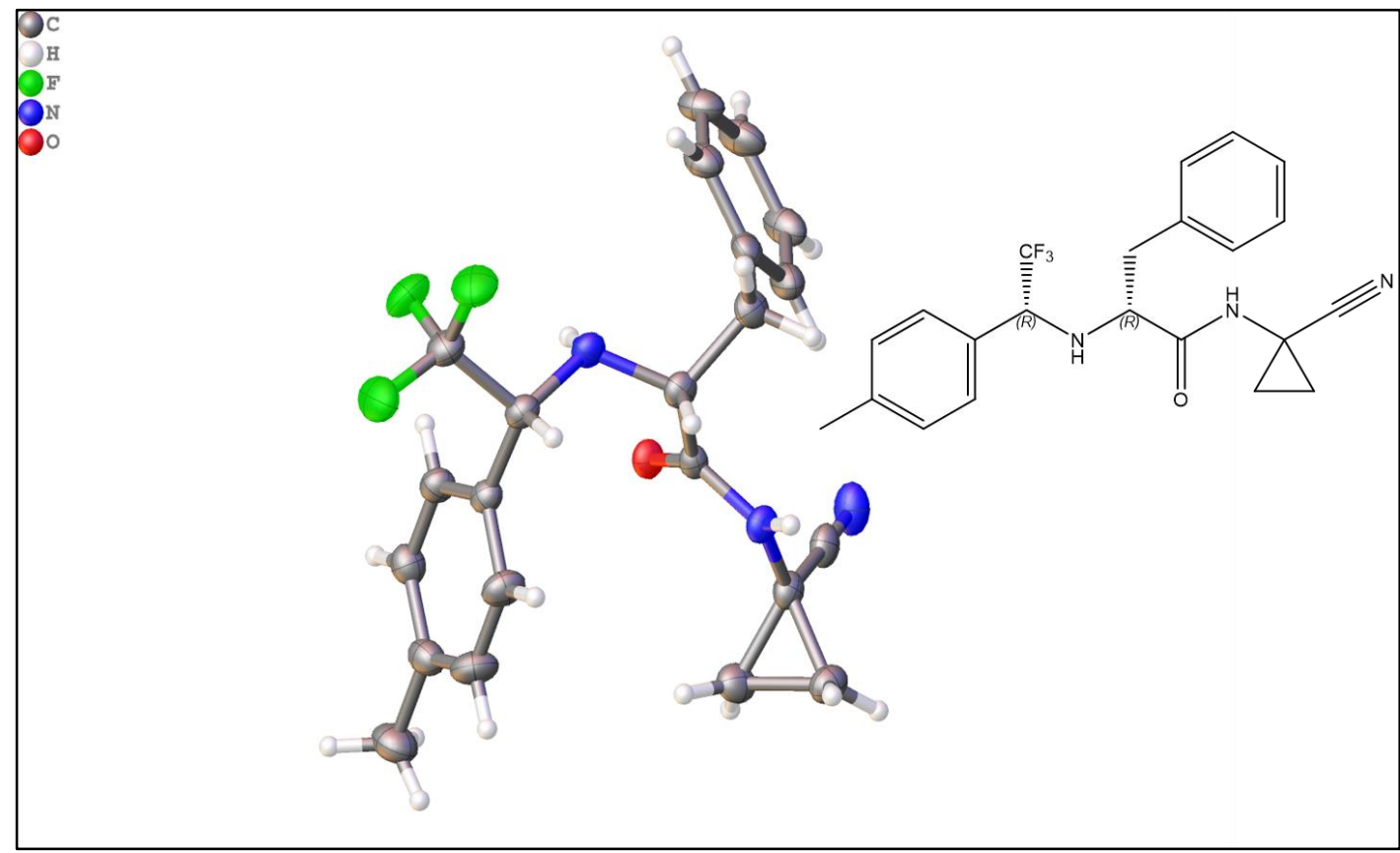

Fonte: Dados obtidos pelo Dr. Nicholas Pierce, especialista em cristalografia na Universidade de Nottingham, Inglaterra.

Dados da determinação da estrutura cristalina [TKNMPA]: $\mathrm{C}_{22} \mathrm{H}_{22} \mathrm{~F}_{3} \mathrm{~N}_{3} \mathrm{O}(\mathrm{M}=401,42$ g/mol): ortorrômbico, grupo espacial P212121 (no. 19), a = 9,65500 (10) $\AA, b=13,59830(10)$ $\AA, \mathrm{c}=15,78070(10) \AA, \mathrm{V}=2071,87(3) \AA 3, \mathrm{Z}=4, \mathrm{~T}=120(2) \mathrm{K}, \mu(\mathrm{CuK \alpha})=0,832 \mathrm{~mm}^{-1}$, Dcalc $=1,287 \mathrm{~g} / \mathrm{cm}^{3}, 19803$ reflexões foram medidas $\left(8,584^{\circ} \leq 2 \Theta \leq 149,212^{\circ}\right)$, Reflexões independentes: 4179 (Rint $=0,0221$, Rsigma =0,0145) utilizados em todos os cálculos. Valor final de R1: 0,0256 (I > 2 $\sigma(\mathrm{I})$ ), wR2: 0,0689 (utilizando todos os dados). Descrição do modelo de refinamento: Número de restrições - nenhuma restrição reportada.

A estereoquímica deste composto pode ser confirmada a partir desta estrutura cristalográfica, o que corrobora com a teoria através do mecanismo da reação utilizando boroidreto de zinco a baixas temperaturas para que ocorresse a formação do isômero syn como produto majoritário formado nesta redução [41].

A Figura 20 trata-se de outra imagem obtida dos cristais de Neq0930, porém salientando o empacotamento das moléculas de Neq0930 na estrutura cristalina observada ao longo do eixo A da célula. Há uma ligação de hidrogênio entre o oxigênio e o nitrogênio do grupo amida para diferentes moléculas de Neq0930 e uma interação hidrogênio-pi entre os anéis aromáticos. Isso leva a uma estrutura cristalina com fortes interações intermoleculares. 
Figura 20. Interações intermoleculares no cristal de Neq0930.

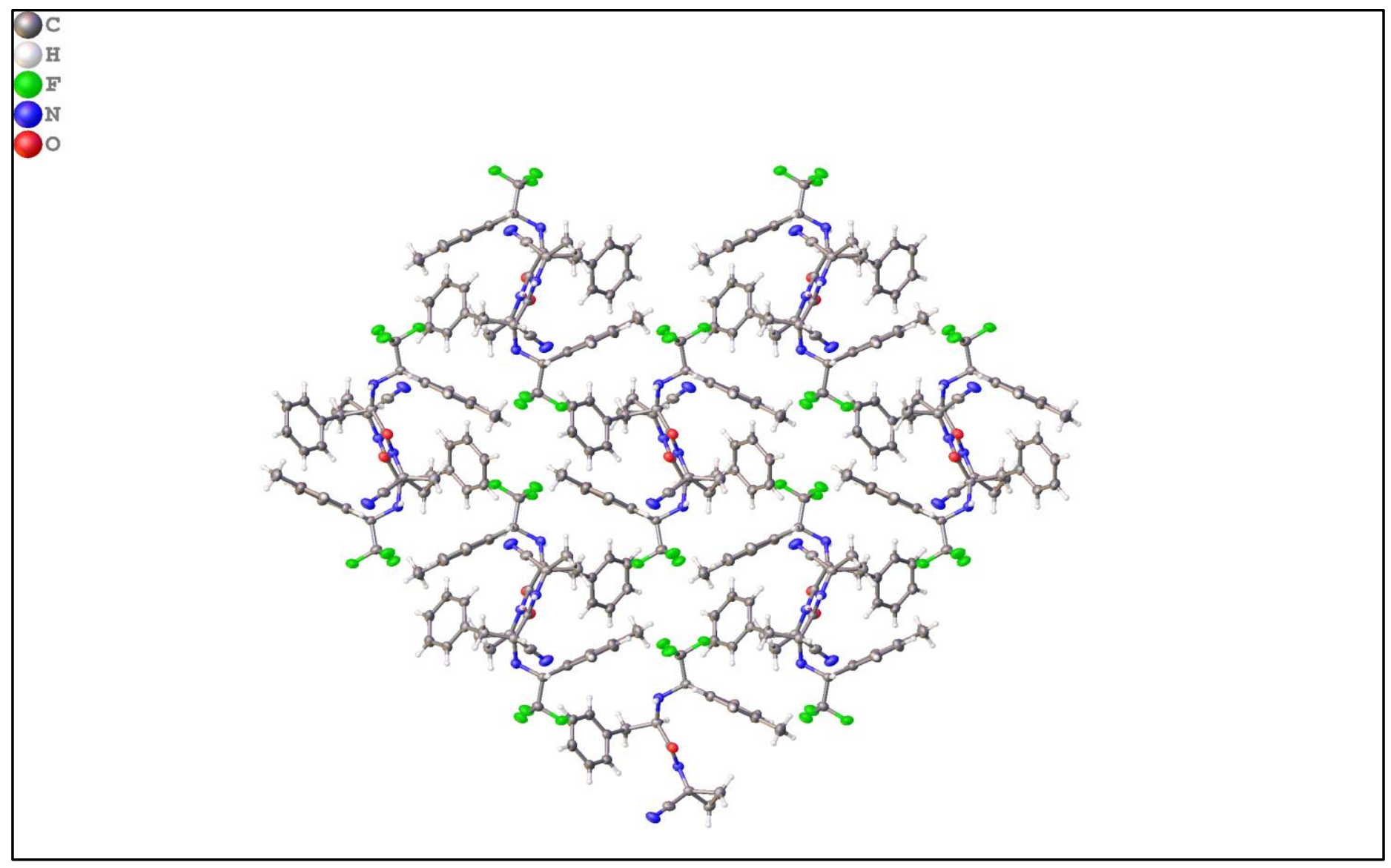

Fonte: autoria própria.

\subsection{Testes de inibição da enzima CPB e Análise de pares moleculares}

A primeira série de compostos sintetizada foi testada frente a enzima CPB para que se pudesse avaliar o potencial de inibição destes compostos. A Tabela 1 mostra os resultados obtidos para os compostos originais sintetizados. O composto Neq0808 (7) não apresentou inibição suficiente para atingir o valor de corte $(10 \mu \mathrm{mol} / \mathrm{L})$.

A partir dos resultados apresentados na Tabela 1 foi possível ser realizada a análise dos pares moleculares. Todos os pares que consistem em uma única transformação química de diferença entre si foram verificados e os resultados foram divididos em três imagens para melhor visualização das mudanças no potencial de inibição contra a enzima CPB. 
Tabela 1. pKi obtidos para a enzima CPB.

\begin{tabular}{c|c|c|c}
\hline Composto & Ki(nmol/L) & pKi & Desvio \\
\hline Neq0631 (1) & 1698 & 5,77 & 0,05 \\
\hline Neq0594 (2) & 1412 & 5,85 & 0,08 \\
\hline Neq0806 (3) & 4400 & 5,4 & 0,02 \\
\hline Neq0807 (4) & 7650 & 5,1 & 0,06 \\
\hline Neq0636 (5) & 151 & 6,82 & 0,03 \\
\hline Neq0810 (6) & 595 & 6,2 & 0,06 \\
\hline Neq0808 (7) & $>10000$ & $<5$ & - \\
\hline Neq0809 (8) & 795 & 6,1 & 0,07 \\
\hline
\end{tabular}

Fonte: autoria própria

A Figura 21 traz os pares possíveis de serem analisados considerando Neq0631 e Neq0636, além de seus respectivos enantiômeros. Os valores em azul próximo a estrutura do análogo tratam-se dos valores de pKi descritos na Tabela 1 e os valores em vermelho próximo às setas se referem à variação de pKi quando a transformação química ocorre.

Figura 21. Análise de pares moleculares - enântiomeros e adição do bromo.

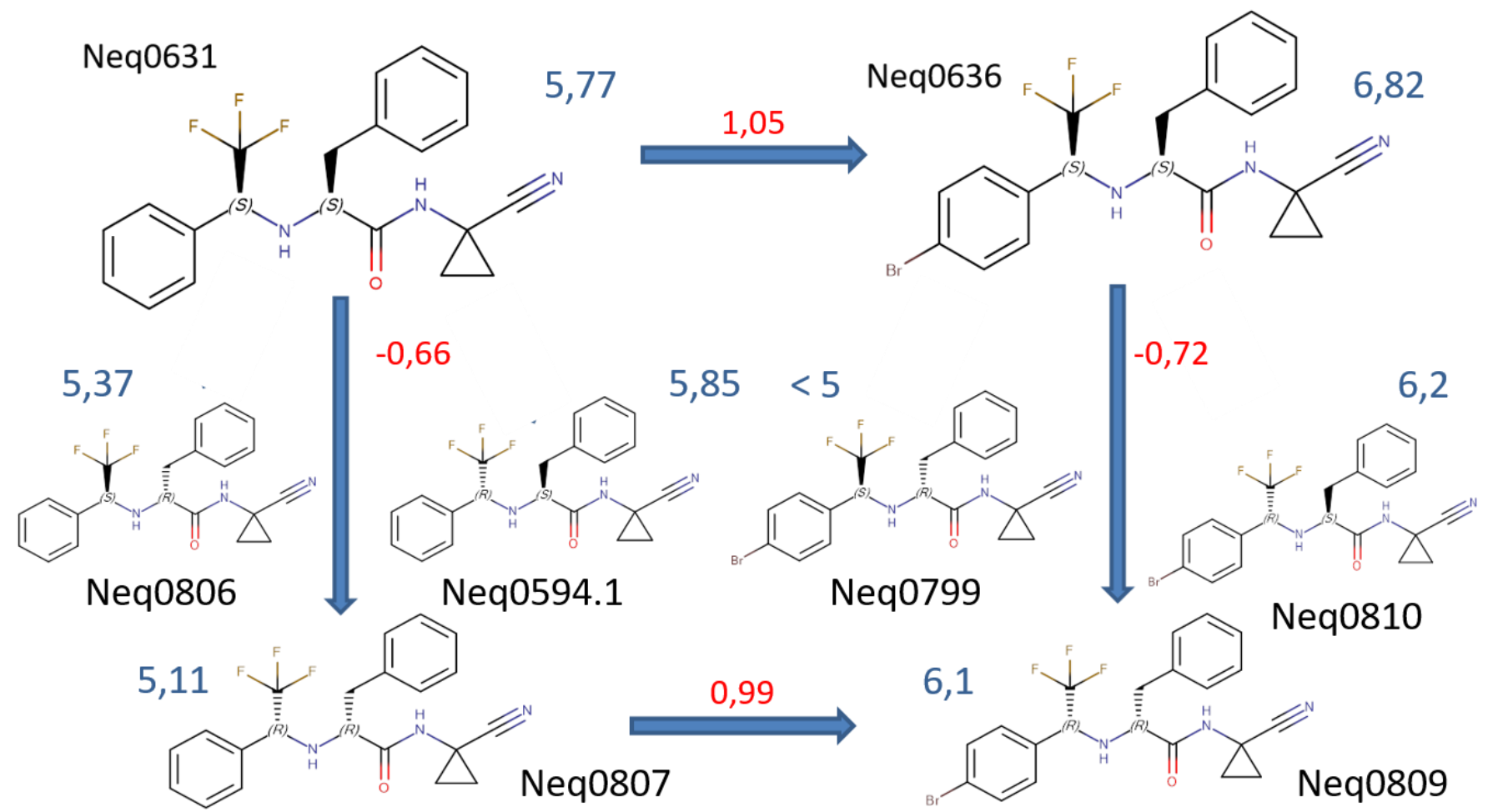

Fonte: Autoria própria. 
Ao observar o valor de pKi dos compostos Neq0807 e Neq0809, enantiômeros respectivos do Neq0631 e do Neq0636, pode-se concluir que, em ambos os casos, existe uma perda no potencial de inibição quando os centros estereogênicos são invertidos. Entretanto, a comparação direta do Neq0807 com o Neq0809, a adição do brometo em para na fenila da posição $\mathrm{P} 3$, nota-se um aumento na mesma ordem de 10 vezes observado anteriormente com o Neq0631 em relação ao Neq0636 e que foi a base para a formulação da hipótese inicial deste trabalho.

Após concluir-se que a inversão dos centros estereogênicos causa uma grande perda no potencial de inibição dos análogos, também foi preciso analisar se existem propriedades aditivas nessa perda de atividade e se alguma inversão de centro estereogênico específica é menos tolerada do que a outra. A Figura 22 traz o segundo bloco de análise de pares moleculares que estuda se existe aditividade nas perdas de potencial de inibição quando os pares analisados são diastereoisômeros do Neq0631 e Neq0636.

Figura 22. Análise de pares moleculares - diastereômeros.
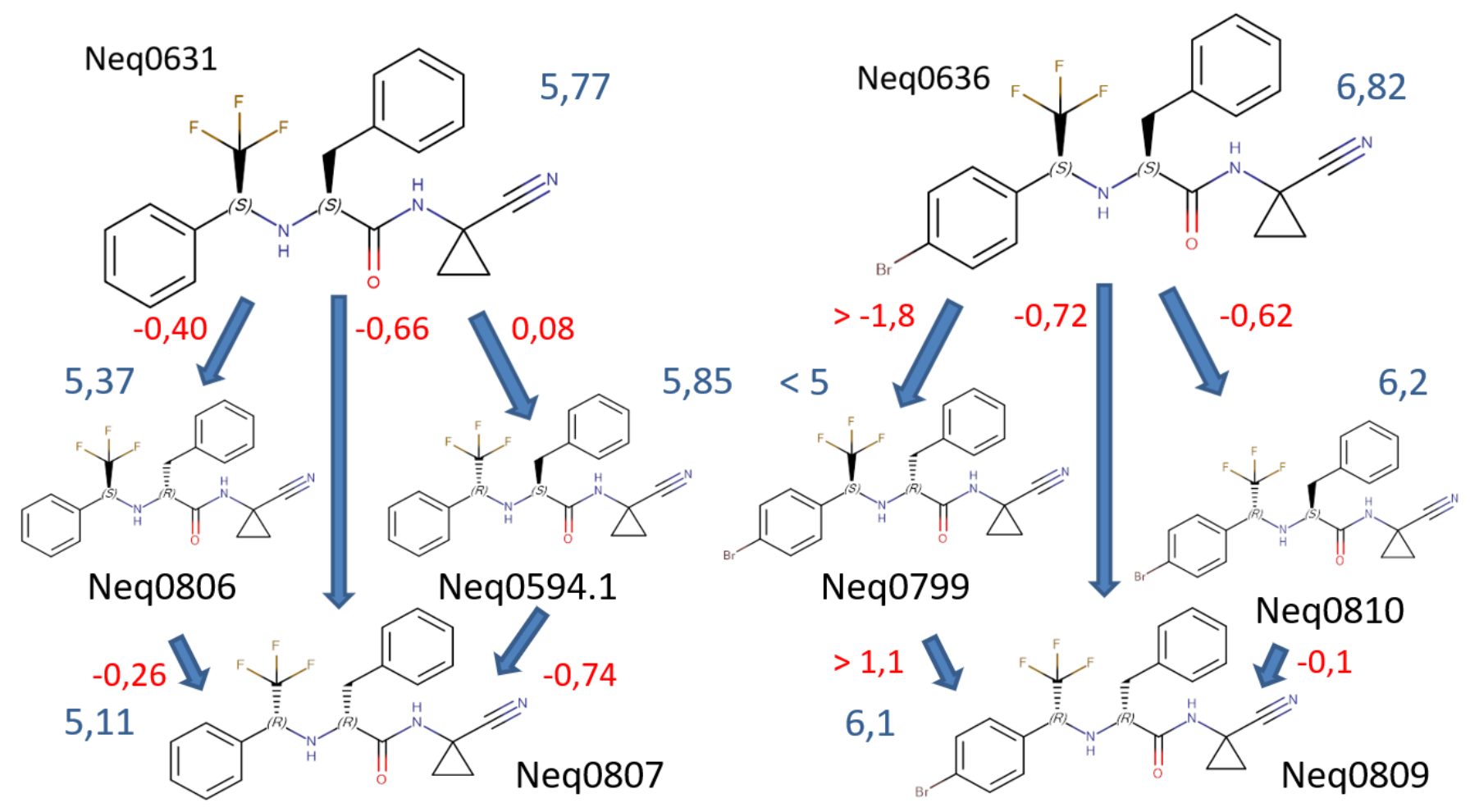

Fonte: Autoria própria. 
A Figura 22 deve ter os dois grupos de análogos interpretados separadamente. Iniciado pelos estereoisômeros do Neq0631 é possível observar que a inversão do centro estereogênico do grupo benzila é muito menos tolerado do que quando há a inversão apenas do centro estereogênico do grupo $\mathrm{CF}_{3}$. $\mathrm{O}$ valor de $\mathrm{pKi}$ do Neq0808 decai numa ordem maior do que o pKi do Neq0594.1. Enquanto a variação de pKi quando comparados o Neq0631 e o Neq0806 diminui em 0,40, não há variação quando se compara o Neq0631 com o Neq0594.1 já que o valor obtido de variação se encontra dentro do valor da margem de erro do experimento.

A segunda inversão de centro estereogênico nos compostos Neq0806 e Neq0594.1 resulta no mesmo composto, Neq0807 (que é o enantiômero do Neq0631) e essa nova inversão causa uma nova perda no potencial de inibição desses compostos. Neste caso, a inversão em Neq0806 leva a uma perda de inibição menos expressiva $(0,26)$ do que Neq0594.1, cuja perda foi de 0,74 . Este resultado mostra que a inversão do centro estereogênico do grupo benzila, mais próximo da posição P2 da molécula, é menos tolerada pela enzima, o que também está de acordo com a importância do subsítio S2, que está relacionado ao mesmo tempo um aumento na potência em compostos planejados para terem substituintes otimizados nesta posição.

No caso da análise dos estereoisômeros do Neq0636 têm-se resultados semelhantes que os obtidos para os análogos do Neq0631, com um único ponto diferente a ser destacado: a inversão do centro estereogênico do grupo benzila no caso do composto Neq0799, quando comparado com o composto Neq0636, causa uma perda de potencial de inibição tão grande que o composto é menos potente do que o valor de corte considerado para o potencial de inibição no trabalho. Valores abaixo de 5 são considerados abaixo do valor de corte nas análises, entretanto, este resultado corroborou que a inversão no centro estereogênico no grupo benzila é a menos tolerada pela enzima.

O último bloco de análise de pares moleculares restante a ser explorado é a adição do brometo em para na fenila da posição P3. A Figura 23 ilustra os pares que ainda não foram analisados. 
Figura 23. Análise de pares moleculares - substituição pelo bromo na posição para.

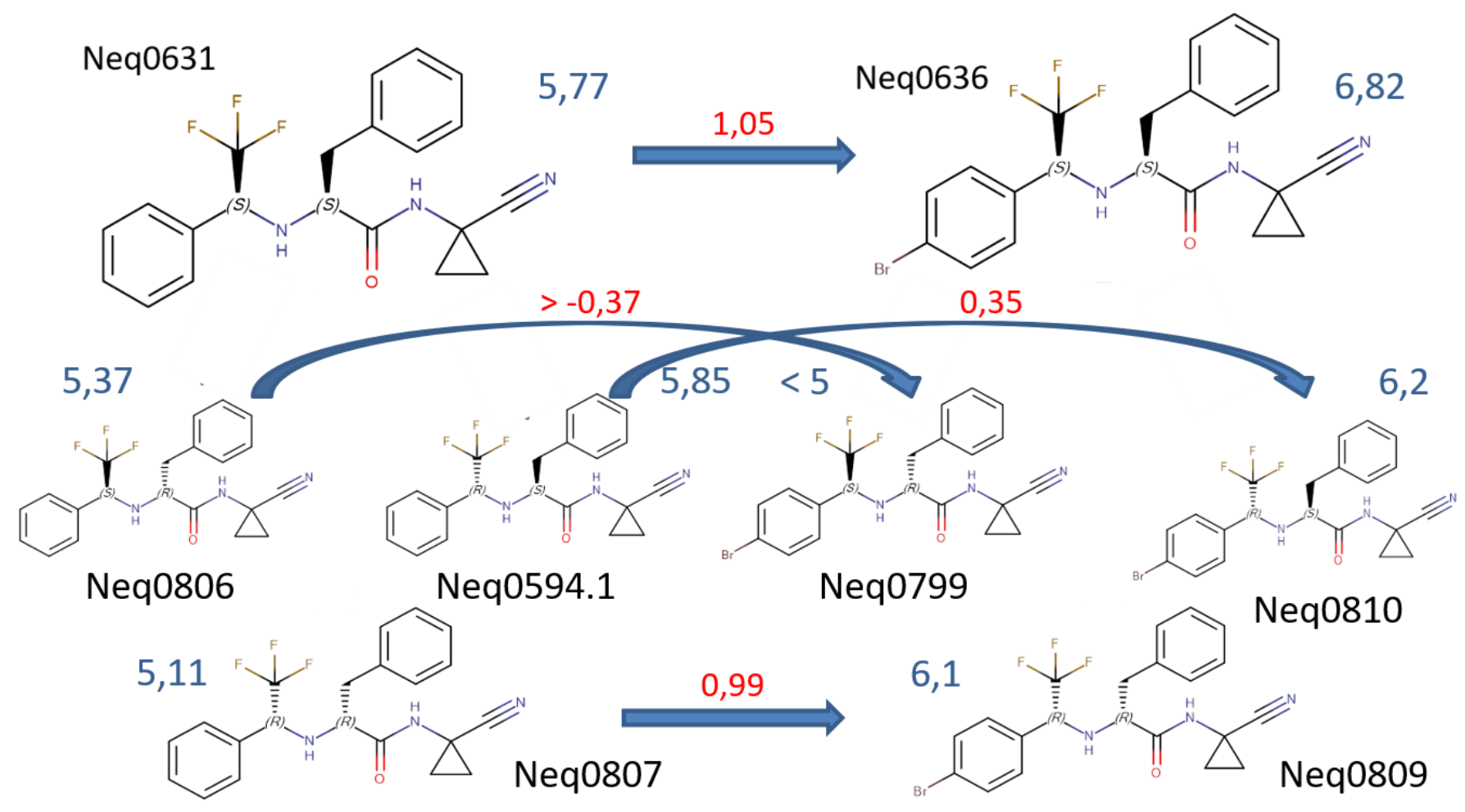

Fonte: Autoria própria.

Os resultados da Figura 23 mostram que a adição do bromo em para na fenila da posição P3 trouxe um aumento na potência dos compostos, com exceção da comparação entre Neq0806 e Neq0799. A comparação entre Neq0594.1 e Neq08010 traz um valor de aumento de potencial de inibição de 0,35 , que é um valor menor do que o obtido quando são analisados os compostos do primeiro bloco de análise de pares moleculares. O motivo desse valor inferior não pode afirmado com certeza absoluta, pois vários fatores podem estar envolvidos nesse processo de inibição, como diferente modo de interação ou influência da estereoisomeria na substituição do bromo, que pode afetar a potência de forma não aditiva.

Após as análises realizadas, foi possível observar que existem efeitos aditivos nas mudanças químicas que foram realizadas nos compostos base do trabalho, Neq0631 e Neq0636 e que o composto Neq0636 possuiu maior potência para a inibição da enzima CPB. 


\section{CONCLUSÃO E PERSPECTIVAS}

Dezesseis compostos foram sintetizados e quinze caracterizados. A análise de SAR para perfil bioativo de inibição da CPB concluiu que os compostos bromados com isômeros $(S, S)$ são mais potentes, como o Neq0636. O mapeamento da estereoisomeria demonstrou que a mudança de $S$ para $R$ na posição P2 leva a perda na potência dos compostos e os efeitos aditivos foram determinados para os derivados do Neq0631 e Neq0636.

Foi possível aperfeiçoar a rota utilizada para melhores rendimentos e também confirmar a estereoquímica absoluta do Neq0930 por meio da obtenção da primeira estrutura cristalográfica de raios- $\mathrm{X}$ de dipeptidil nitrilas no grupo.

O composto que possui o código TK teve a sua caracterização submetida no banco de dados do Nequimed e, após receber o código do grupo, poderá prosseguir para os testes bioquímicos.

A partir dos resultados destes derivados, dentro do ciclo de síntese-teste-análise-síntese desenvolvido neste trabalho, novas séries poderão ser planejadas para que, em futuros projetos, seja possível aprofundar ainda mais o estudo deste tipo de inibidores de cisteíno proteases. Tal estudo pode ser realizado usando outros halogênios como substituintes no grupo fenila na posição P3 em para e meta. 


\section{BIBLIOGRAFIA}

1. Silverman, R. B.; Holladay, M. W. The Organic chemistry of drug design and drug action. 3a. ed. Evanston, Il: Elsevier Inc, 2014.

2. Harvey, A. L. Natural products in drug discovery. Drug Discovery Today, Outubro 2008. 894-901.

3. Khan, M. O.; Deimling, M. J.; Philip, A. Medicinal chemistry and the pharmacy curriculum. American journal of pharmaceutical education, v. 75, n. 8, p. 161, 2011.

4. Adams , C. P.; Brantner, V. V. Estimating the cost of new drug development: is it really \$802 million? HealthAffairs, v. 25, n. 2, p. 420-428, 2006.

5. Agência Nacional De Vigilância Sanitária (Anvisa), n. 10, 10 Júlio 2013.

6. Henry, ; Lexchi, J. The pharmaceutical industry as a medicines provider. The Lancet, $V$. 30, 2002. 1590-1595.

7. Trouiller, et al. Drug development for neglected diseases: a deficient market and a publichealth policy failure. The Lancet, V. 359, 2002. 2188-2194.

8. Camargo, E. P. Doenças tropicais. Estud. Avançados, v. 22, p. 95-110, 2008.

9. Widdus, R. Public-private partnerships for health: Their main targets, their diversity, and their future directions. Bull. World Health Organ, v. 79, p. 713-720, 2001.

10. Herwaldt, B. L. Leishmaniasis. Lancet, v. 354, p. 1191-1199, 1999.

11. Mesquita, et al. Activity of imidazole compounds on Leishmania (L.) infantum chagasi: reactive oxygen species induced by econazole. Mol Cell Biochem, 2014. 293-300.

12. Santos, D. O.; Coutinho, C. E. R. Leishmaniasis treatment - a challenge that remains: a review. Parasitol Res, 2008. 1-10.

13. Murray, H. W. et al. Advances in leishmaniasis. The Lancet, Vol. 366, 2005. 1561-1577.

14. Moore, T. A. Visceral leishmaniasis. N. Engl. J. Med, v. 25, p. 535-551, 1997.

15. Thalhofer, C. J. et al. Leukocytes infiltrate the skin and draining lymph nodes in response to the protozoan leishmania infantum chagasi. Infect. Immun, v. 79, p. 108-117, 2011. 
16. Ashford, R. W. The leishmaniasis as emerging and reemerging zoonoses. Int. J. Parasitol, v. 30, p. 1269-1281, 2000.

17. Minodier, P.; Parola, P. Cutaneous leishmaniasis treatment. Travel Med. Infect. Dis., v. 5, p. 150-158, 2007.

18. Reithinger, R. E. A. Cutaneous leishmaniasis. Lancet, v. 7, p. 581-596, 2007.

19. Davidson, R. N. Leishmaniasis. Protozoal Trop. Infect., v. 33, p. 43-46, 2005.

20. Zulfiqar , ; Shelper, T. B.; Avery, V. M. Leishmaniasis drug discovery: recent progress and challenges in assay development. Drug Discovery Today, p. 1-16, Julho 2017.

21. Siklos, ; Benaissa, M.; Thatcher, G. R. J. Cysteine proteases as therapeutic targets: does selectivity matter? A systematic review of calpain and cathepsin inhibitors. Acta Pharmaceutica Sinica B, 2015. 506-519.

22. Arafet, K. . F. S. \&. M. V. Computational study of the catalytic mechanism of the cruzain cysteine protease. ACS Catal, v. 7, p. 1207-1215, 2017.

23. Powers, J. C. . A. J. L. . E. Ö. D. \&. J. K. E. Irreversible inhibitors of serine, cysteine, and threonine proteases. Chem. Rev., v. 102, p. 4639-4750, 2002.

24. Lecaille, F. . K. J. \&. B. D. Human and parasitic papain-like cysteine proteases: their role in physiology and pathology and recent developments in inhibitor design. Chem. Rev., $v$. 102, p. 4459-4488, 2002.

25. Wiggers HJ, R. J. F. W. S.-C. R. C. Z. E. A. Non-peptidic cruzain inhibitors with trypanocidal activity discovered by virtual screening and in vitro assay. PLOS neglected tropical diseases, v. 7, n. 8, p. 1-11, 2013.

26. Mullard, A. Merck \& Co. drops osteoporosis drug odanacatib. Nat. Rev Drug Discov., v. 15, p. 669, 2016.

27. Avelar, L. A.; AL., E. Molecular design, synthesis and trypanocidal activity of dipeptidyl nitrile as cruzain inhibitors. PLoS Negl. Trop. Dis, 2015.

28. Farady, C. J.; Craik, C. S. Mechanisms of Macromolecular Protease Inhibitors. ChemBioChem, v. 11, n. 17, p. 2341-2346, 2010. 
29. Black, W. C.; Bayly, C. I.; Et Al. Trifluoroethylamines as amide isosteres in inhibitors of cathepsin K. Bioorganic \& Medicinal Chemistry Letters, v. 15, p. 4741-4744, 2005.

30. Hopkins, A. L.; Groom, C. R. The druggable genome. Nat Rev Drug Discov [S.I.], v. 1, n. 9, p. 727-730, 2002.

31. Spring, D. R. Diversity-oriented synthesis; a challenge for synthetic chemists. Organic and Biomolecular Chemistry, v. 1, n. 22, p. 3867-3870, 2003.

32. Carey, J. S. et al. Analysis of the reactions used for the preparation of drug candidate molecules. Organic \& Biomolecular Chemistry, v. 4, n. 12, p. 2337-2347, 2006.

33. Burke, M. D.; Schreiber, S. L. A planning strategy for diversity-oriented synthesis. Angewandte Chemie - International Edition, v. 43, n. 1, p. 46-58, 2004.

34. Schultes, S. et al. Ligand efficiency as a guide in fragment hit selection and optimization. Drug Discovery Today: Technologies, v. 7(3), n. e157, 2010.

35. Congreve, M. et al. Recent developments in fragment-based drug discovery 51 (13): 3661, 2008. Journal of Medicinal Chemistry, v. 51 (13), p. 3661-3680, 2008.

36. Plowright, A. T. et al. Hypothesis driven drug design: improving quality and effectiveness of the design-make-test-analyses cycle. Drug Discovery Today, v. 17 (1-2), p. 56-62, 2012.

37. O'Reilly, B. How to implement hypothesis-driven development. Barry O'Reilly: experimental by design, 2015. Disponivel em: <http://barryoreilly.com/2013/10/21/howto-implement-hypothesis-driven-development/>. Acesso em: 28 September 2018.

38. Turk, et al. Coupling matched molecular pairs with machine learning for virtual compound optimization. J. Chem. Inf. Model, v. 57, p. 3079 - 3085, 2017.

39. Kerns, E. H.; DI, L. Drug-like Properties - Concepts, Structure Design and Methods from ADME to Toxicity Optimization. First. ed. [S.l.]: Elsevier Inc., 2008. 552 p.

40. Chen, C. Y. et al. Diastereoselective reductive amination process US 20060030731 A1 Patent. [S.l.]. 2006.

41. Hughes, G. E. A. Diastereoselective Reductive Amination of Aryl Trifluoromethyl Ketones and $\alpha$-Amino Esters. . Angewandte Chemie. Int. Ed., v. 46, p. 1839-1842, 2007. 
42. Valeur, E., Bradley, M. Amide bond formation: beyond the myth of coupling reagents. Chem. Soc. Rev. 2009, 38, 606-631.

43. Gomes, C. Síntese de análogos do K11777 e de dipeptidil nitrilas. Universidade de São Paulo. São Carlos, p. 106. 2015. (Processo nº 2014/18443-9).

44. Verma, S. . D. R. \&. P. K. C. Cysteine proteases: modes of activation and future prospects as pharmacological targets. Front. Pharmacol, v. 7, p. 1-12, 2016.

45. Yung-Chi, C. \&. P. W. H. Relationship between the inhibition constant (KI) and the concentration of inhibitor which causes 50 per cent inhibition (I50) of an enzymatic reaction. Biochem. Pharmacol, v. 22, p. 3099-3108, April 1973.

46. Burtoloso, C. B. et al. Anti-trypanosomal activity of non-peptidic nitrile-based cysteine protease inhibitors. PLOS Neglected Tropical Diseases, 2017. 1-16.

47. Skoog, D. A.; Holler, F. J.; Nieman, T. A. Principles of Instrumental Analysis. 5. ed. [S.1.]: [s.n.], 2002.

48. Chen, Y. et al. Optimum concentration of trifluoroacetic acid for reversed-phase liquid chromatography of peptides revisited. Journal of Chromatography A, v. 1043, p. 9-18, 2004.

49. Rayner-Canham, ; Overton,. Descriptive Inorganic Chemistry. 5. ed. [S.l.]: [s.n.], 2009.

50. Lee, J. D. Química Inorgânica não tão concisa. Tradução da $5^{\mathrm{a}}$ ed. inglesa. ed. [S.1.]: [s.n.], 1999.

51. Silverstein, R. M.; Bassler, G. C.; Morrill, T. C. Identificação espectrométrica de compostos orgânicos. 7. ed. [S.1.]: LTC, 2006.

52. Carey, F. Organic Chemistry. [S.1.]: McGraw-Hill, v. 4, 2000.

53. Clayden, J.; Greeves, N. Organic Chemistry. [S.1.]: Oxford University Press, 2000.

54. Pavia, D. E. A. Introduction to Spectroscopy. 4. ed. [S.1.]: Brooks Cole, 2008.

55. Carey, F. E. A. Advanced Organic Chemistry part A. 5. ed. [S.1.]: Springer, 2007.

56. Welch, J. T.; Seper, K. W. Synthesis, regioselective deprotonation, and stereoselective alkylation of fluoro ketimines. J. Org. Chem., v. 53, p. 2991-2999, 1988. 
57. Kummerlowe , G.; Luy, B. Residual dipolar couplings for the configurational and conformational analysis of organic molecules. Annual Reports on NMR Spectroscopy, $v$. 68, 2009.

58. Spear, R. J.; Forsyth, D. A.; Olah, G. A. Carbon-fluorine spin-spin coupling in carbocations. Journal of the American Chemical Society, v. 98, n. 9, p. 2493-2500, 1976.

59. Lin-Vien, D. et al. The Handbook of infrared and raman characteristic frequencies of organic molecules. 1. ed. [S.1.]: Academic Press, 1991.

60. Dolomanov, O. V. et al. OLEX2: a complete structure solution, refinement and analysis program. Journal of Applied Crystallography, v. 42, p. 339-341, 2009.

61. Sheldrick, G. M. SHELXT - Integrated space-group and crystal-structure determination. Acta Crystallographica Section A Foundations and Advances, v. 71, p. 3-8, 2015.

62. Sheldrick,. Crystal structure refinement with SHELXL. Acta Crystallographica Section C Structural Chemistry, v. 71, p. 3-8, 2015. 


\section{APÊNDICE}

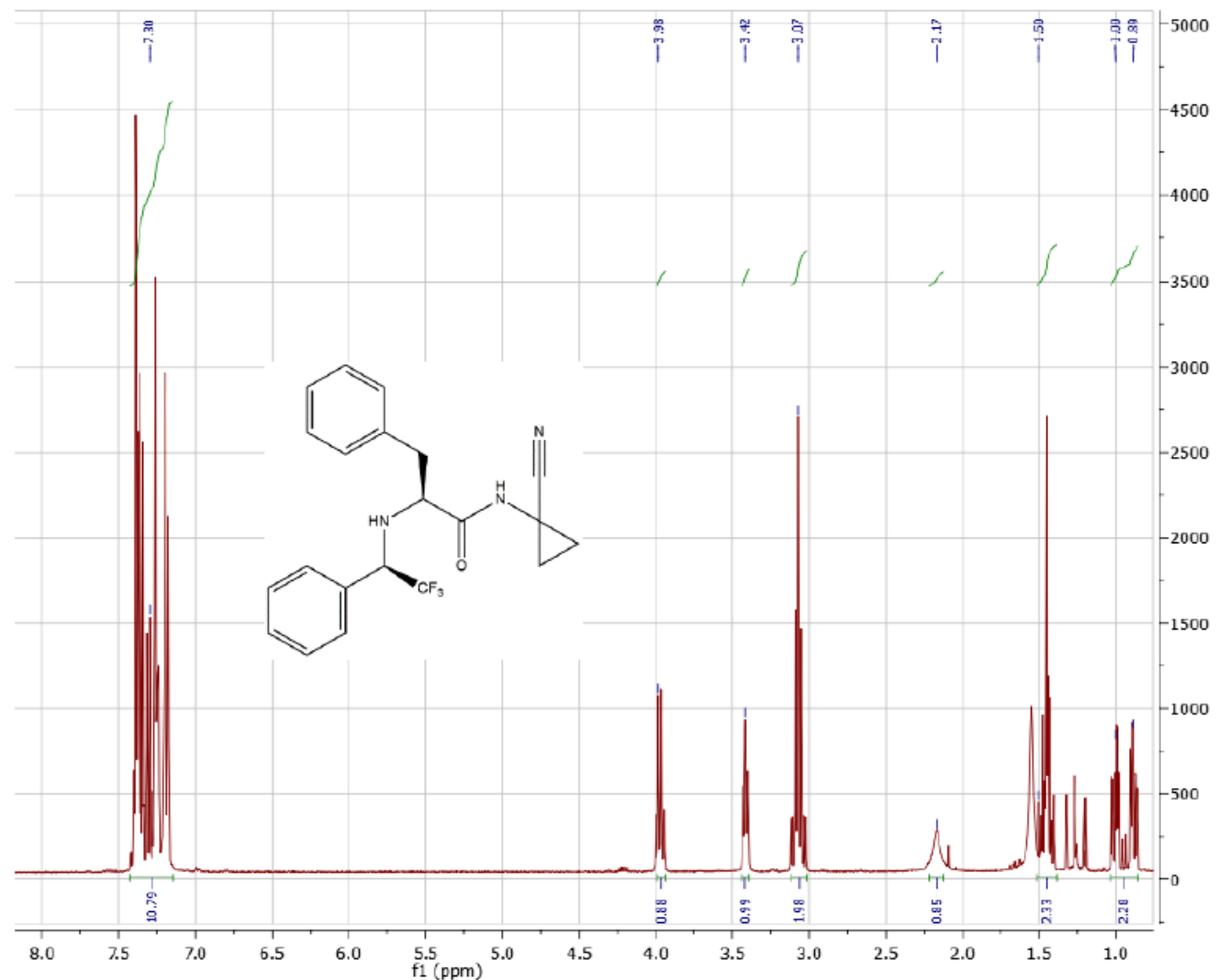

Espectro de $\mathrm{RMN}$ de ${ }^{1} \mathrm{H}\left(500 \mathrm{MHz}, \mathrm{CDCl}_{3}\right)$ da dipeptidil-nitrila (1).

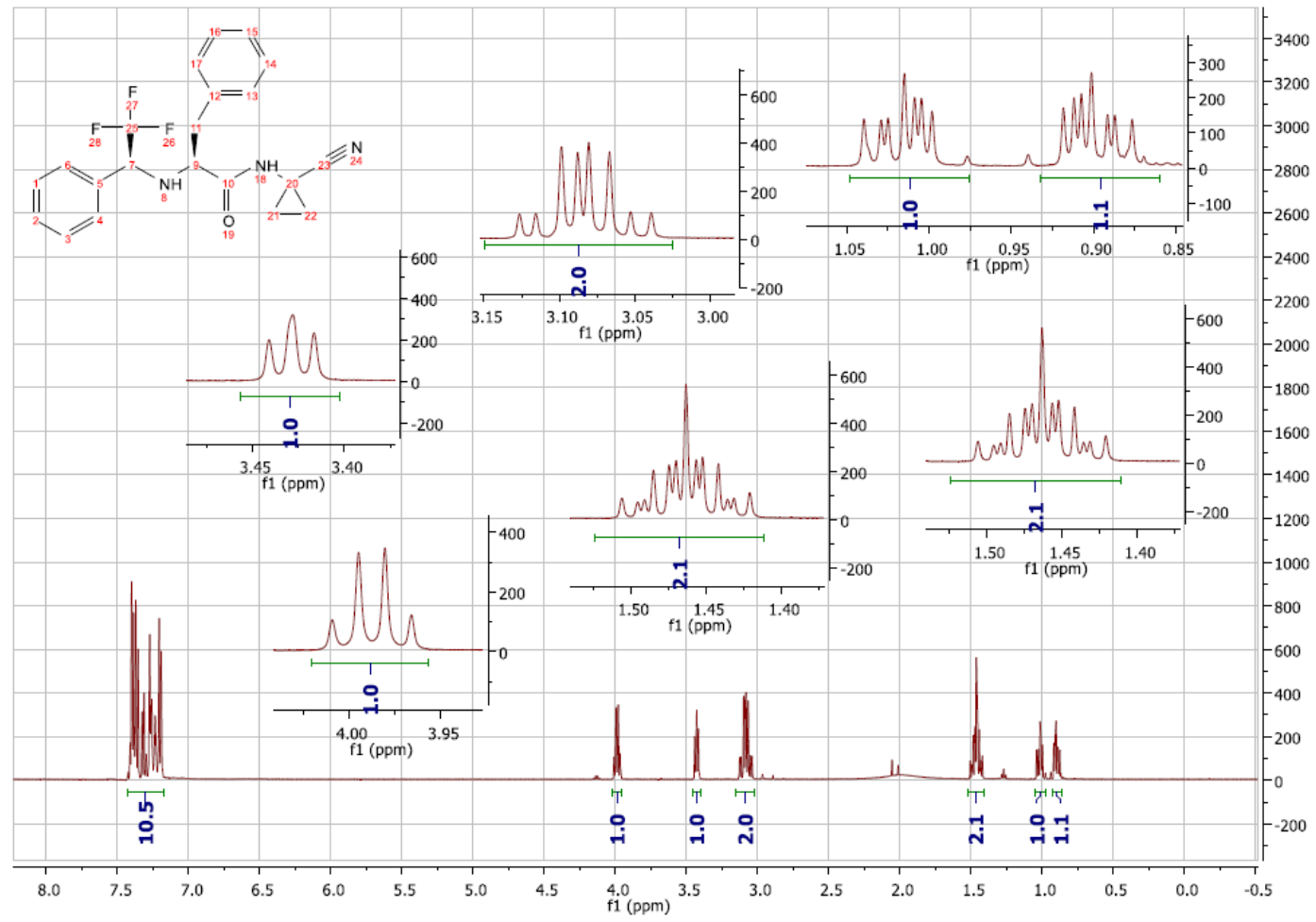

Espectro de RMN de ${ }^{1} \mathrm{H}$ referência (400 MHz, $\mathrm{CDCl}_{3}$ ) da dipeptidil-nitrila (1) [43]. 


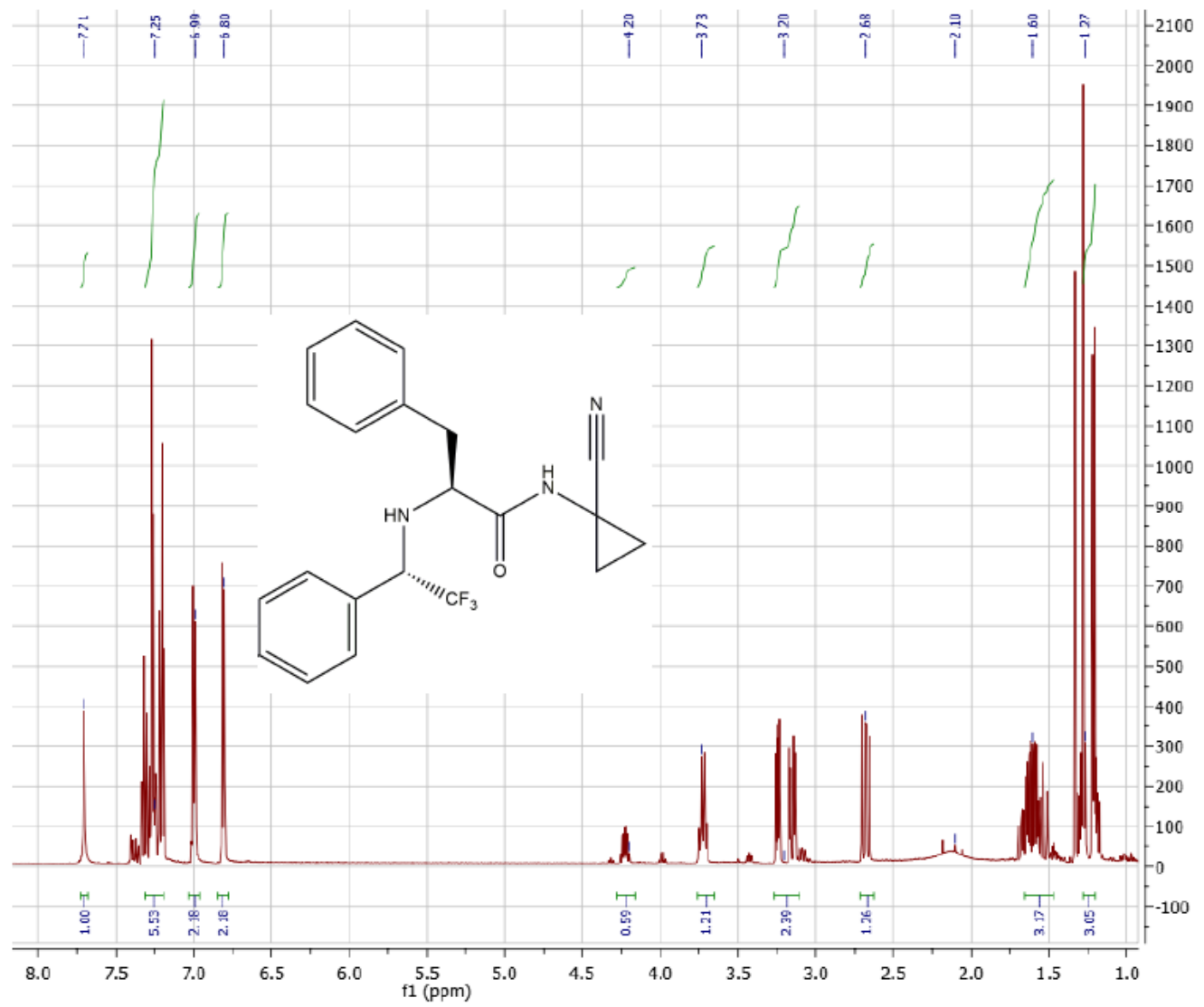

Espectro de RMN de ${ }^{1} \mathrm{H}\left(500 \mathrm{MHz}, \mathrm{CDCl}_{3}\right)$ da dipeptidil-nitrila (2).

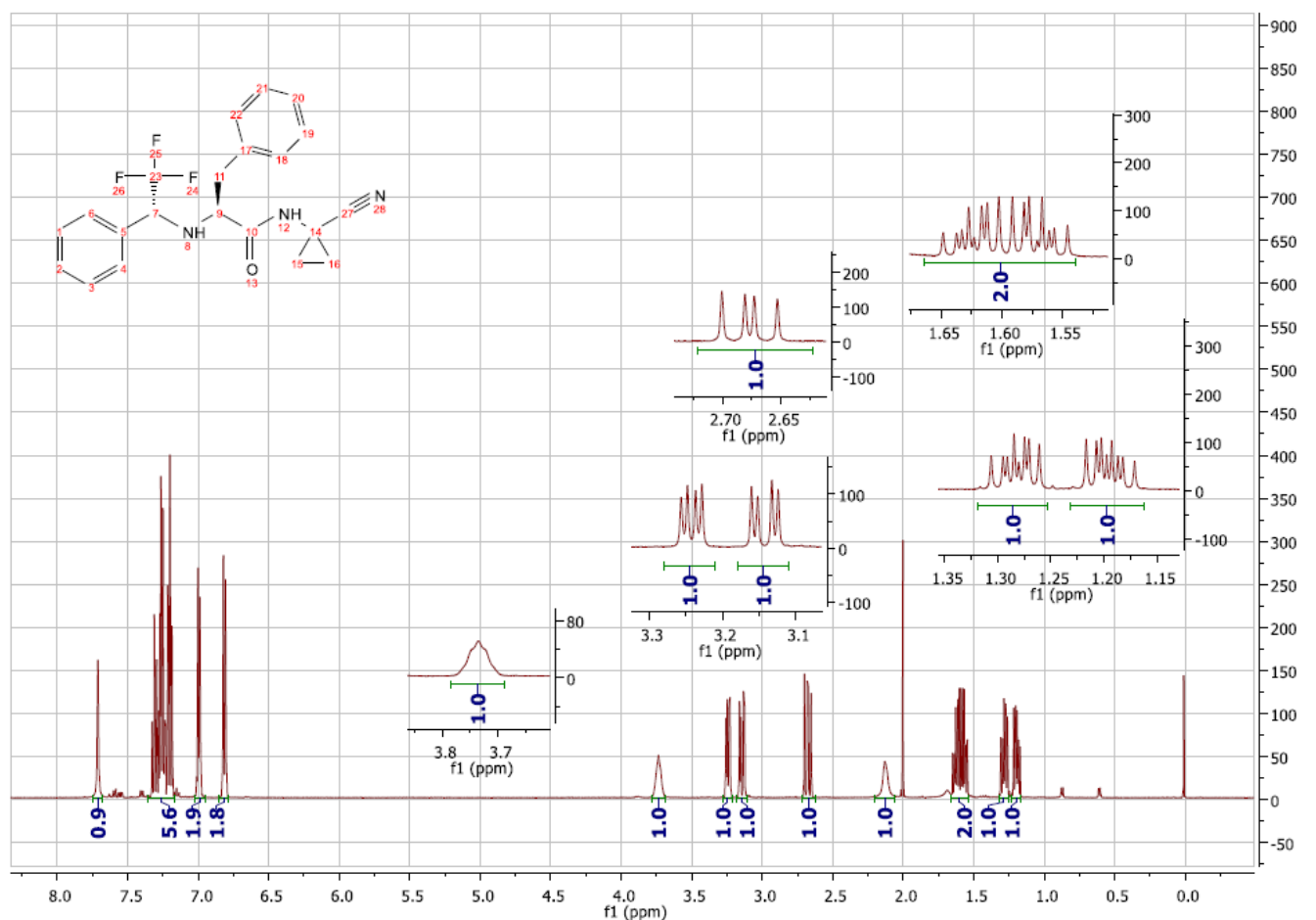

Espectro de $\mathrm{RMN}$ de ${ }^{1} \mathrm{H}$ referência (400 $\mathrm{MHz}, \mathrm{CDCl}_{3}$ ) da dipeptidil-nitrila (2) [43]. 


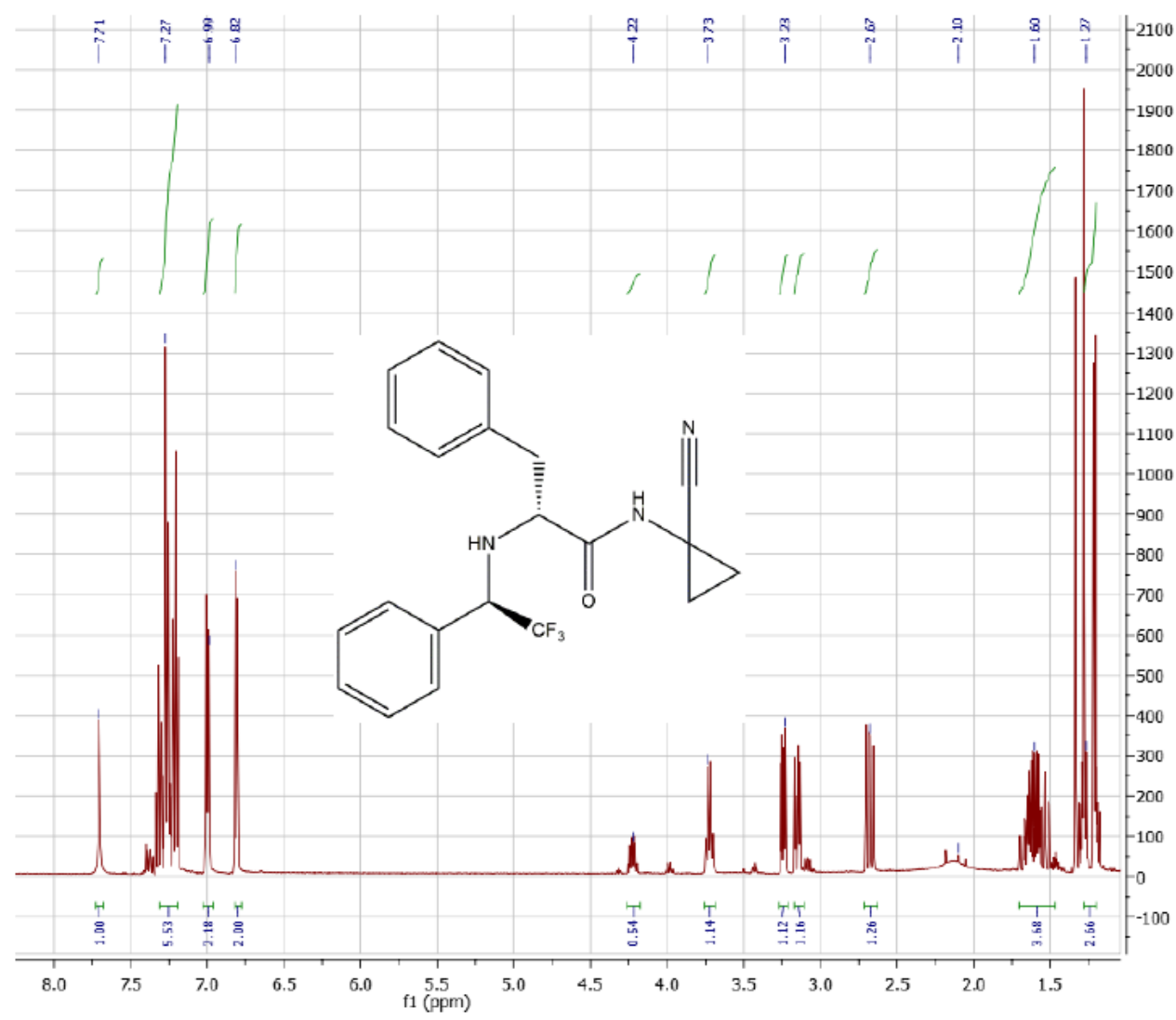

Espectro de RMN de ${ }^{1} \mathrm{H}\left(500 \mathrm{MHz}, \mathrm{CDCl}_{3}\right)$ da dipeptidil-nitrila (3).

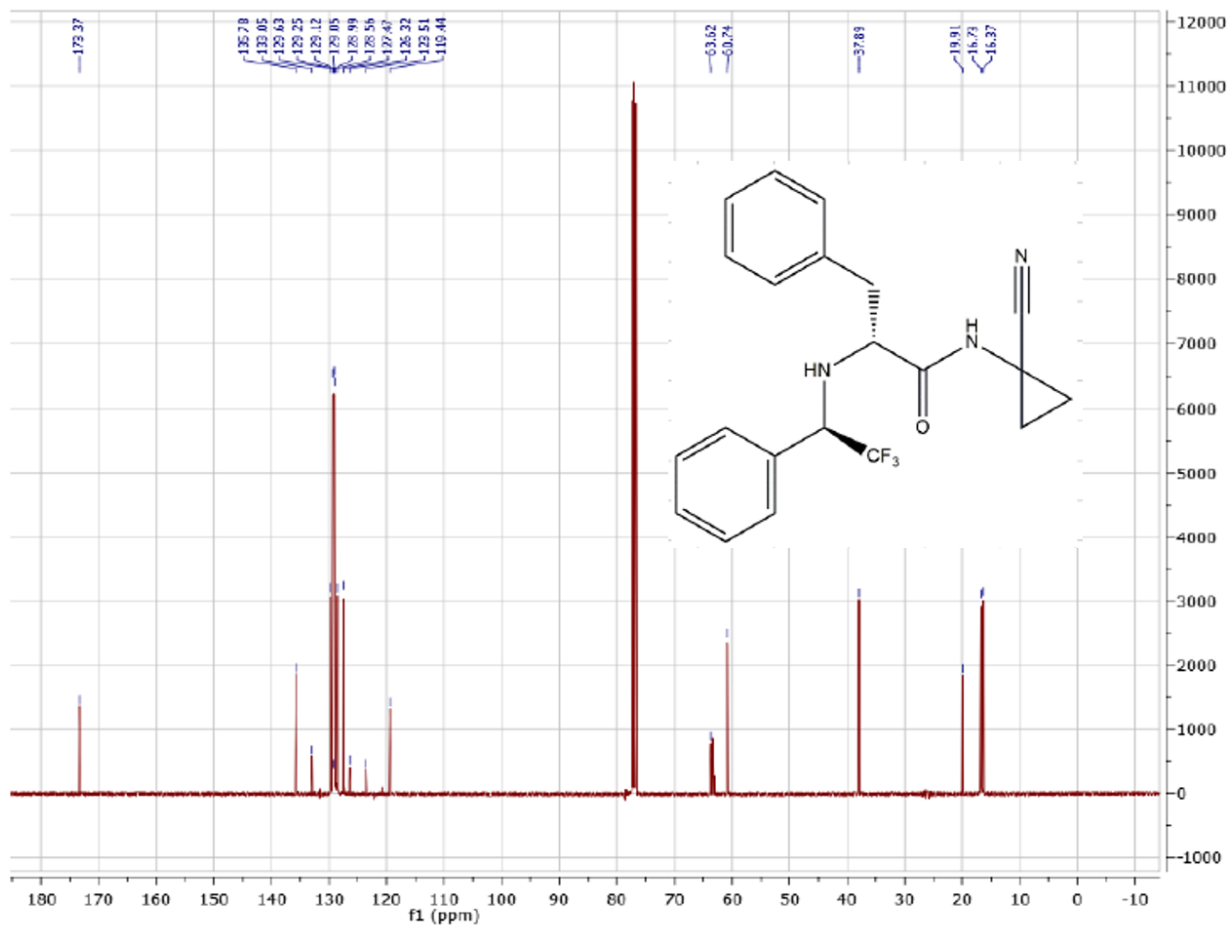

Espectro de $\mathrm{RMN}$ de ${ }^{13} \mathrm{C}\left(125 \mathrm{MHz}, \mathrm{CDCl}_{3}\right)$ da dipeptidil-nitrila (3). 


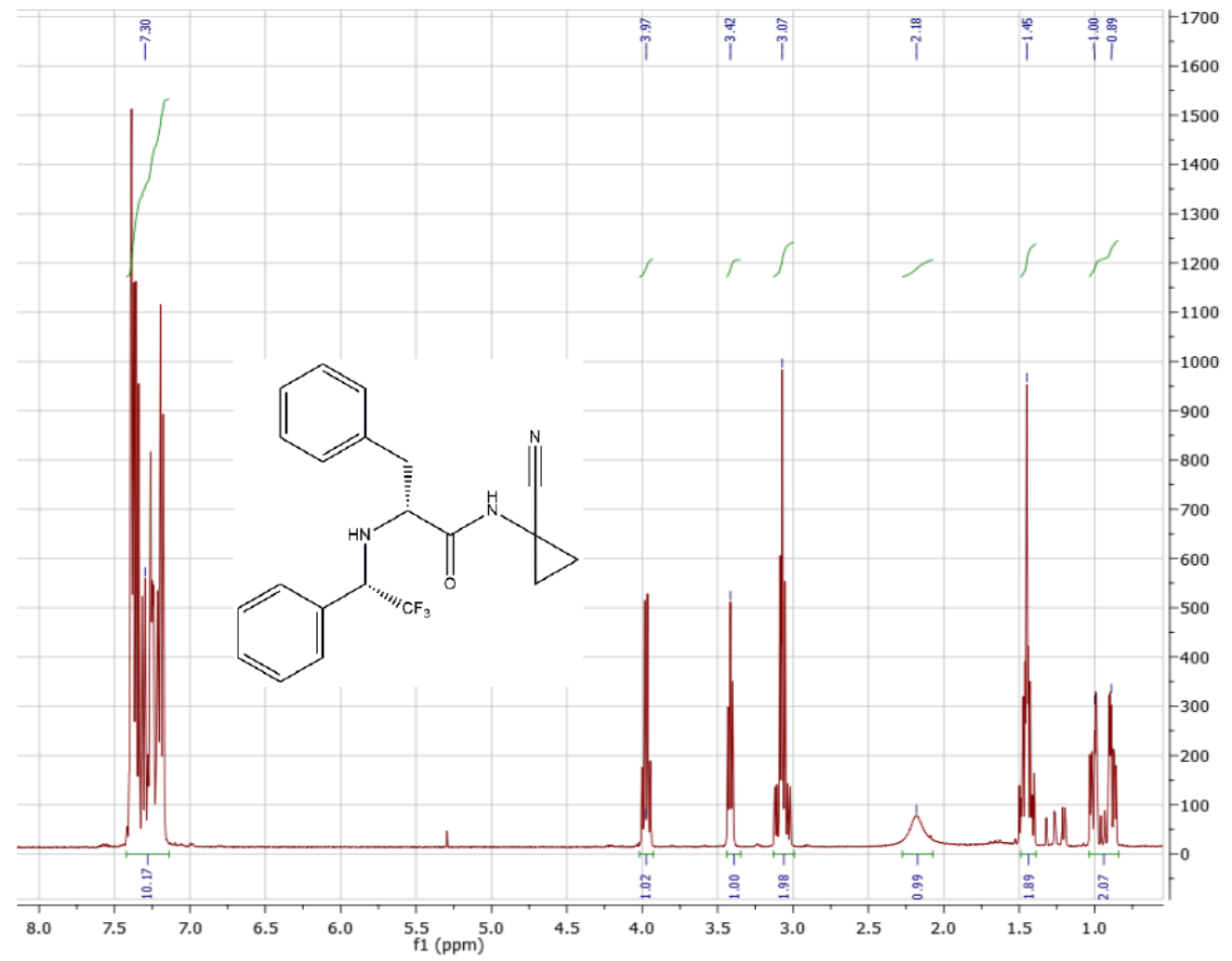

Espectro de RMN de ${ }^{1} \mathrm{H}\left(500 \mathrm{MHz}, \mathrm{CDCl}_{3}\right)$ da dipeptidil-nitrila (4).

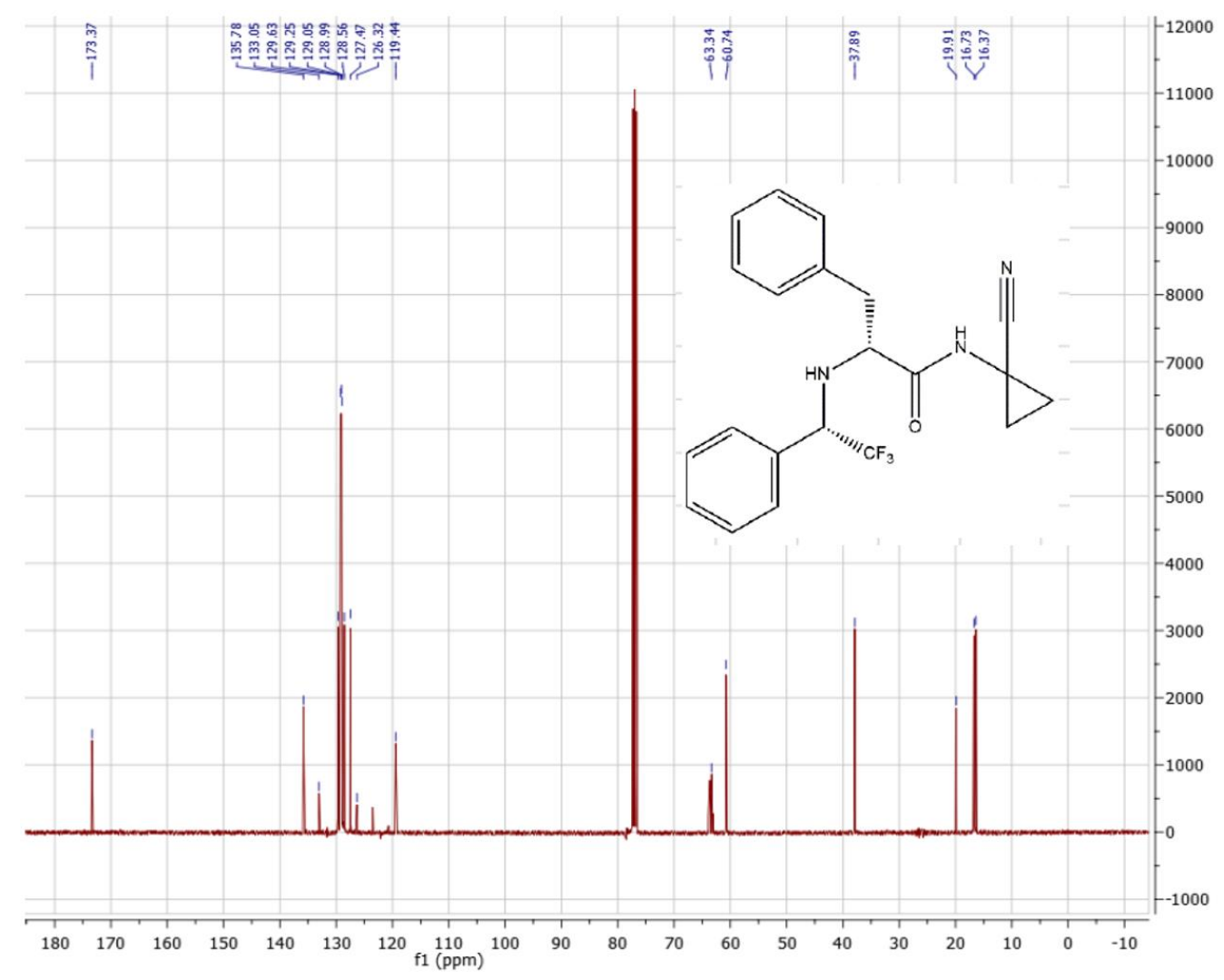

Espectro de $\mathrm{RMN}$ de ${ }^{13} \mathrm{C}\left(125 \mathrm{MHz}, \mathrm{CDCl}_{3}\right)$ da dipeptidil-nitrila (4). 


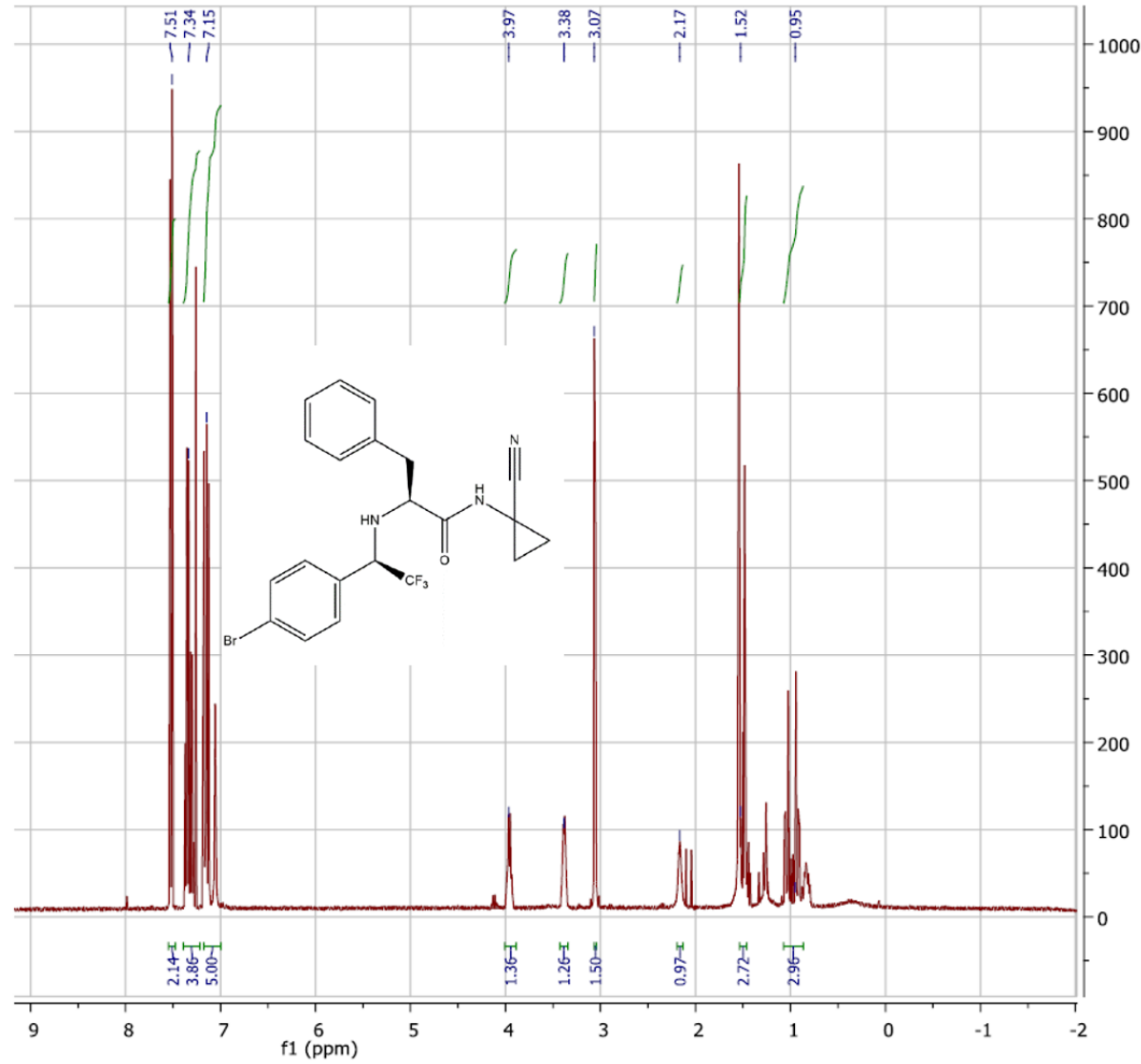

Espectro de RMN de ${ }^{1} \mathrm{H}\left(500 \mathrm{MHz}, \mathrm{CDCl}_{3}\right)$ da dipeptidil-nitrila (5).

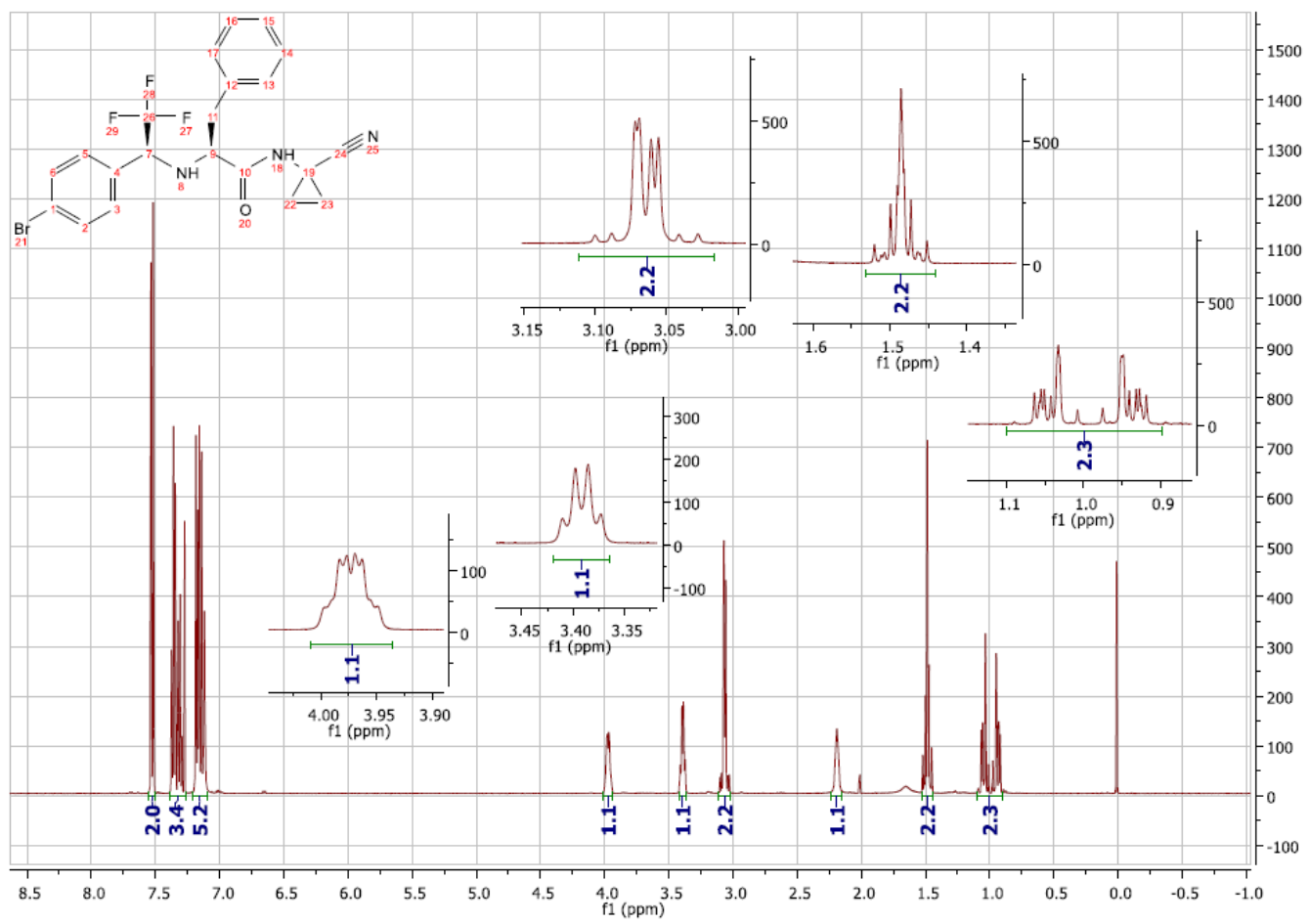

Espectro de RMN de ${ }^{1} \mathrm{H}$ referência (400 MHz, $\mathrm{CDCl}_{3}$ ) da dipeptidil-nitrila (5) [43]. 


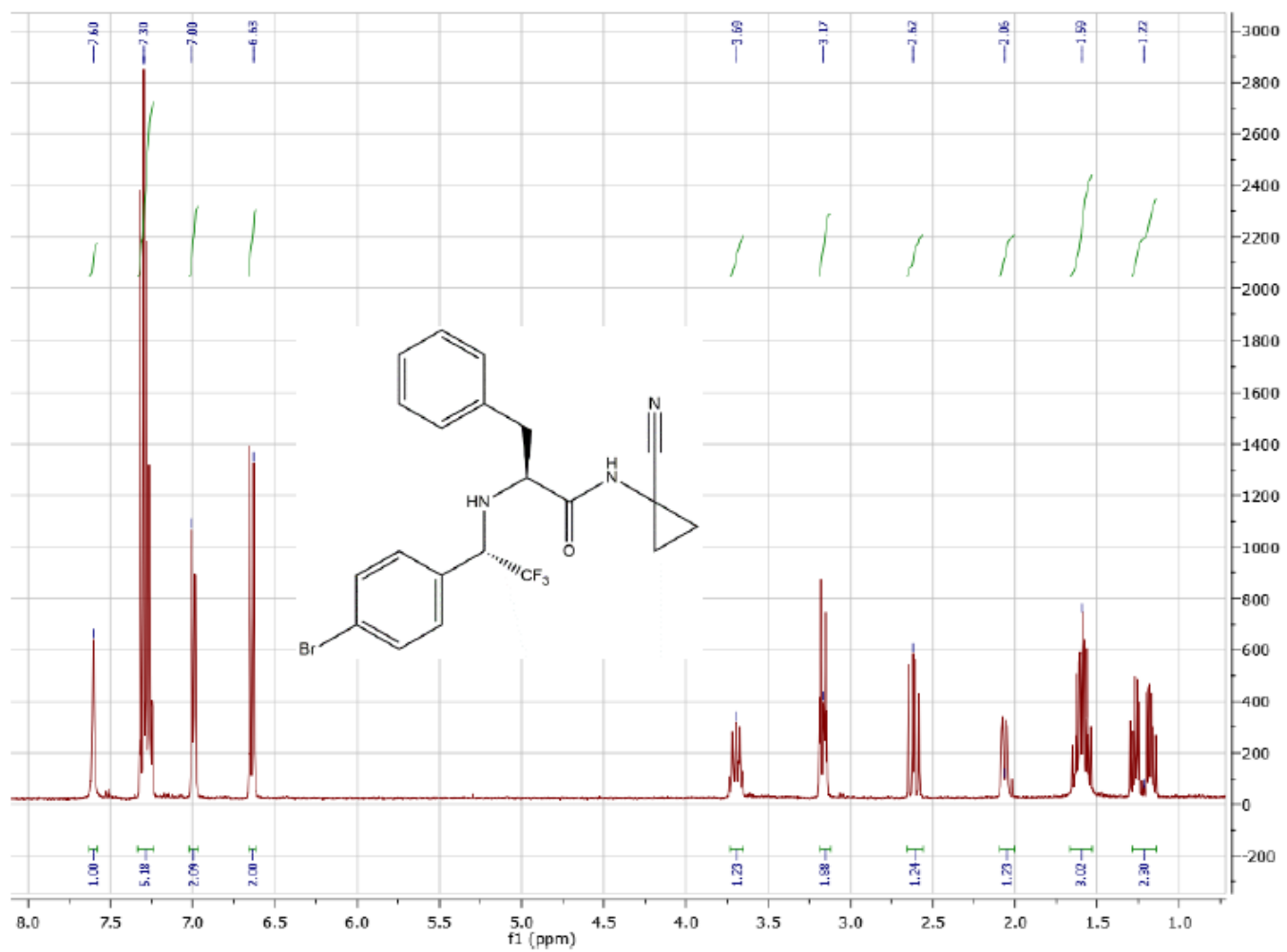

Espectro de RMN de ${ }^{1} \mathrm{H}\left(500 \mathrm{MHz}, \mathrm{CDCl}_{3}\right)$ da dipeptidil-nitrila (6).

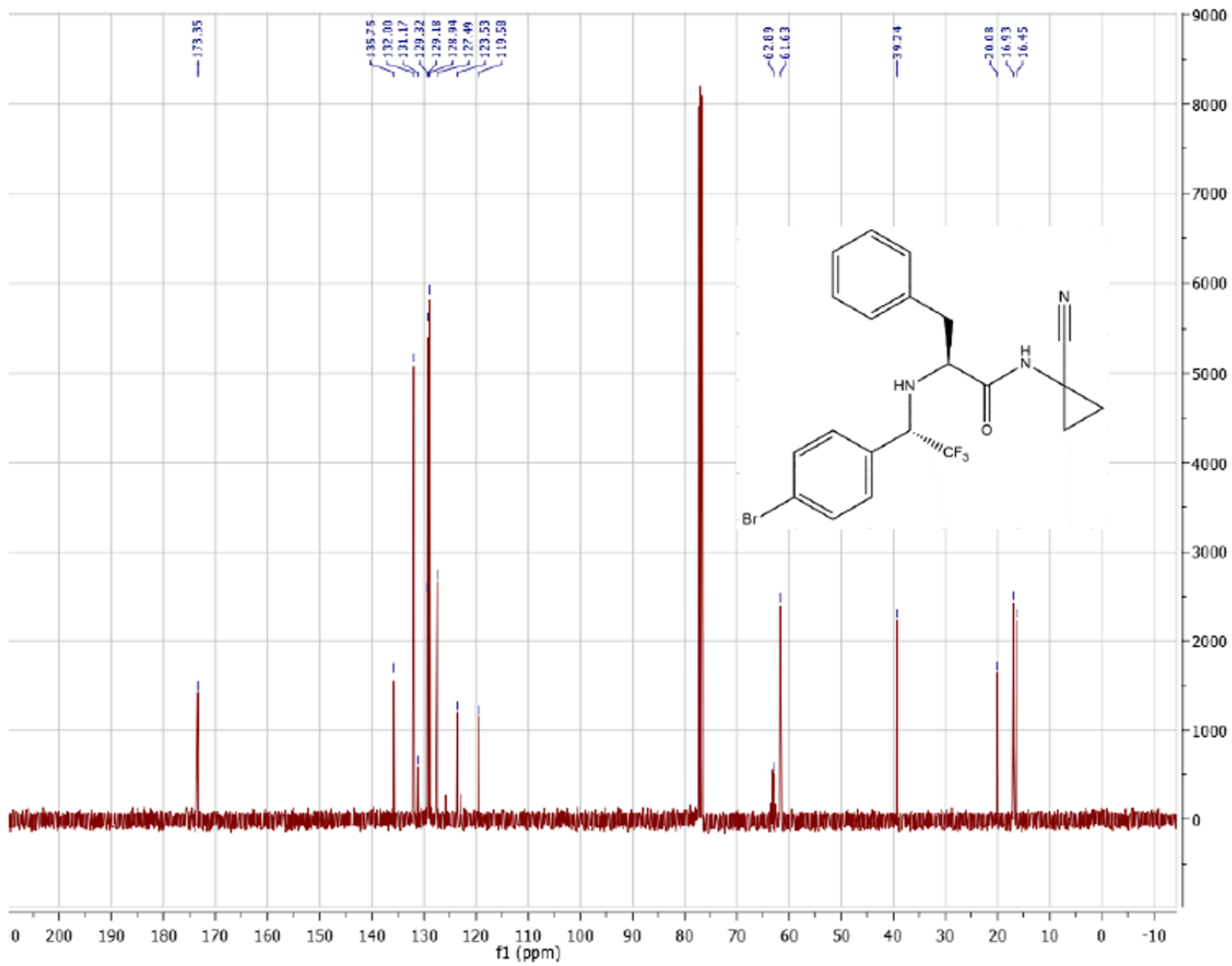

Espectro de $\mathrm{RMN}$ de ${ }^{13} \mathrm{C}\left(125 \mathrm{MHz}, \mathrm{CDCl}_{3}\right)$ da dipeptidil-nitrila (6). 


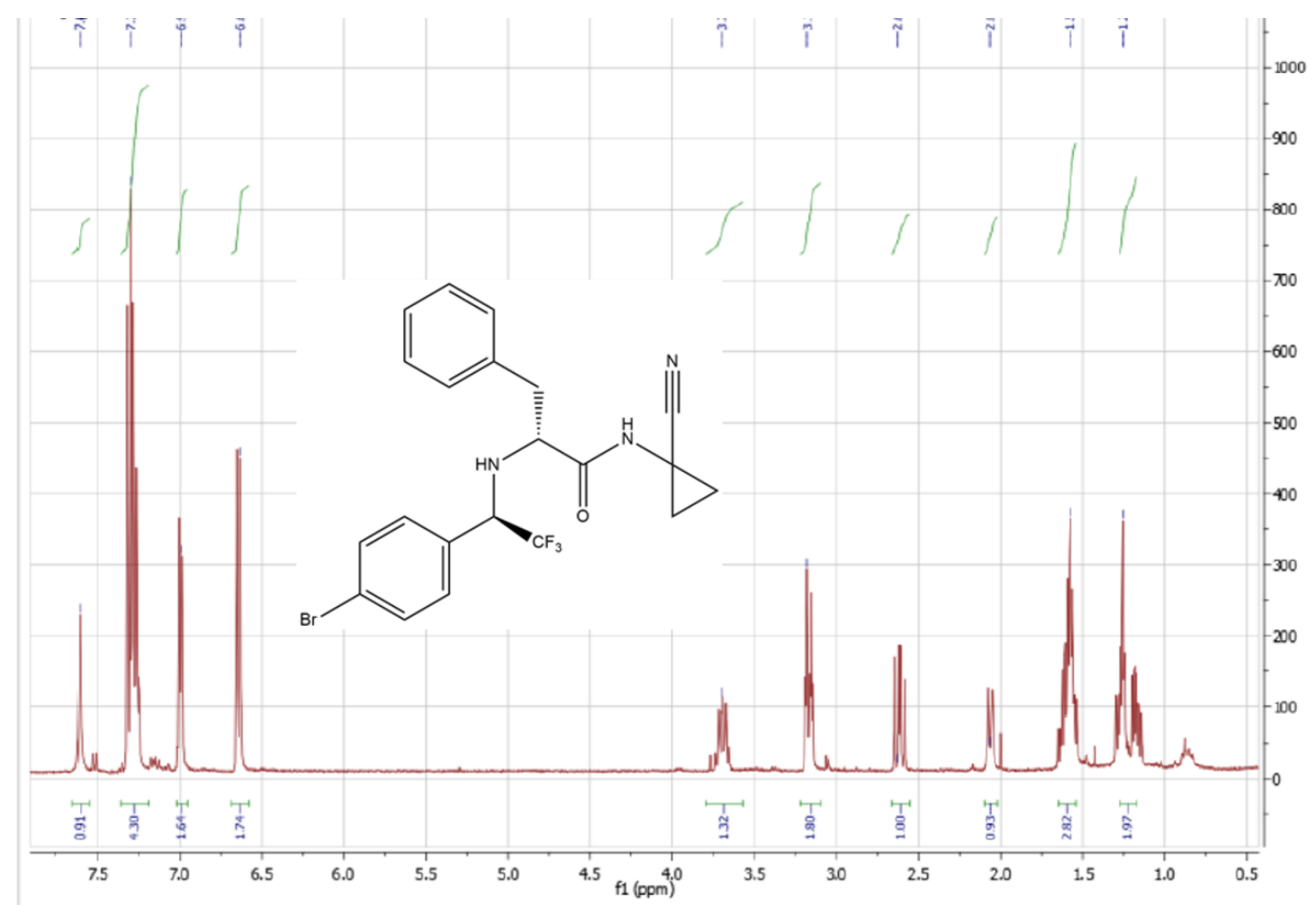

Espectro de RMN de ${ }^{1} \mathrm{H}\left(500 \mathrm{MHz}, \mathrm{CDCl}_{3}\right)$ da dipeptidil-nitrila (7).

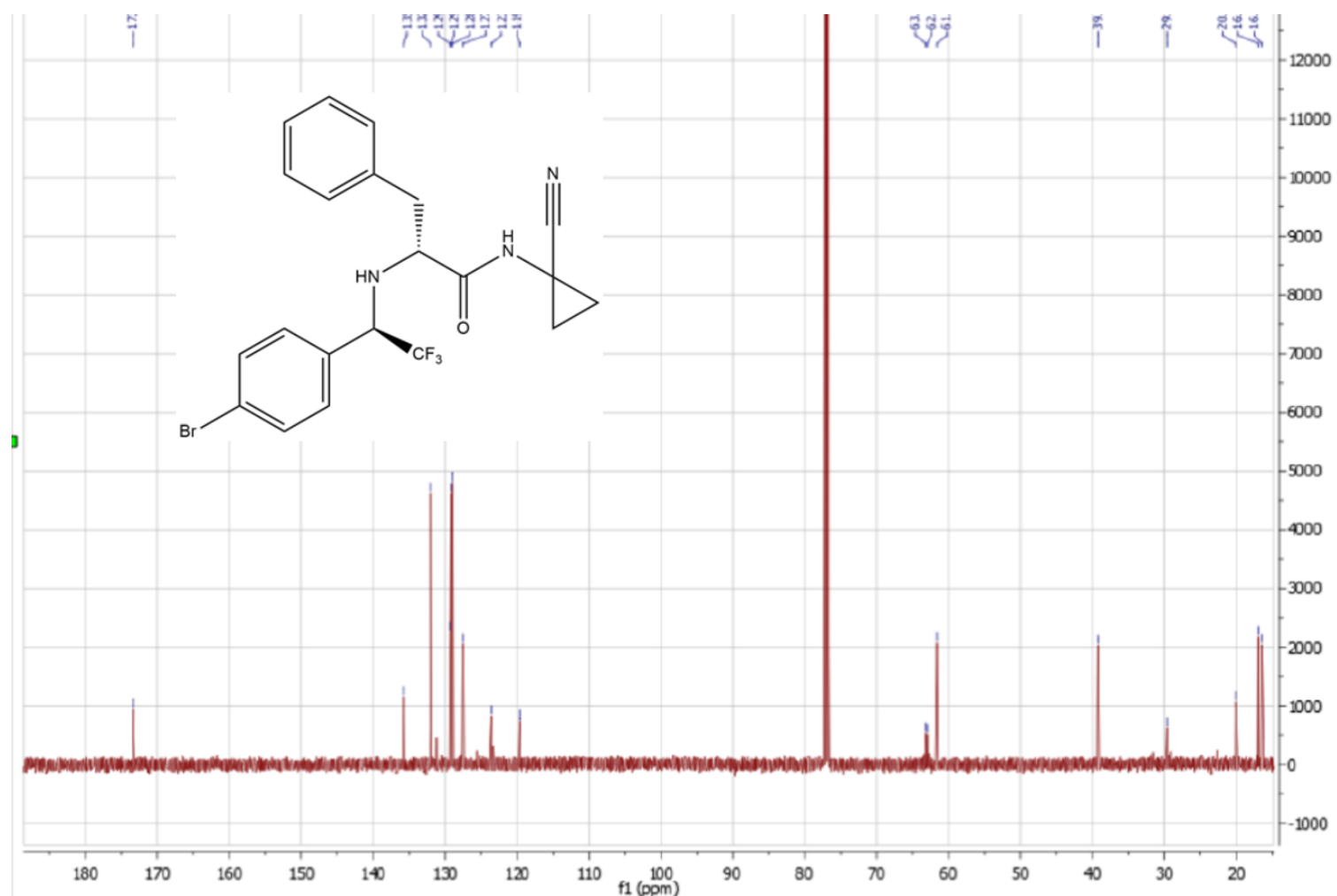

Espectro de $\mathrm{RMN}$ de ${ }^{13} \mathrm{C}\left(125 \mathrm{MHz}, \mathrm{CDCl}_{3}\right)$ da dipeptidil-nitrila (7). 


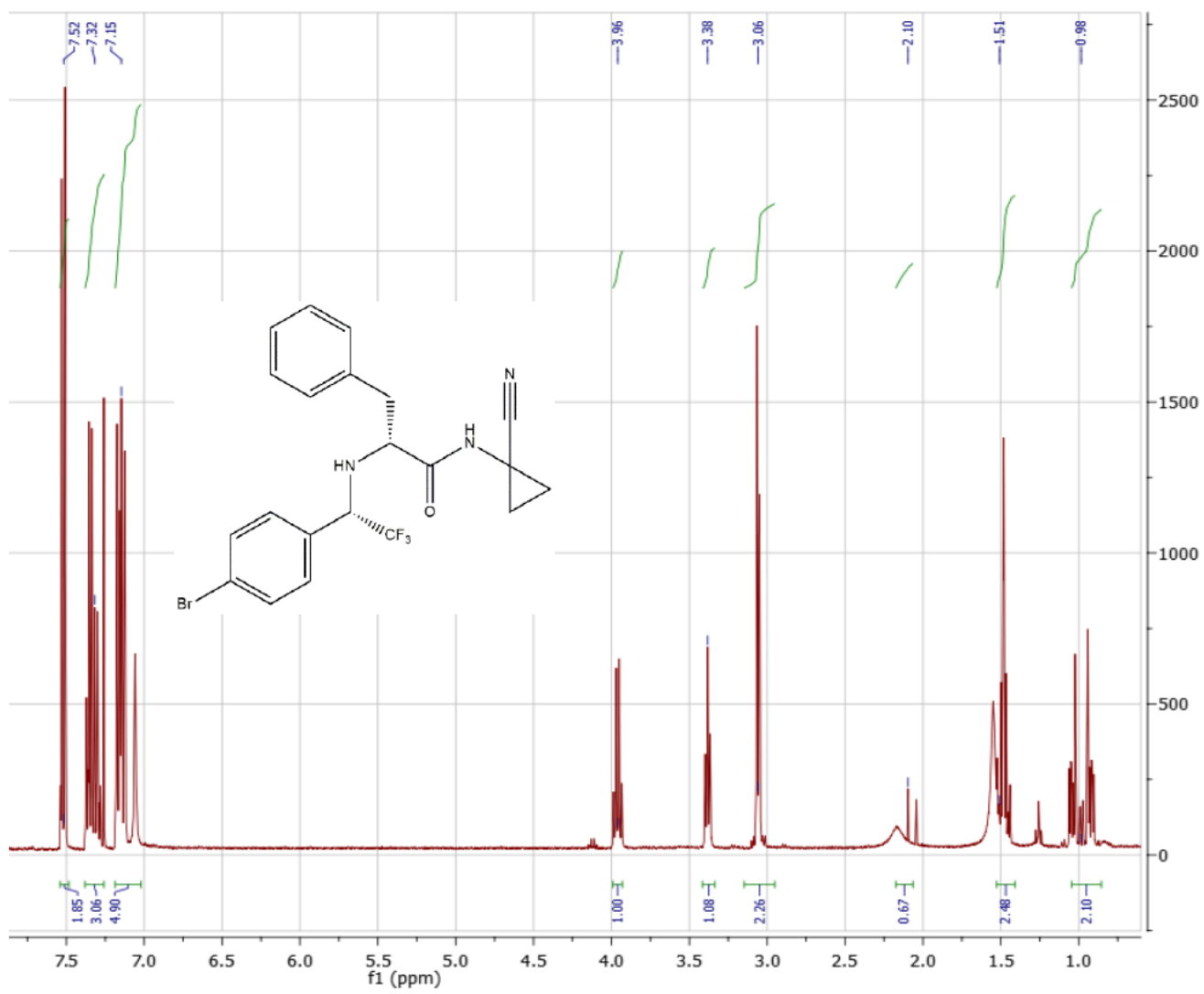

Espectro de RMN de ${ }^{1} \mathrm{H}\left(500 \mathrm{MHz}, \mathrm{CDCl}_{3}\right)$ da dipeptidil-nitrila (8).

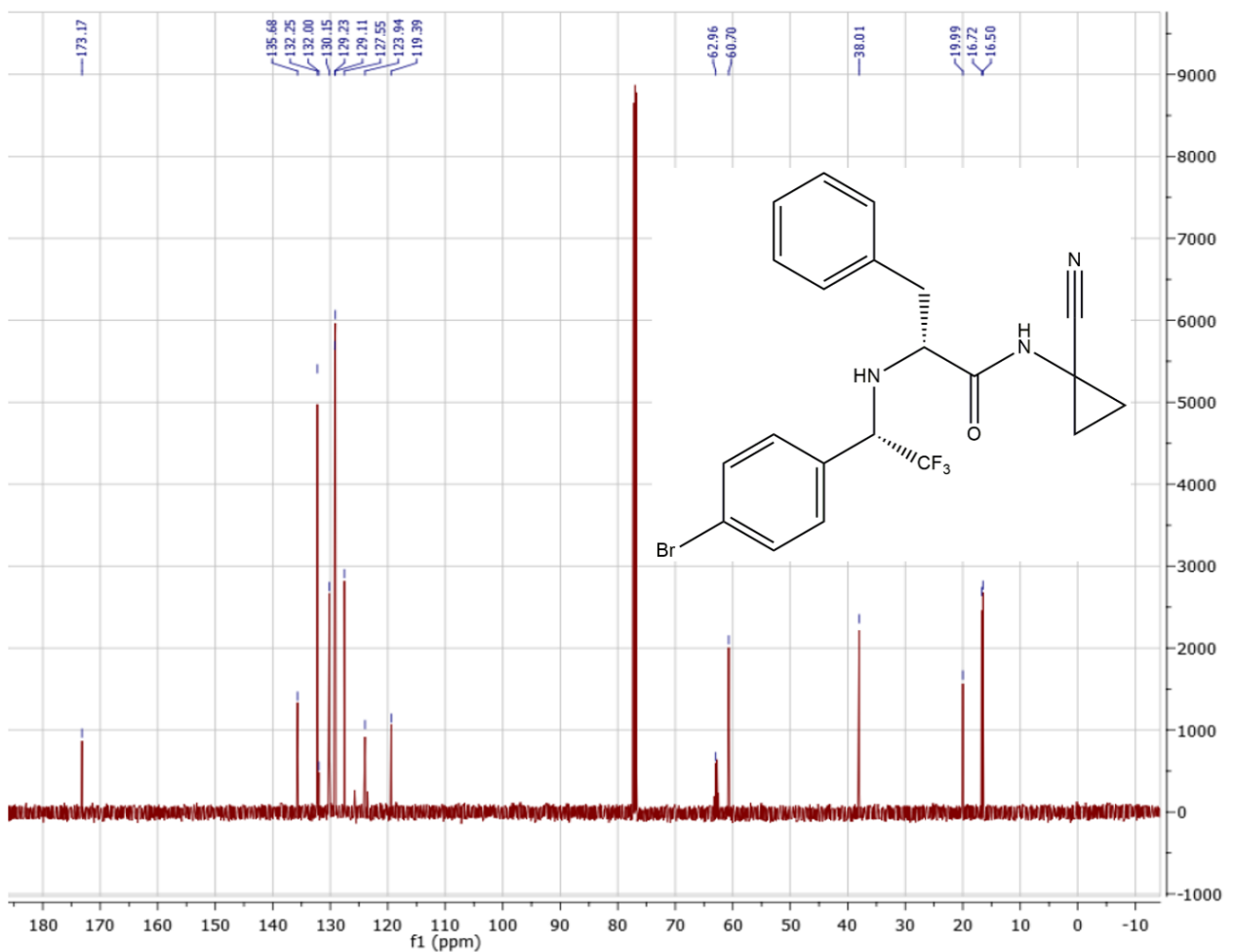

Espectro de $\mathrm{RMN}$ de ${ }^{13} \mathrm{C}\left(125 \mathrm{MHz}, \mathrm{CDCl}_{3}\right)$ da dipeptidil-nitrila (8). 


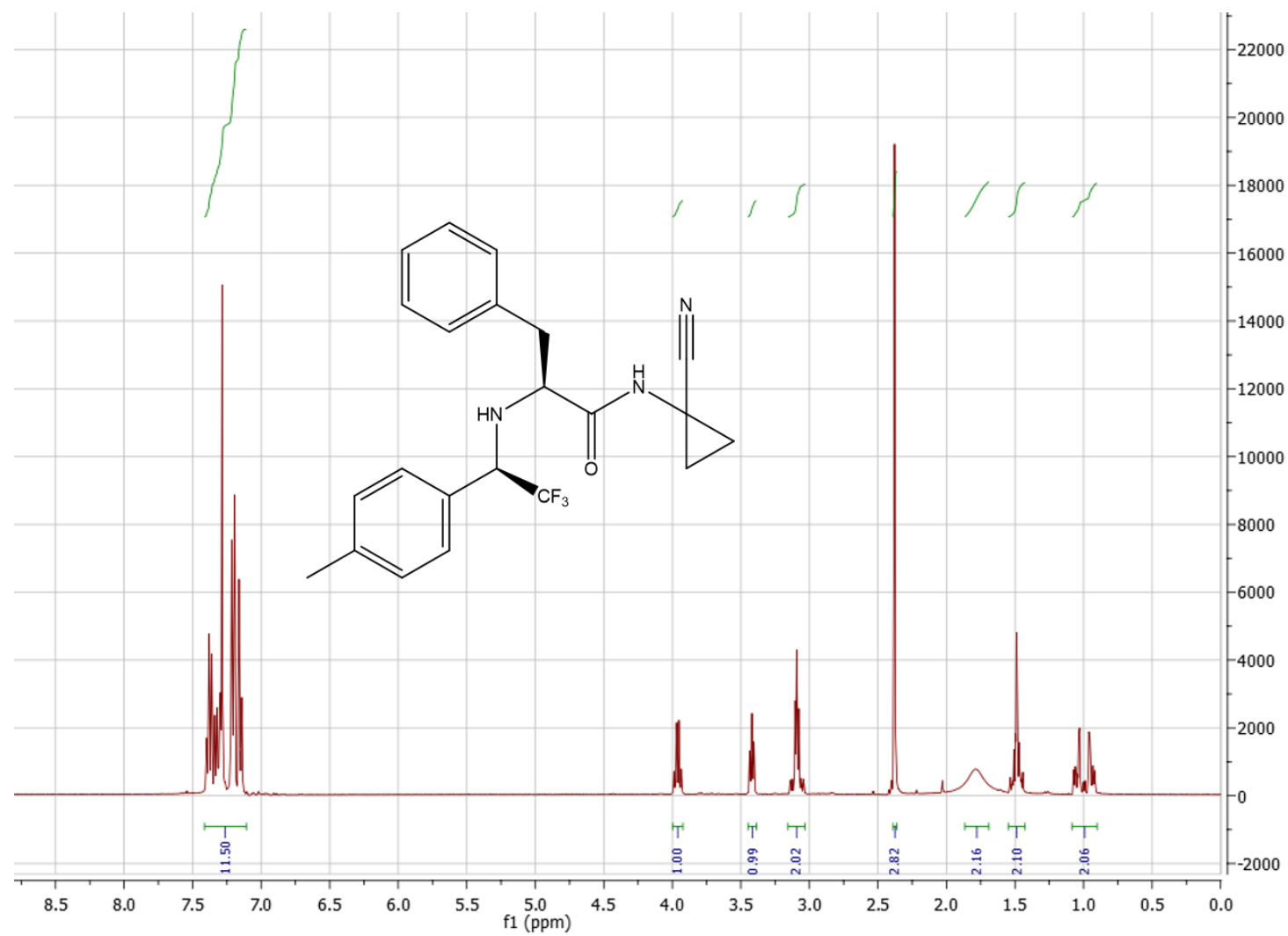

Espectro de $\mathrm{RMN}$ de ${ }^{1} \mathrm{H}\left(400 \mathrm{MHz}, \mathrm{CDCl}_{3}\right)$ da dipeptidil-nitrila (9).

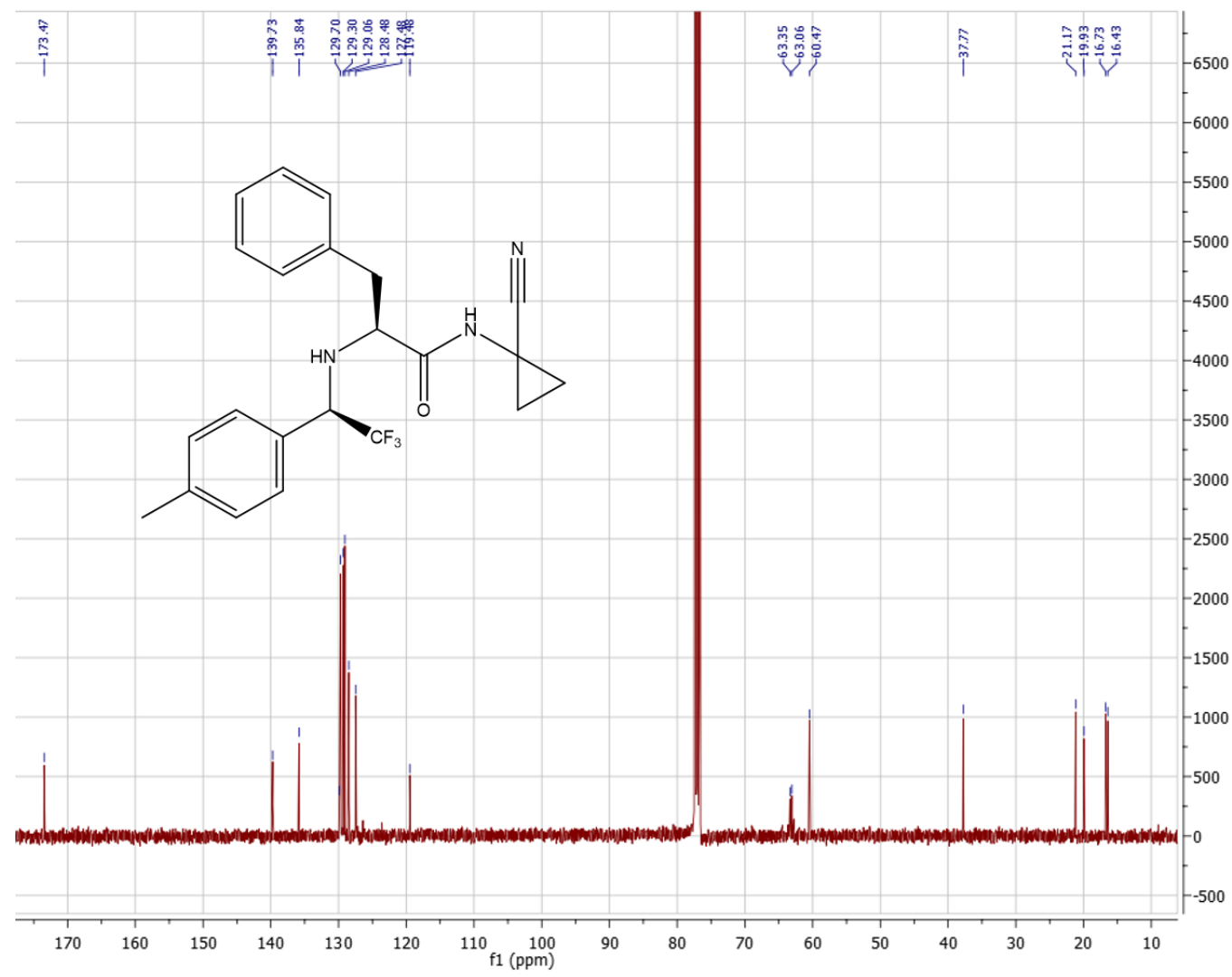

Espectro de RMN de ${ }^{13} \mathrm{C}\left(100 \mathrm{MHz}, \mathrm{CDCl}_{3}\right)$ da dipeptidil-nitrila (9). 


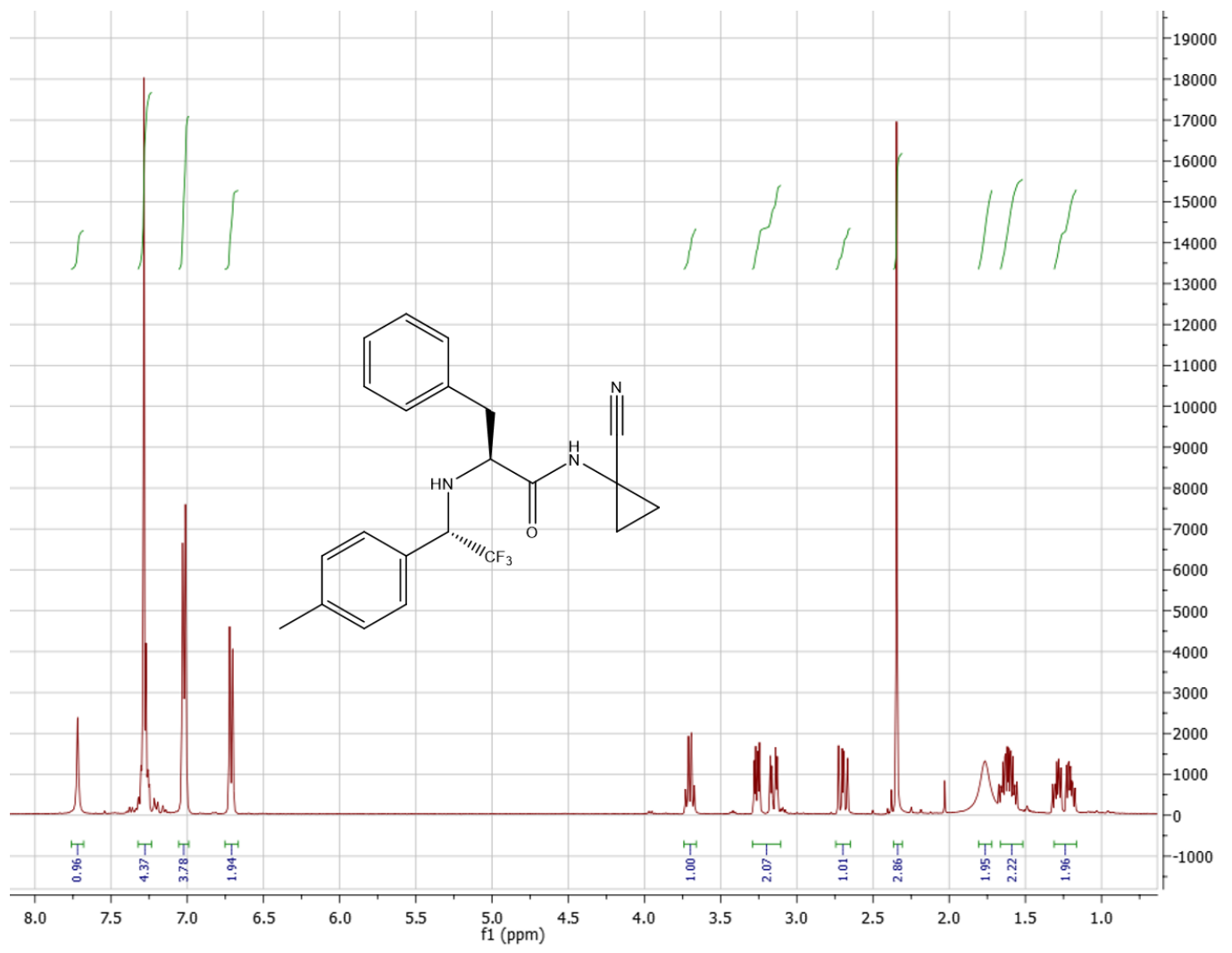

Espectro de RMN de ${ }^{1} \mathrm{H}\left(400 \mathrm{MHz}, \mathrm{CDCl}_{3}\right)$ da dipeptidil-nitrila (10).

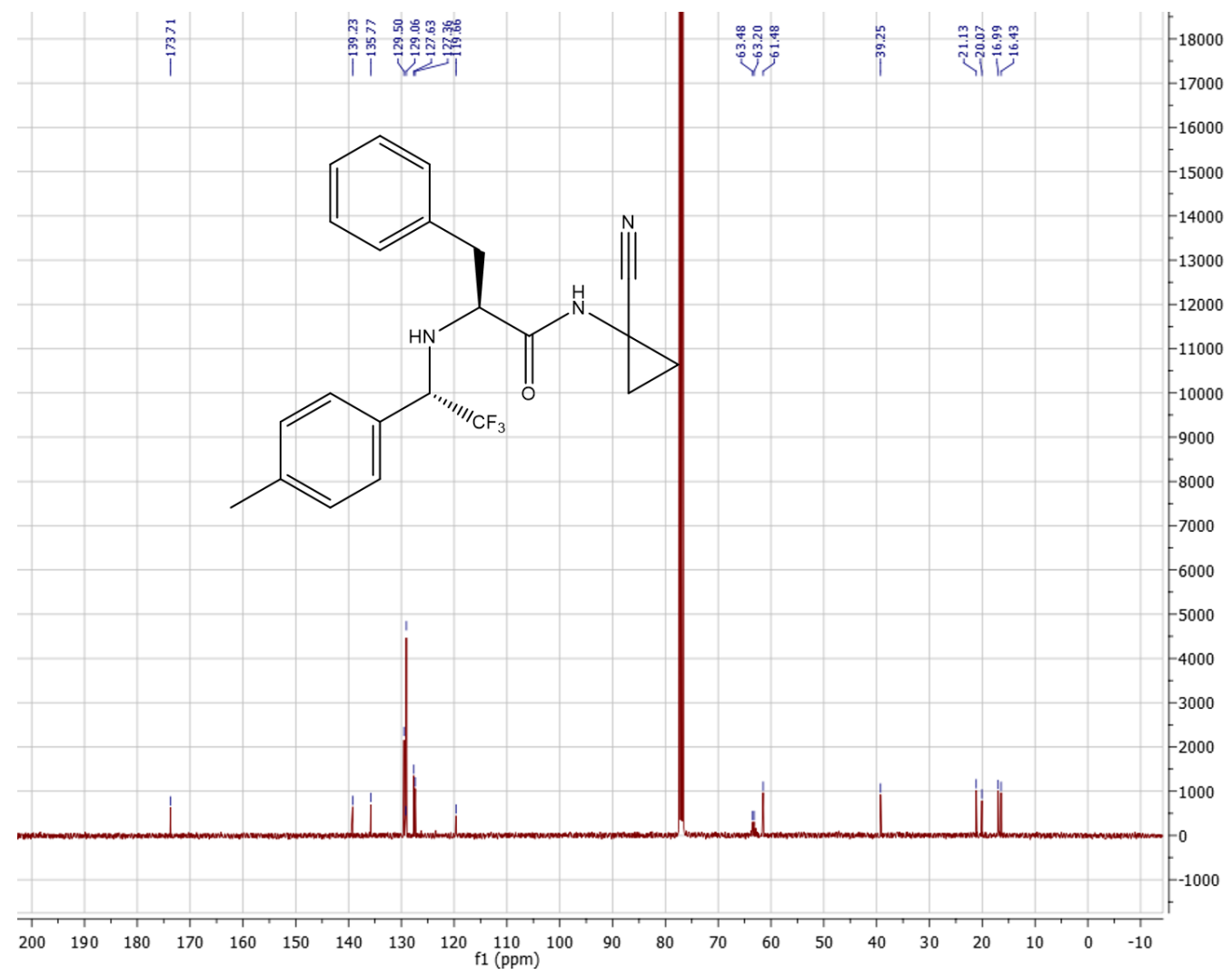

Espectro de $\mathrm{RMN}$ de ${ }^{13} \mathrm{C}\left(100 \mathrm{MHz}, \mathrm{CDCl}_{3}\right)$ da dipeptidil-nitrila (10). 


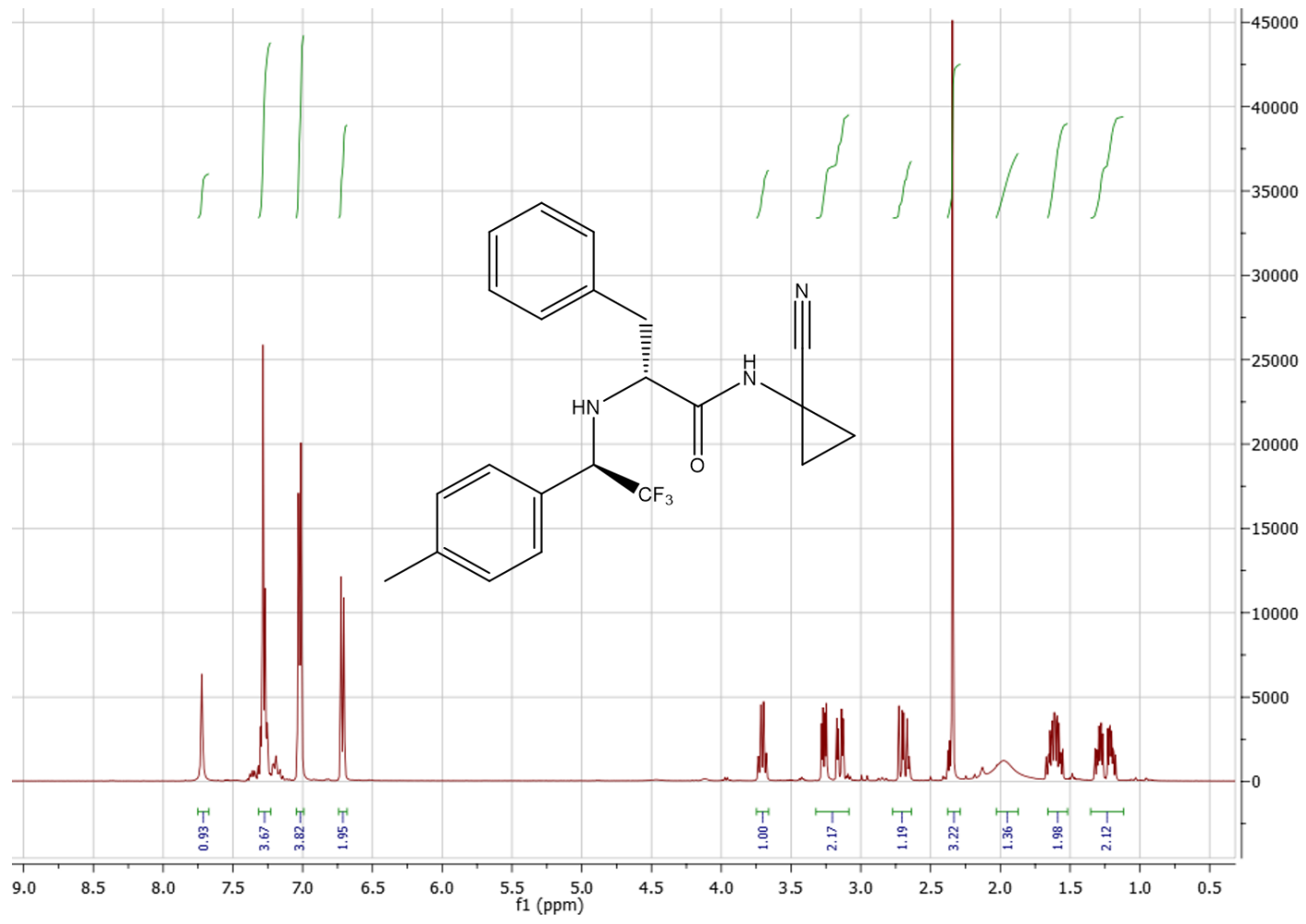

Espectro de RMN de ${ }^{1} \mathrm{H}\left(400 \mathrm{MHz}, \mathrm{CDCl}_{3}\right)$ da dipeptidil-nitrila (11).

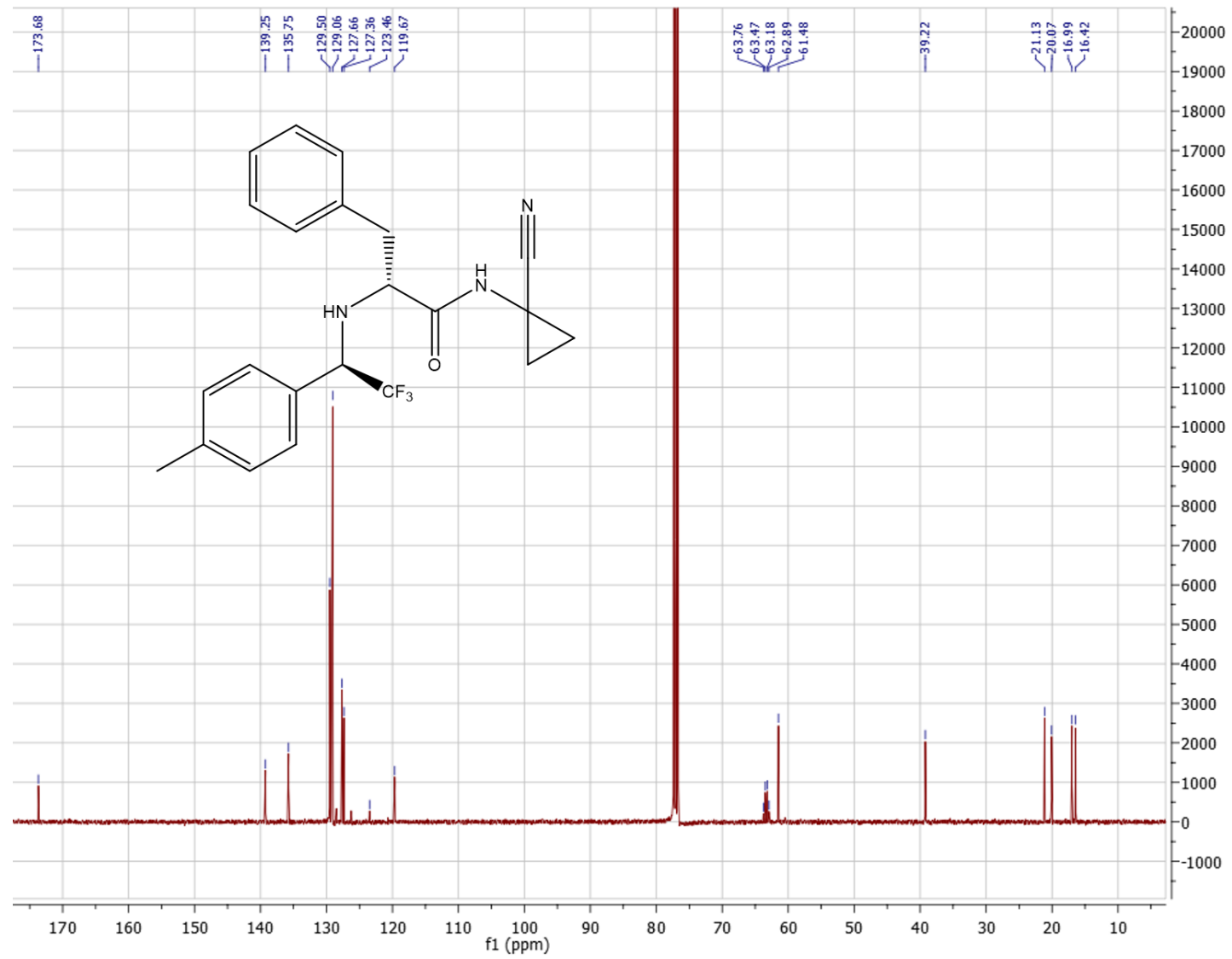

Espectro de $\mathrm{RMN}$ de ${ }^{13} \mathrm{C}\left(100 \mathrm{MHz}, \mathrm{CDCl}_{3}\right)$ da dipeptidil-nitrila (11). 


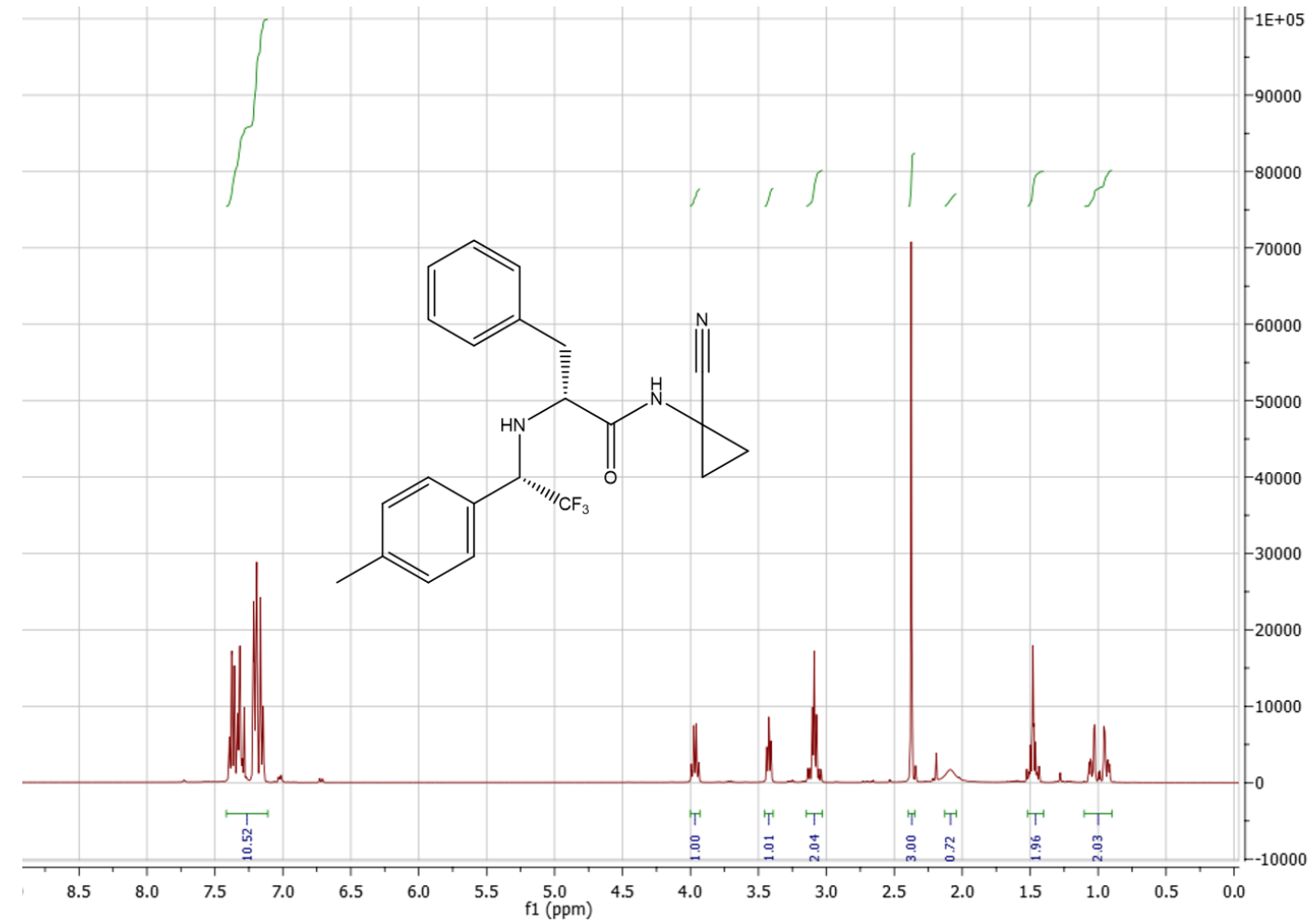

Espectro de $\mathrm{RMN}$ de ${ }^{1} \mathrm{H}\left(400 \mathrm{MHz}, \mathrm{CDCl}_{3}\right)$ da dipeptidil-nitrila (12).

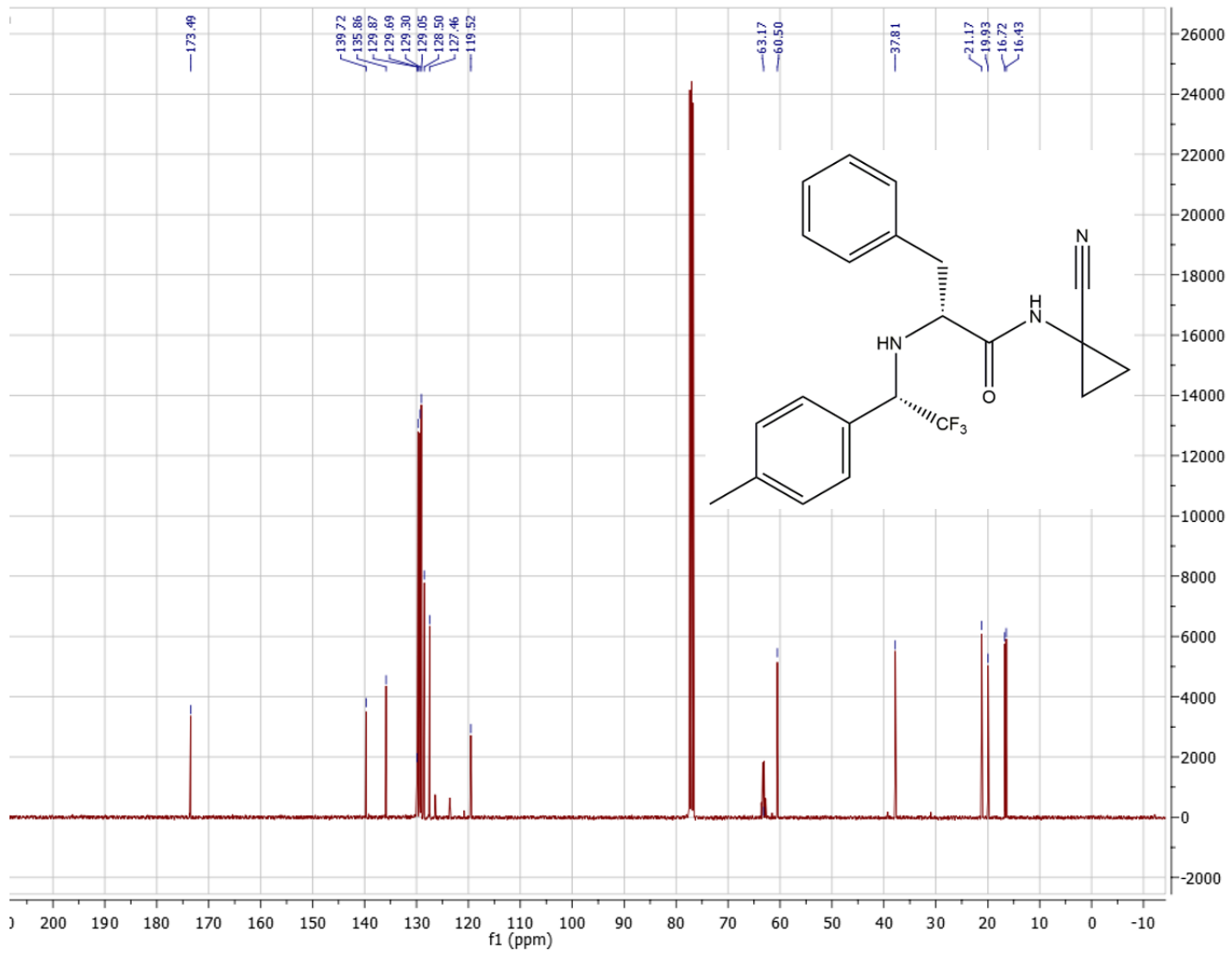

Espectro de $\mathrm{RMN}$ de ${ }^{13} \mathrm{C}\left(100 \mathrm{MHz}, \mathrm{CDCl}_{3}\right)$ da dipeptidil-nitrila (12). 


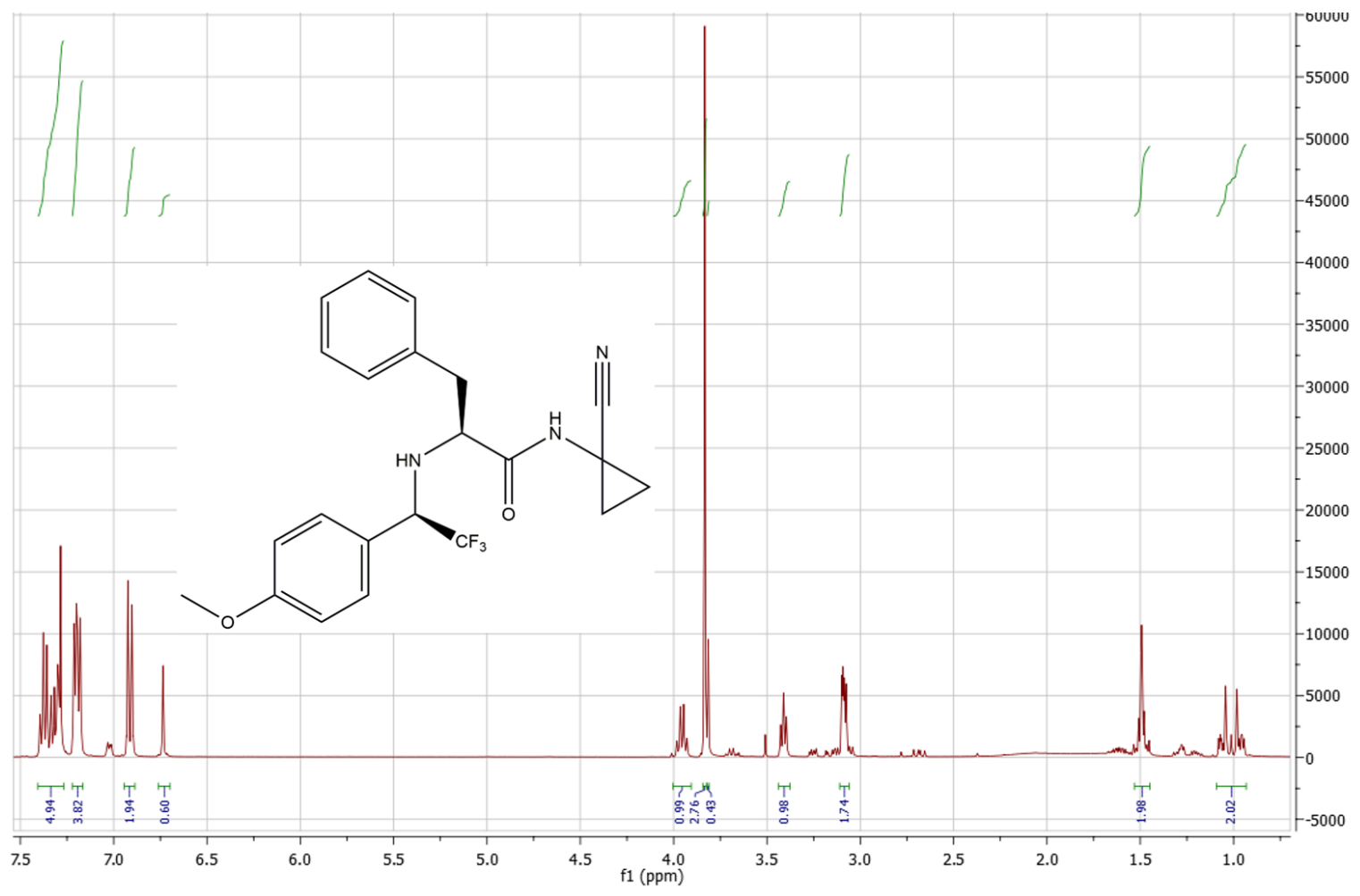

Espectro de RMN de ${ }^{1} \mathrm{H}\left(400 \mathrm{MHz}, \mathrm{CDCl}_{3}\right)$ da dipeptidil-nitrila (13).

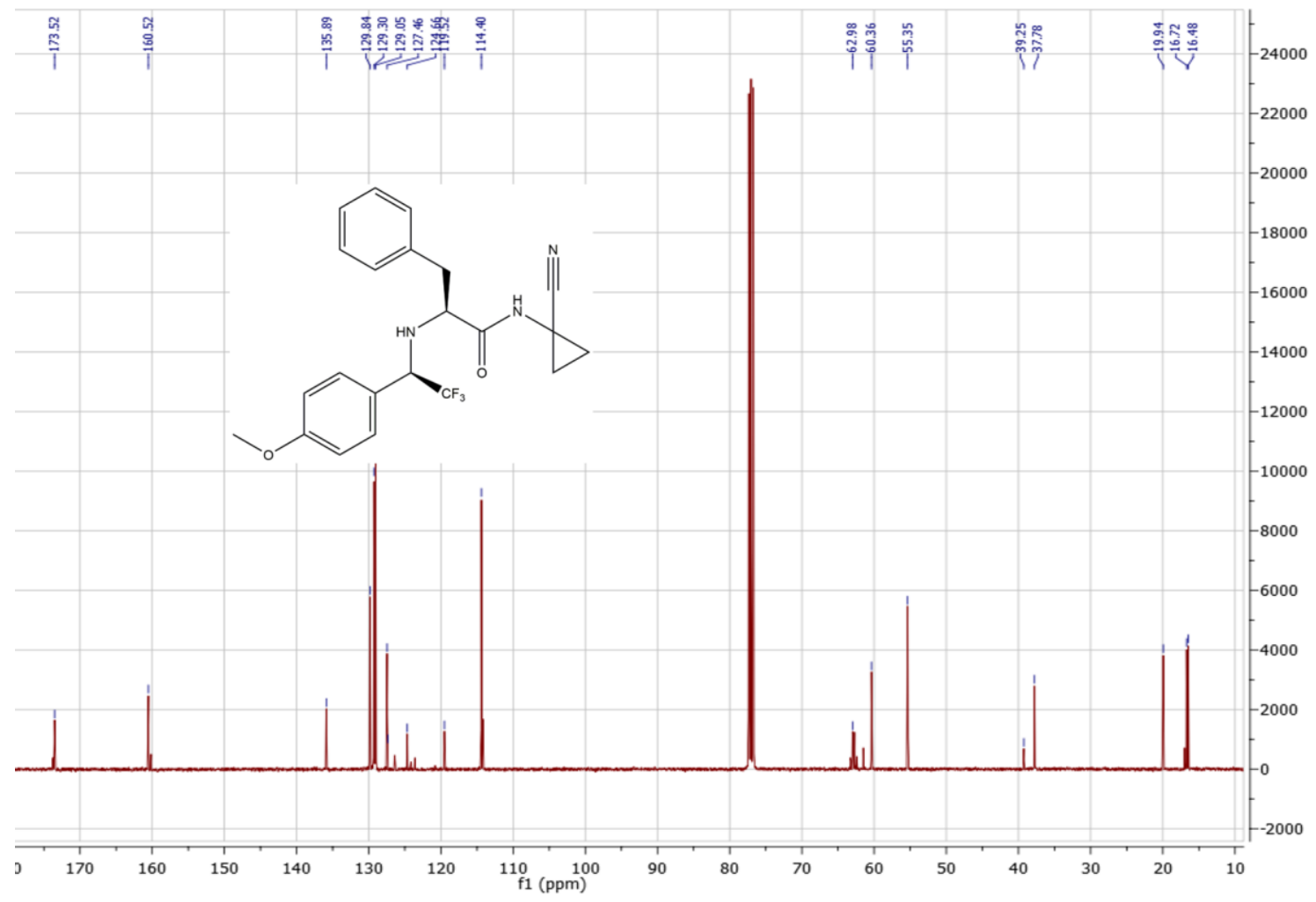

Espectro de RMN de ${ }^{13} \mathrm{C}\left(100 \mathrm{MHz}, \mathrm{CDCl}_{3}\right)$ da dipeptidil-nitrila (13). 


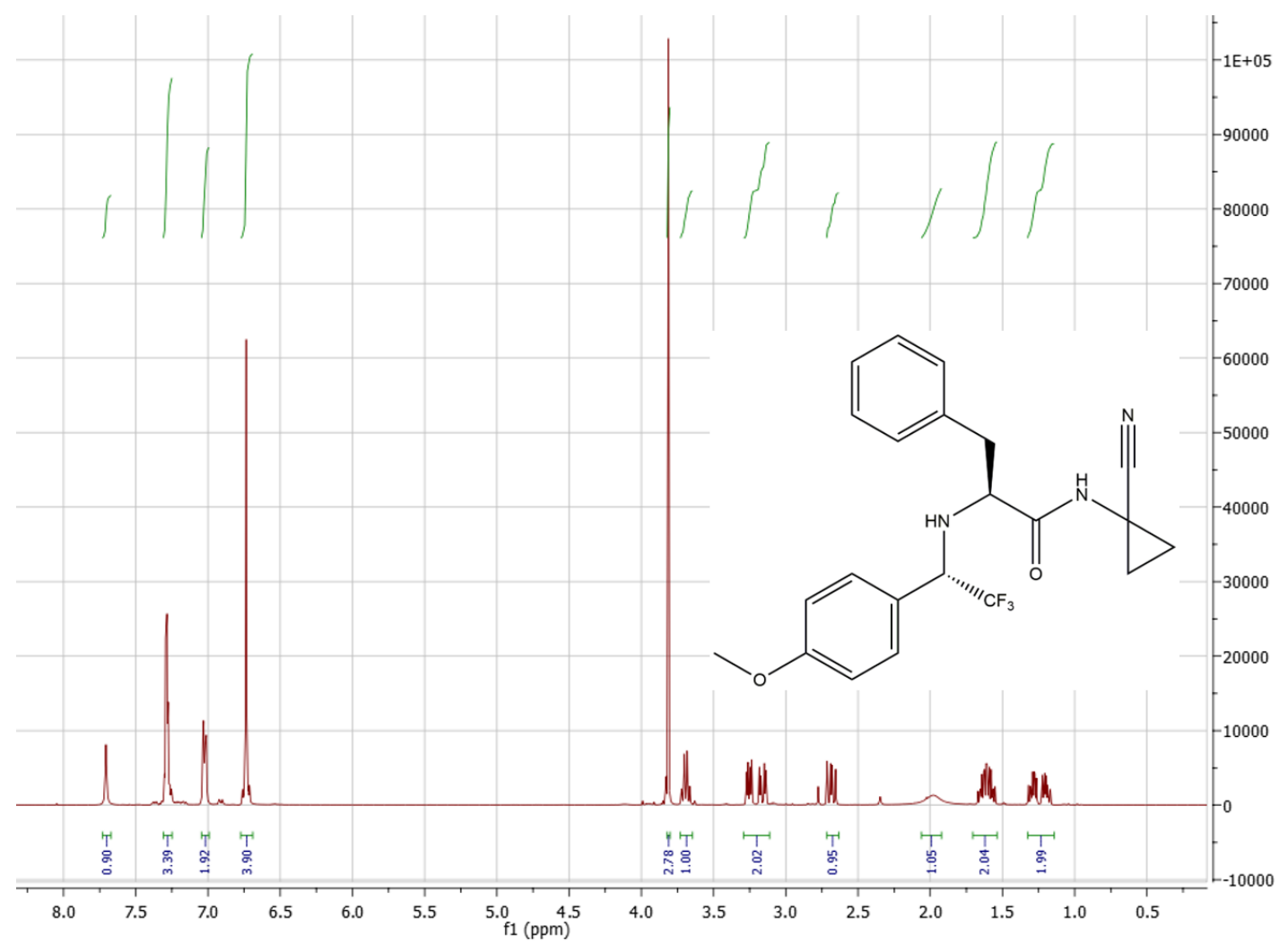

Espectro de RMN de ${ }^{1} \mathrm{H}\left(400 \mathrm{MHz}, \mathrm{CDCl}_{3}\right)$ da dipeptidil-nitrila (14).

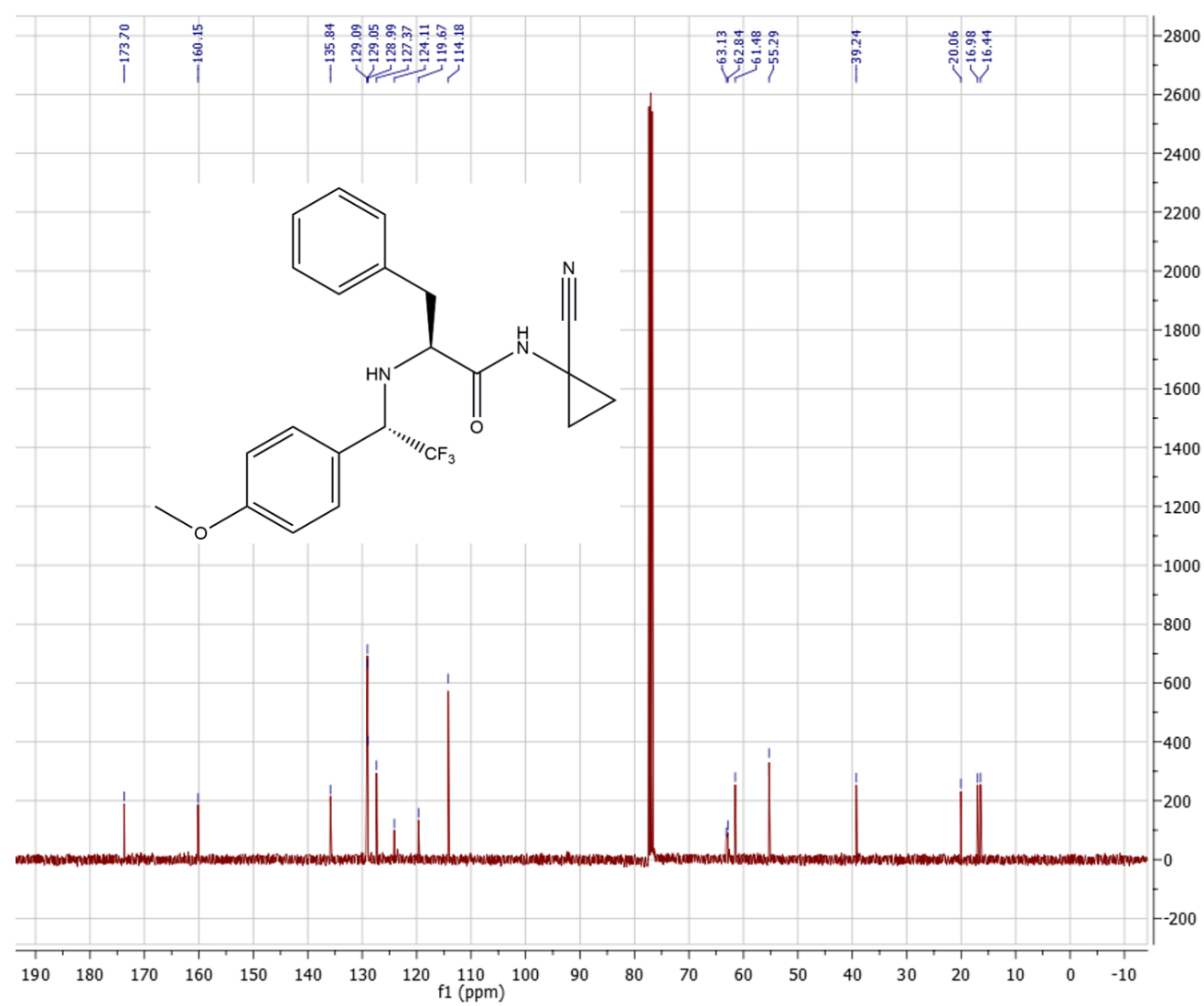

Espectro de $\mathrm{RMN}$ de ${ }^{13} \mathrm{C}\left(100 \mathrm{MHz}, \mathrm{CDCl}_{3}\right)$ da dipeptidil-nitrila (14). 


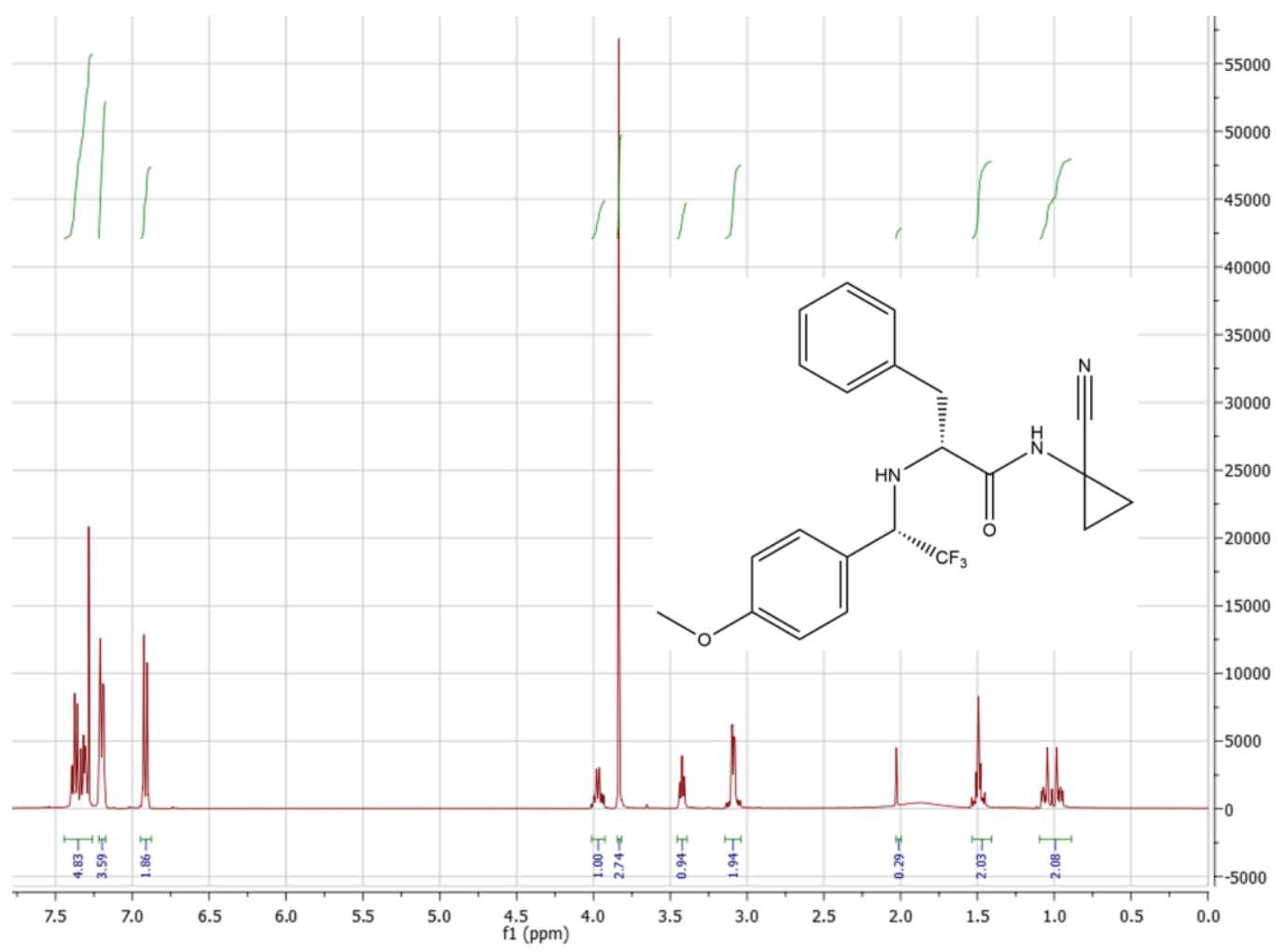

Espectro de $\mathrm{RMN}$ de ${ }^{1} \mathrm{H}\left(400 \mathrm{MHz}, \mathrm{CDCl}_{3}\right)$ da dipeptidil-nitrila (15).

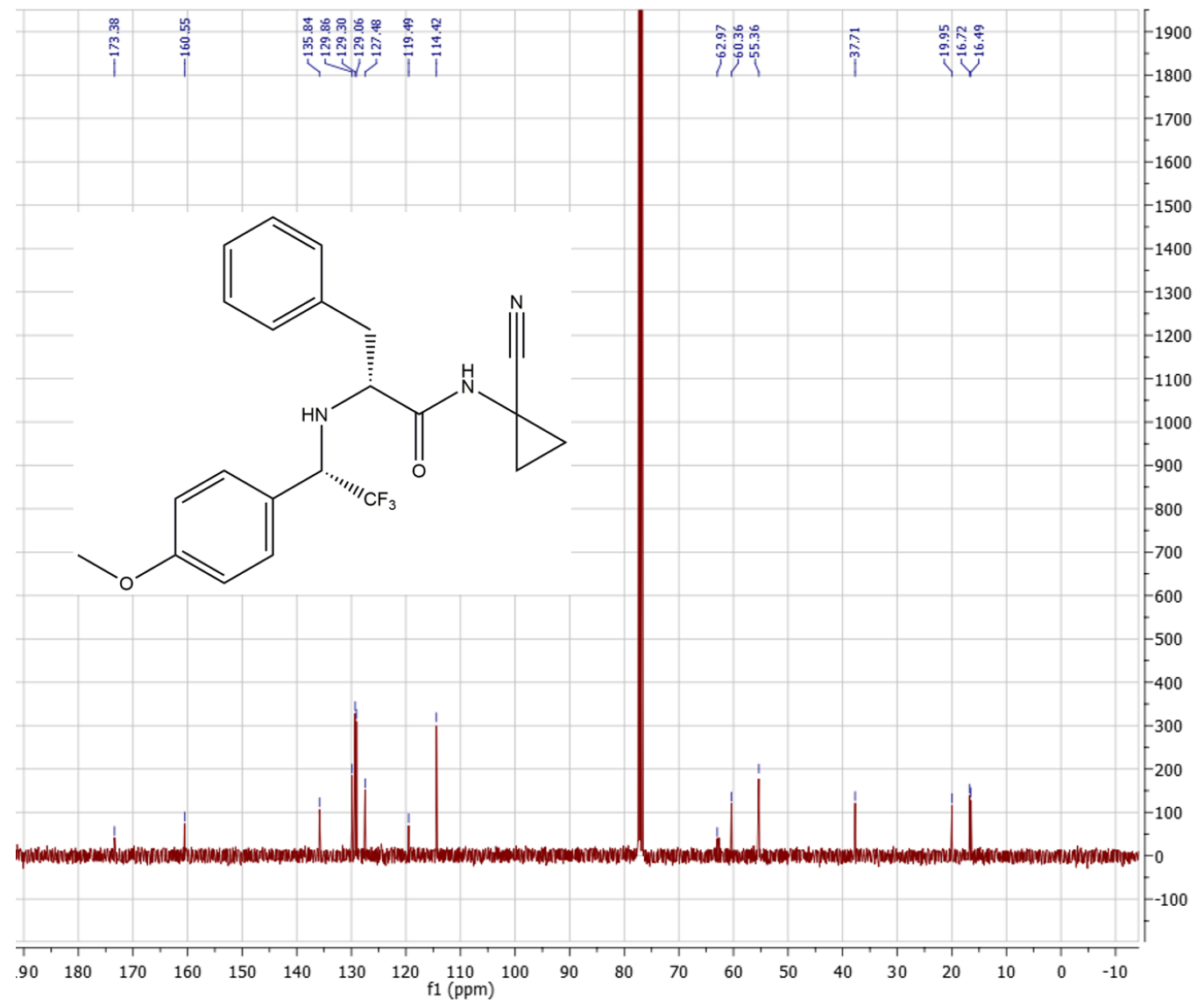

Espectro de $\mathrm{RMN}$ de ${ }^{13} \mathrm{C}\left(100 \mathrm{MHz}, \mathrm{CDCl}_{3}\right)$ da dipeptidil-nitrila (15). 


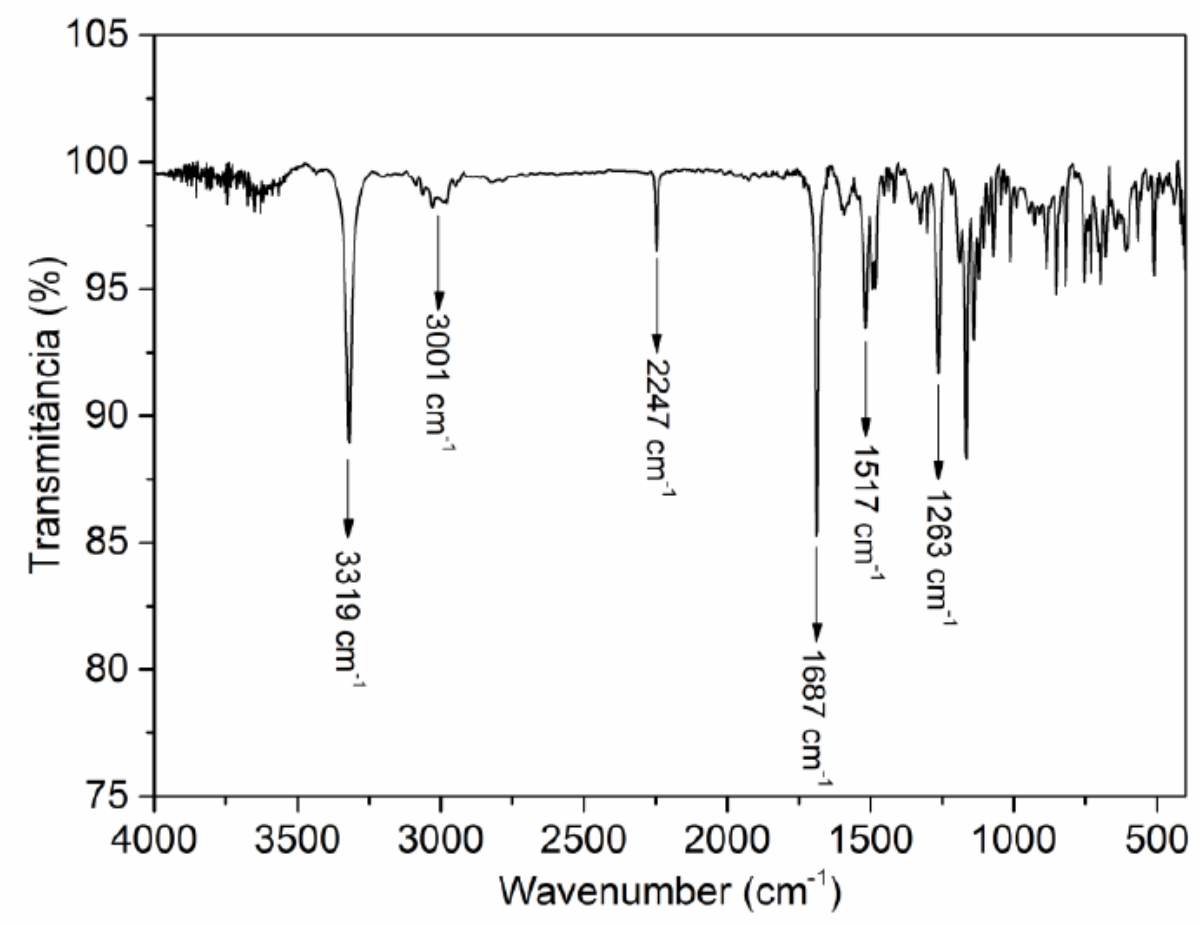

Espectro de infravermelho da dipeptidil-nitrila (3) em pastilha de $\mathrm{KBr}$

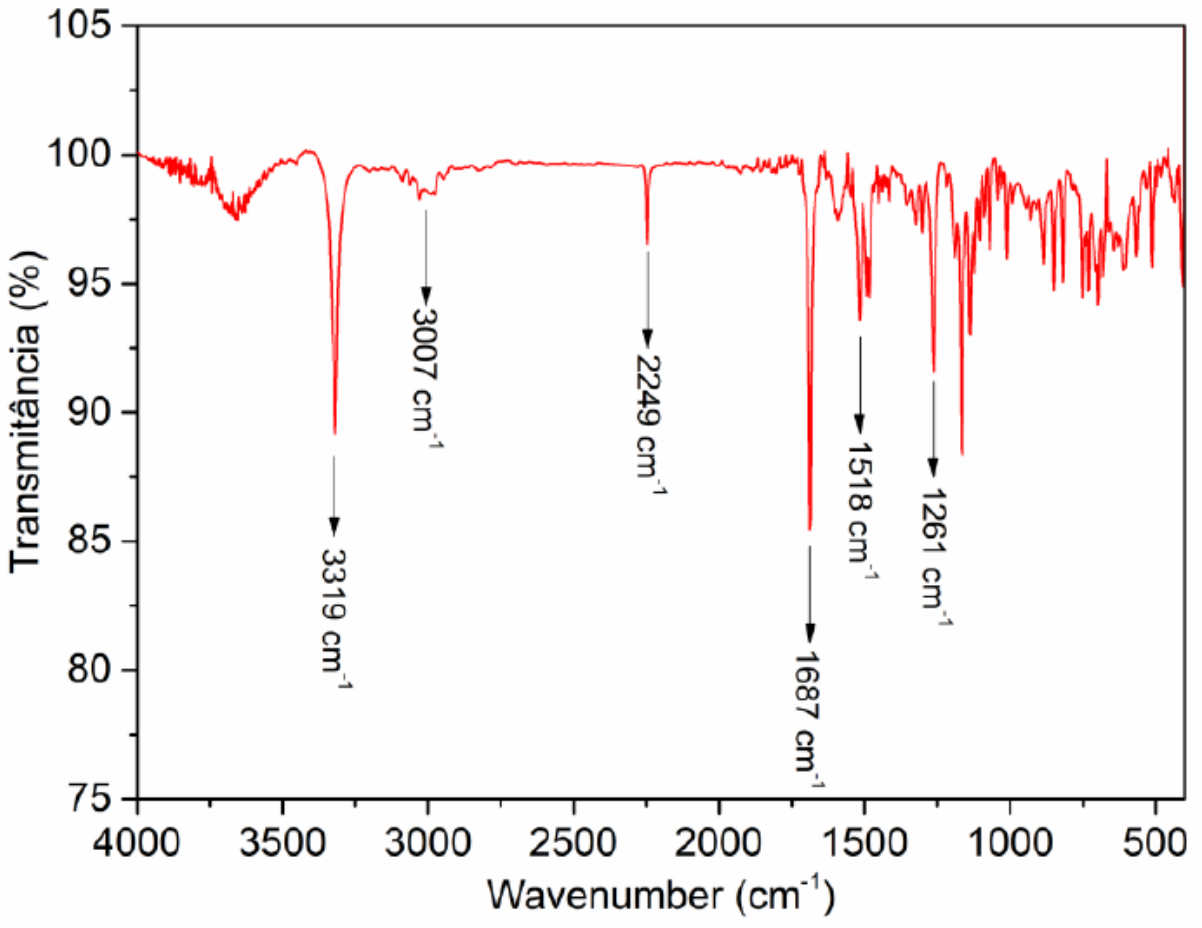

Espectro de infravermelho da dipeptidil-nitrila (4) em pastilha de $\mathrm{KBr}$ 


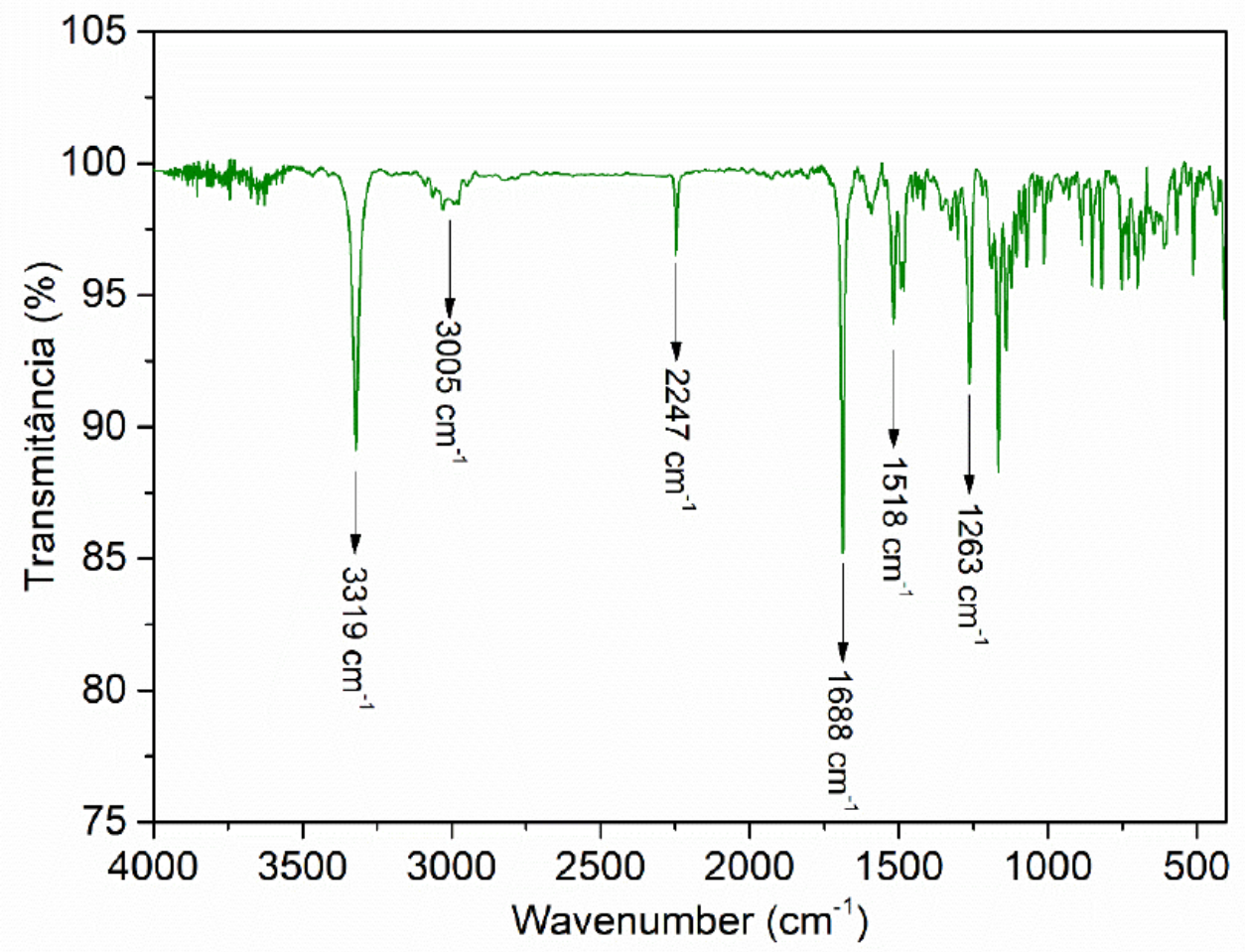

Espectro de infravermelho da dipeptidil-nitrila (7) em pastilha de $\mathrm{KBr}$

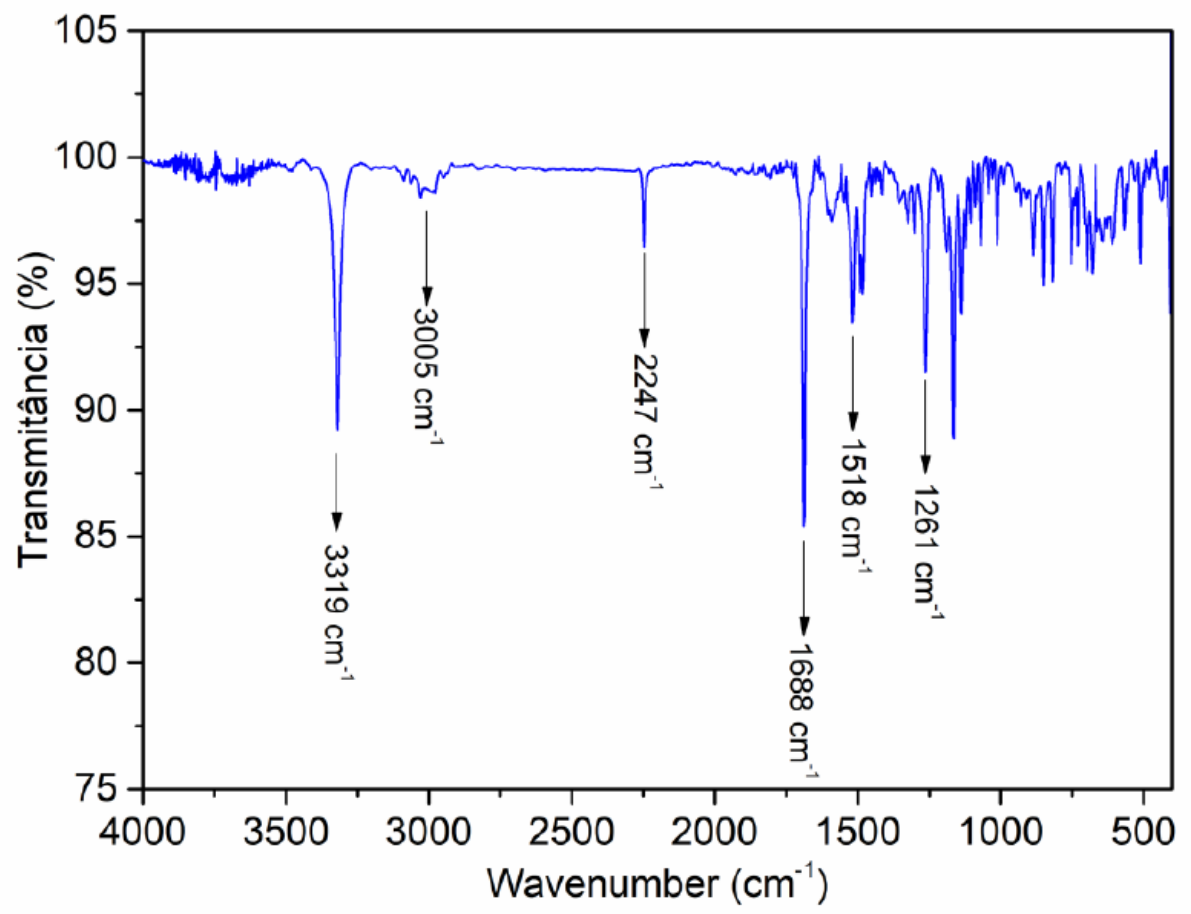

Espectro de infravermelho da dipeptidil-nitrila $(\mathbf{8})$ em pastilha de $\mathrm{KBr}$ 


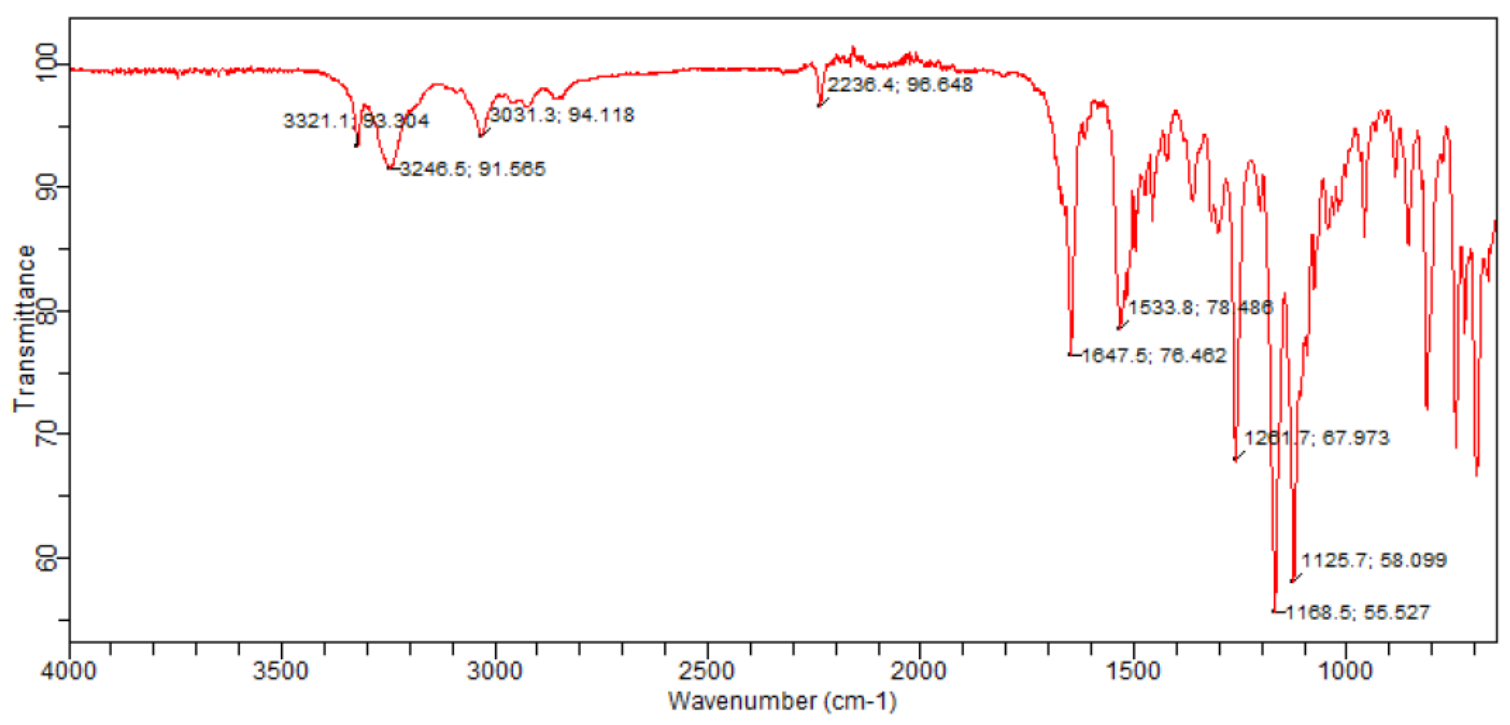

Espectro de infravermelho da dipeptidil-nitrila (9) em sistema ATR

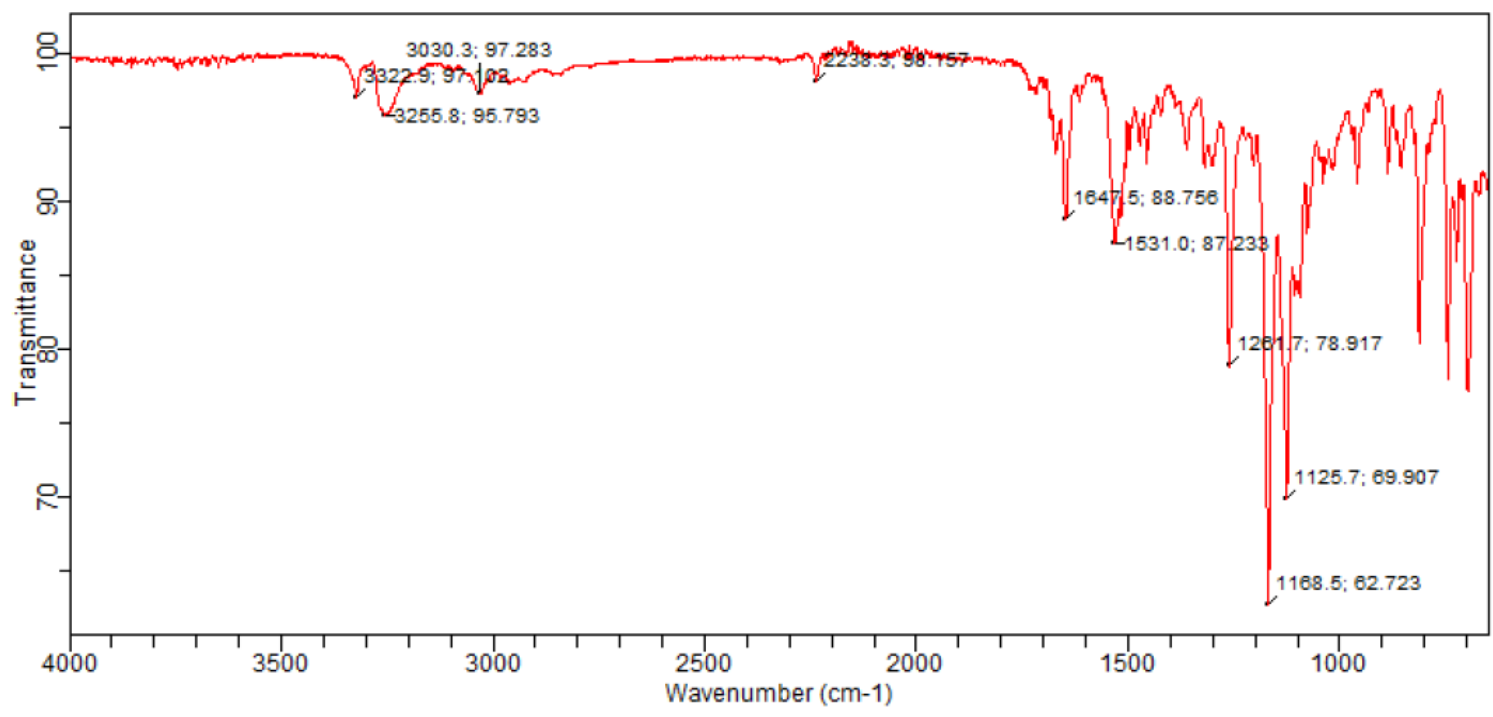

Espectro de infravermelho da dipeptidil-nitrila (10) em sistema ATR 


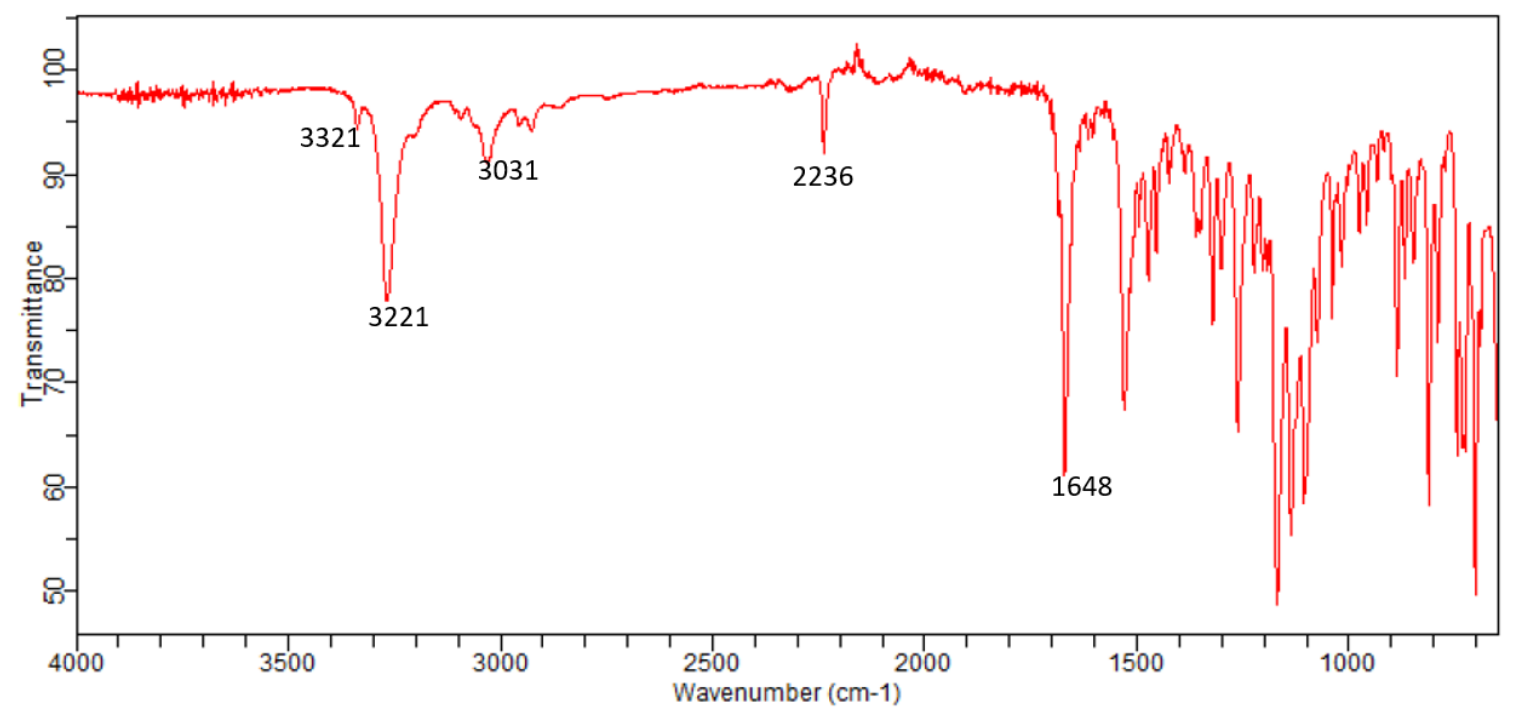

Espectro de infravermelho da dipeptidil-nitrila (11) em sistema ATR

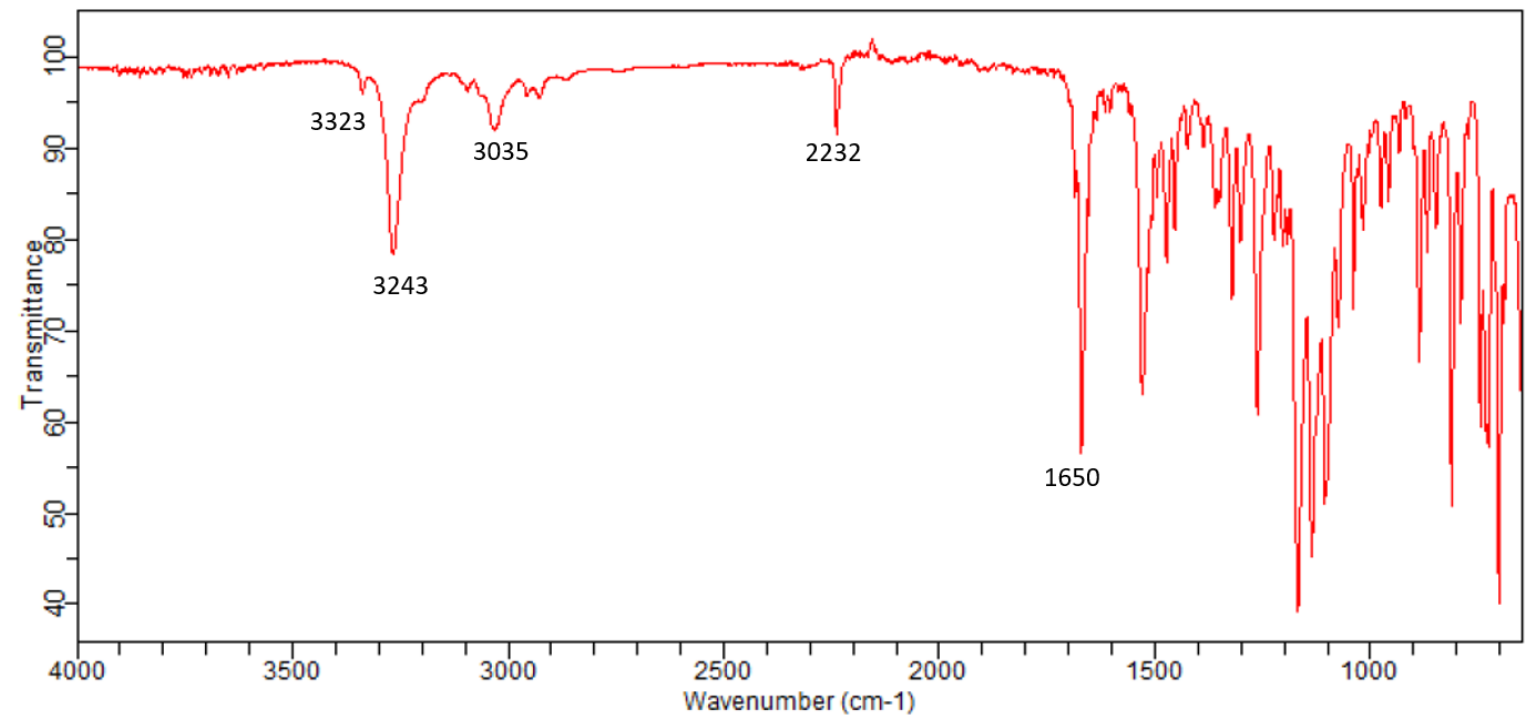

Espectro de infravermelho da dipeptidil-nitrila (12) em sistema ATR 


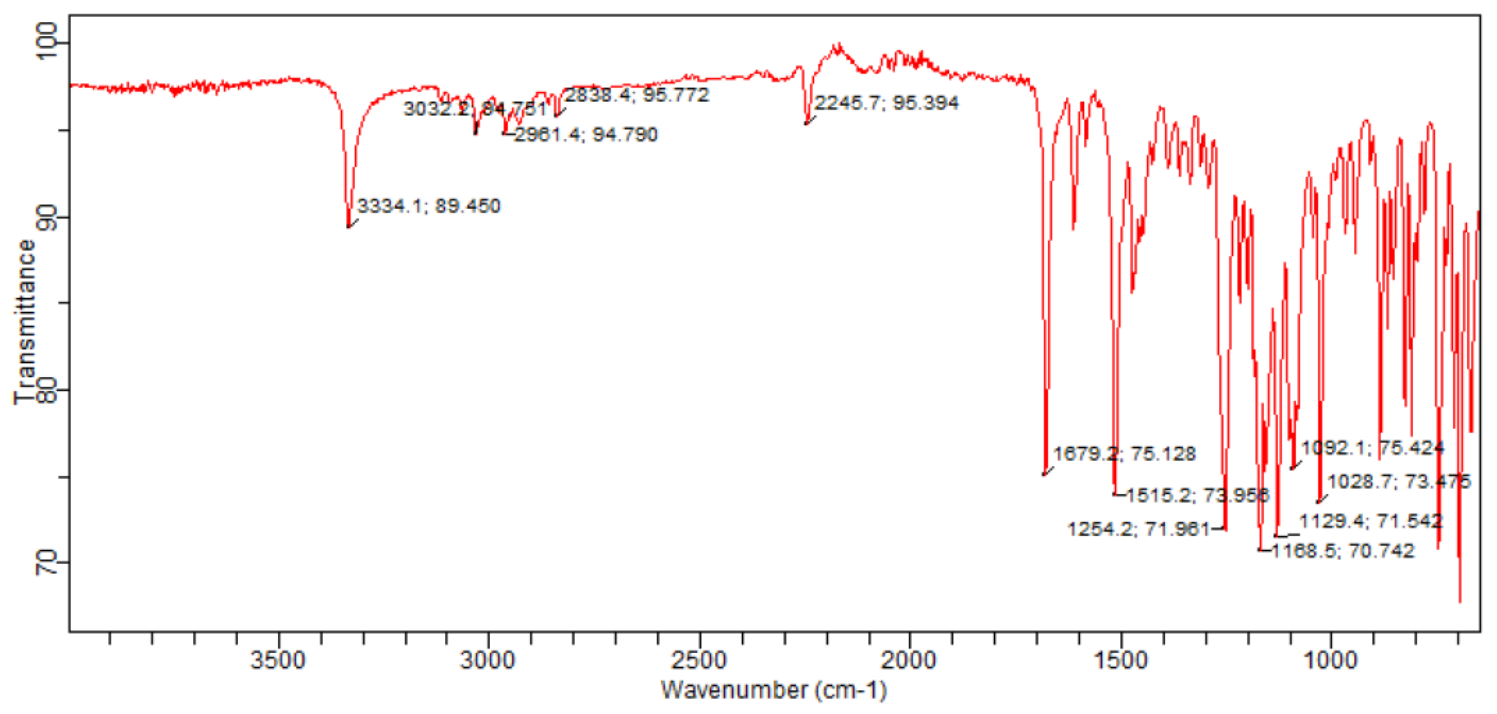

Espectro de infravermelho da dipeptidil-nitrila (13) em sistema ATR

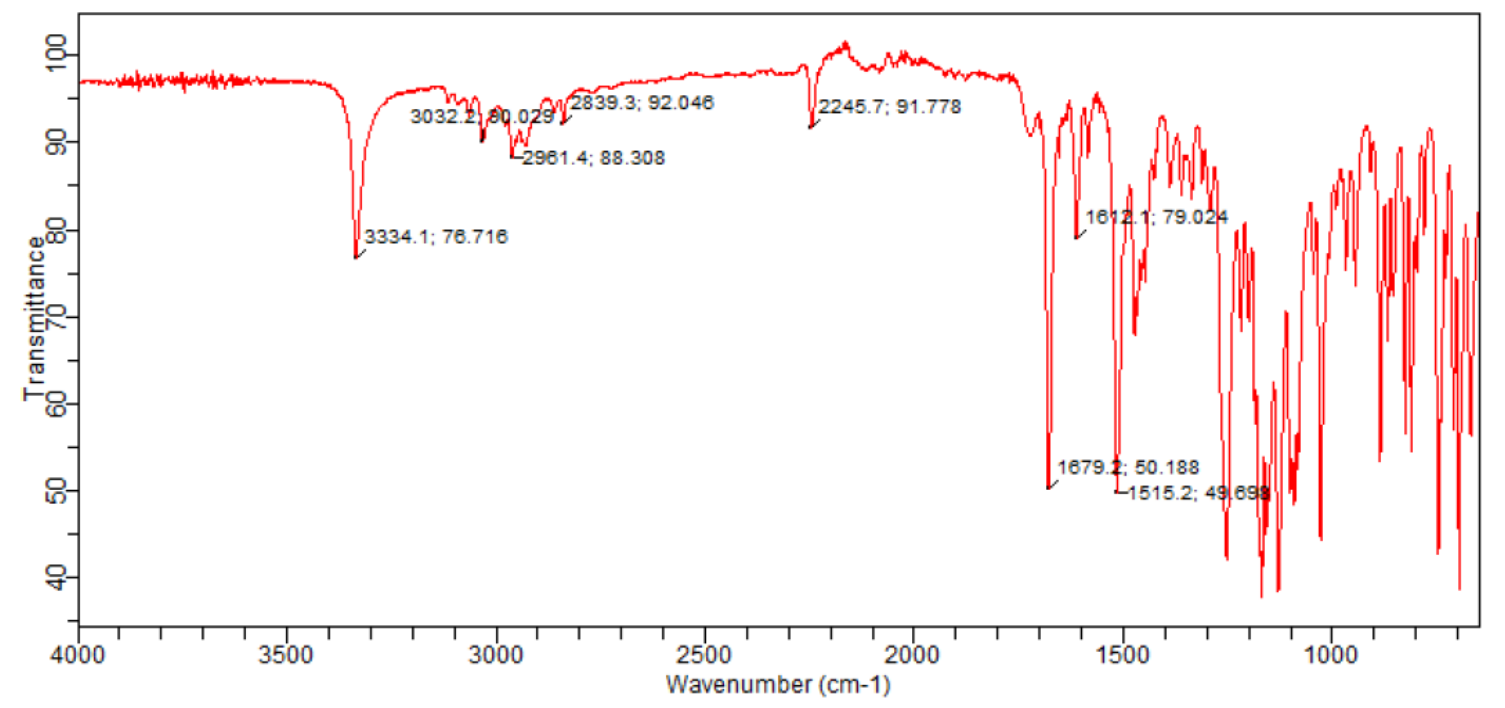

Espectro de infravermelho da dipeptidil-nitrila (14) em sistema ATR 


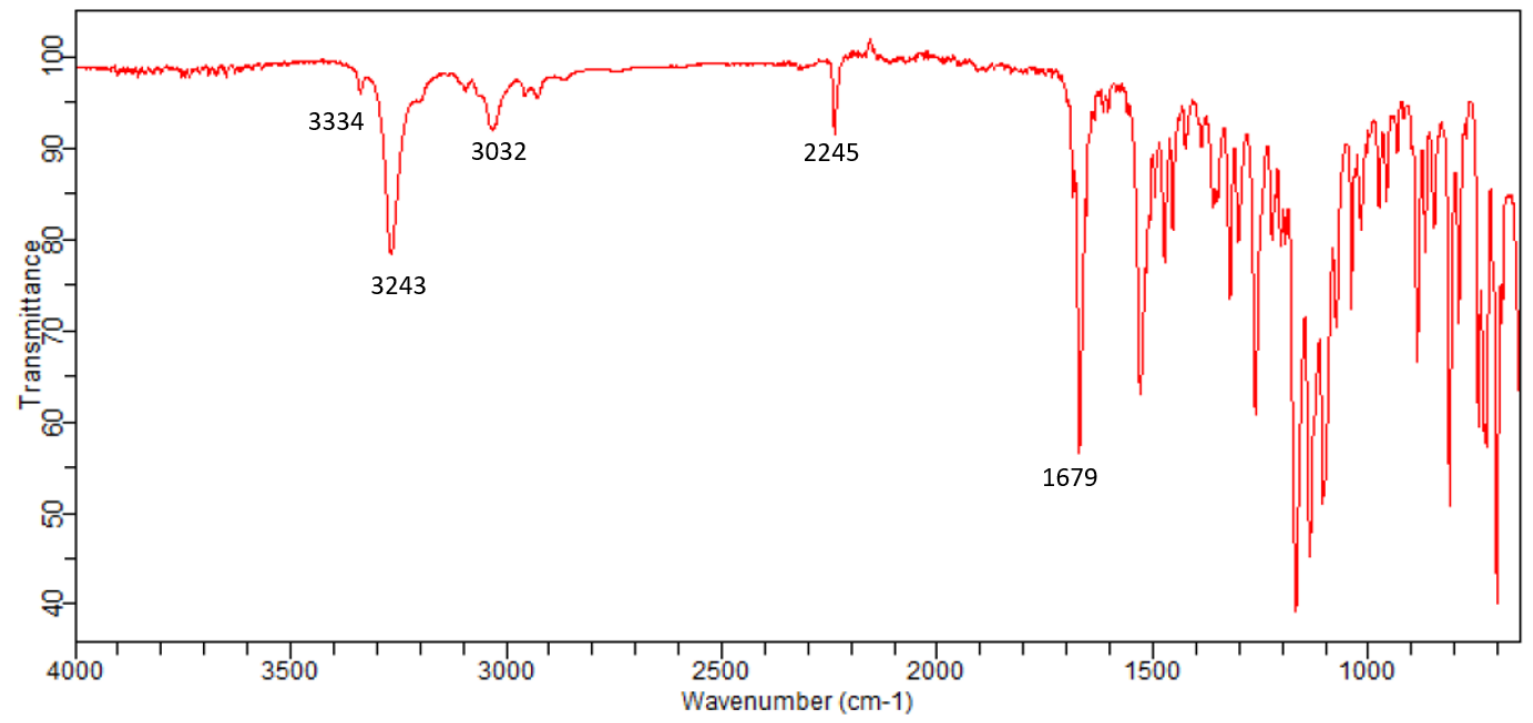

Espectro de infravermelho da dipeptidil-nitrila (15) em sistema ATR

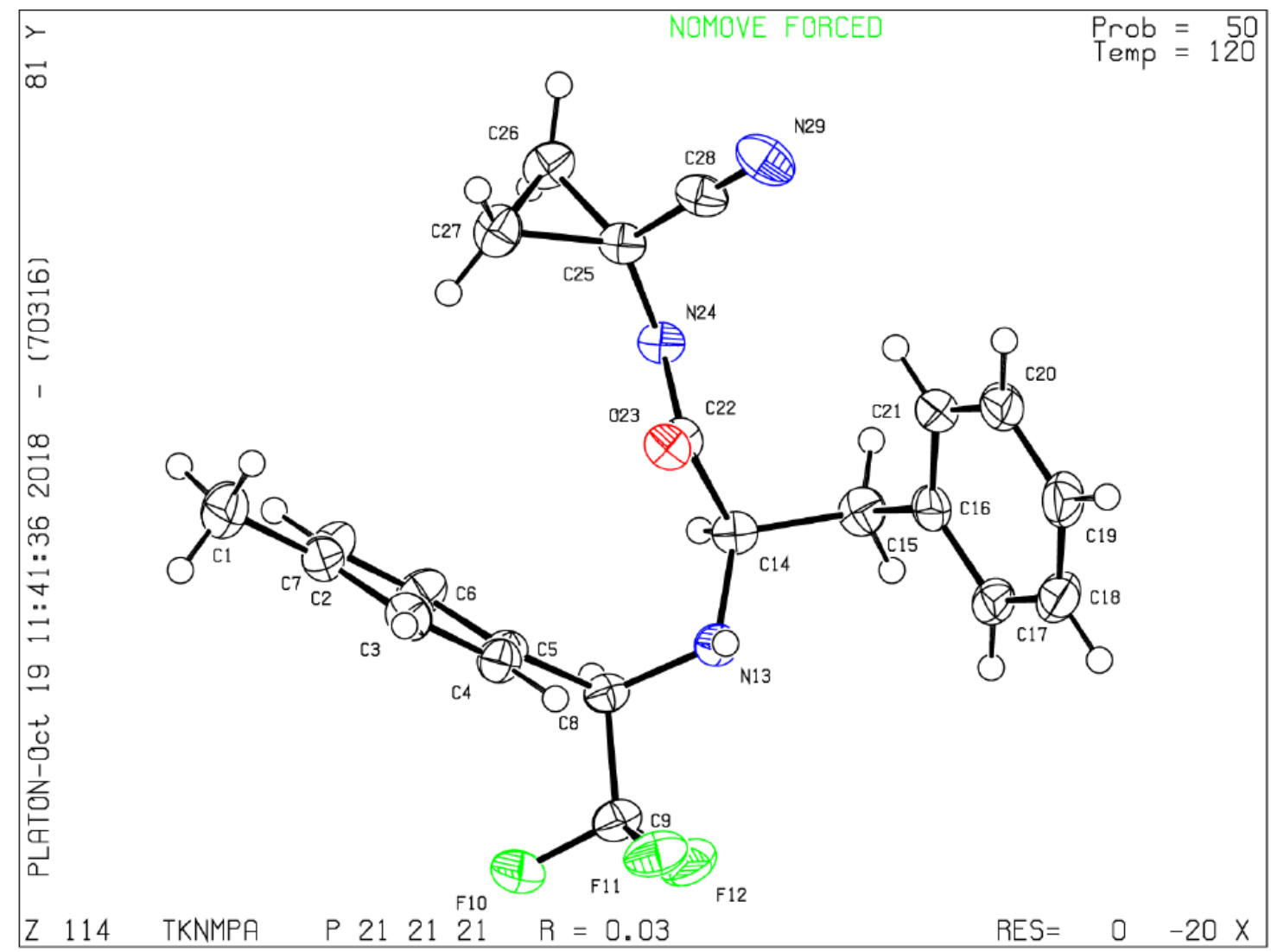

Estrutura cristalina do Neq0930 (12) com numeração dos átomos 
Table 4 Bond Lengths for TKNMPA.

\section{Atom Atom Length $/ \boldsymbol{\AA}$}

F12 C9 $1.342(2)$

F10 C9 $1.340(2)$

F11 C9 $1.341(2)$

O23 C22

$\mathrm{N} 24 \quad \mathrm{C} 22$

N24 C25

N13 C14

N13 C8

N29 C28

$\mathrm{C} 22 \mathrm{C} 14$

C25 C28

C25 C26

C25 C27

$\mathrm{C} 5 \mathrm{C} 4$

C5 $\mathrm{C} 8$

C5 C6
1.2259

(18)

1.3483

(19)

1.4292

(19)

1.4594

1.4646

$1.148(2)$

$1.530(2)$

$1.508(2)$

$1.520(2)$

$1.393(2)$

$1.517(2)$

$1.387(2)$
$1.449(2)$
Atom Atom Length $/ \AA$

C3 C2 1.393(2)

C3 C4 1.383(2)

C16 C17 $1.397(2)$

C16 C21 $1.395(2)$

C16 C15 1.508(2)

C2 C7 $1.385(3)$

C2 C1 $1.510(2)$

C14 C15 1.545(2)

C8 C9 $1.519(2)$

C26 C27 1.495(2)

C17 C18 $1.388(3)$

C21 C20 1.384(3)

C6 C7 $1.391(3)$

$\begin{array}{lll}\mathrm{C} 19 & \mathrm{C} 20 & 1.387(3)\end{array}$

C19 $\mathrm{C} 18 \quad 1.384(2)$

Tabela dos comprimentos de ligação do composto Neq0930 (12) 
Table 5 Bond Angles for TKNMPA.

\begin{tabular}{|c|c|c|c|c|c|c|c|}
\hline \multicolumn{3}{|c|}{ Atom Atom Atom } & \multirow{2}{*}{$\begin{array}{l}\text { Angle } /^{\circ} \\
121.85(12)\end{array}$} & \multicolumn{3}{|c|}{ Atom Atom Atom } & \multirow{2}{*}{$\begin{array}{l}\text { Angle } /^{\circ} \\
113.60 \text { (12) }\end{array}$} \\
\hline $\mathrm{C} 22$ & N24 & $\mathrm{C} 25$ & & N13 & $\mathrm{C} 14$ & $\mathrm{C} 22$ & \\
\hline $\mathrm{C} 14$ & N13 & $\mathrm{C} 8$ & $114.19(12)$ & N13 & $\mathrm{C} 14$ & $\mathrm{C} 15$ & $110.33(12)$ \\
\hline $\mathrm{O} 23$ & $\mathrm{C} 22$ & N24 & $122.38(13)$ & $\mathrm{C} 22$ & $\mathrm{C} 14$ & $\mathrm{C} 15$ & $110.21(12)$ \\
\hline $\mathrm{O} 23$ & $\mathrm{C} 22$ & $\mathrm{C} 14$ & $122.67(13)$ & N13 & $\mathrm{C} 8$ & $\mathrm{C} 5$ & $116.65(12)$ \\
\hline $\mathrm{N} 24$ & $\mathrm{C} 22$ & $\mathrm{C} 14$ & $114.87(12)$ & N13 & $\mathrm{C} 8$ & $\mathrm{C} 9$ & $107.48(12)$ \\
\hline N24 & $\mathrm{C} 25$ & $\mathrm{C} 28$ & $114.33(14)$ & $\mathrm{C} 5$ & $\mathrm{C} 8$ & C9 & $111.68(12)$ \\
\hline N24 & $\mathrm{C} 25$ & $\mathrm{C} 26$ & $116.69(13)$ & $\mathrm{C} 27$ & $\mathrm{C} 26$ & $\mathrm{C} 25$ & $60.80(11)$ \\
\hline N24 & $\mathrm{C} 25$ & $\mathrm{C} 27$ & $119.55(13)$ & $\mathrm{C} 18$ & $\mathrm{C} 17$ & $\mathrm{C} 16$ & $120.77(15)$ \\
\hline $\mathrm{C} 28$ & $\mathrm{C} 25$ & $\mathrm{C} 26$ & $118.88(14)$ & $\mathrm{C} 20$ & $\mathrm{C} 21$ & $\mathrm{C} 16$ & $121.23(16)$ \\
\hline $\mathrm{C} 28$ & $\mathrm{C} 25$ & $\mathrm{C} 27$ & $117.42(13)$ & F12 & $\mathrm{C} 9$ & $\mathrm{C} 8$ & $111.78(14)$ \\
\hline $\mathrm{C} 26$ & $\mathrm{C} 25$ & $\mathrm{C} 27$ & $59.16(11)$ & F10 & $\mathrm{C} 9$ & F12 & $106.59(13)$ \\
\hline $\mathrm{C} 4$ & $\mathrm{C} 5$ & $\mathrm{C} 8$ & $122.22(13)$ & F10 & $\mathrm{C} 9$ & F11 & $107.04(15)$ \\
\hline C6 & $\mathrm{C} 5$ & $\mathrm{C} 4$ & $118.28(15)$ & F10 & $\mathrm{C} 9$ & $\mathrm{C} 8$ & $111.65(13)$ \\
\hline $\mathrm{C} 6$ & $\mathrm{C} 5$ & $\mathrm{C} 8$ & $119.48(14)$ & F11 & $\mathrm{C} 9$ & F12 & $106.54(13)$ \\
\hline $\mathrm{C} 4$ & C3 & $\mathrm{C} 2$ & $121.42(15)$ & F11 & $\mathrm{C} 9$ & $\mathrm{C} 8$ & $112.85(13)$ \\
\hline $\mathrm{C} 17$ & $\mathrm{C} 16$ & $\mathrm{C} 15$ & $121.16(15)$ & $\mathrm{C} 16$ & $\mathrm{C} 15$ & $\mathrm{C} 14$ & $115.32(13)$ \\
\hline $\mathrm{C} 21$ & $\mathrm{C} 16$ & $\mathrm{C} 17$ & $117.90(15)$ & $\mathrm{C} 26$ & $\mathrm{C} 27$ & $\mathrm{C} 25$ & $60.04(10)$ \\
\hline $\mathrm{C} 21$ & $\mathrm{C} 16$ & $\mathrm{C} 15$ & $120.93(15)$ & $\mathrm{C} 5$ & C6 & $\mathrm{C} 7$ & $120.86(16)$ \\
\hline C3 & $\mathrm{C} 2$ & $\mathrm{C} 1$ & $121.06(17)$ & $\mathrm{C} 18$ & C19 & $\mathrm{C} 20$ & $119.22(17)$ \\
\hline $\mathrm{C} 7$ & $\mathrm{C} 2$ & $\mathrm{C} 3$ & $117.80(16)$ & $\mathrm{C} 21$ & $\mathrm{C} 20$ & C19 & $120.30(16)$ \\
\hline $\mathrm{C} 7$ & $\mathrm{C} 2$ & $\mathrm{C} 1$ & $121.14(17)$ & $\mathrm{C} 2$ & $\mathrm{C} 7$ & C6 & $121.07(16)$ \\
\hline N29 & $\mathrm{C} 28$ & $\mathrm{C} 25$ & $178.44(17)$ & C19 & $\mathrm{C} 18$ & $\mathrm{C} 17$ & $120.58(16)$ \\
\hline $\mathrm{C} 3$ & $\mathrm{C} 4$ & $\mathrm{C} 5$ & $120.56(15)$ & & & & \\
\hline
\end{tabular}

Tabela com os ângulos de ligação da molécula Neq0930 (12) 